\title{
THERMAL MODELING FOR A POTENTIAL HIGH-LEVEL NUCLEAR WASTE REPOSITORY AT YUCCA MOUNTAIN, NEVADA
}

\author{
by \\ Karsten Pruess and Yvonne Tsang \\ Earth Sciences Division, Lawrence Berkeley Laboratory \\ University of California, Berkeley, CA 94720
}

March 1994

This work was supported by the Director, Office of Civilian Radioactive Waste Management, Yucca Mountain Site Characterization Project Office, Regulatory and Site Evaluation Division, through U.S. Department of Energy Contract No. DE-AC0376 SF00098. 


\section{Executive Summary}

This report presents a comparison of recent modeling data and performance predictions for a potential high-level nuclear waste repository at Yucca Mountain, Nevada. Special emphasis is placed on thermal performance of the repository, and on the likelihood that liquid water may contact the waste packages.

Repository performance models based on numerical simulation of fluid and heat flows have recently been developed by several different groups. Model conceptualizations generally focus on large-scale average behavior. Our comparison finds that current performance assessment (PA) models use generally similar approximations and parameters. Certain differences exist in some performance-relevant parameters, especially absolute permeabilities, characteristic curves, and thermal conductivities. These reflect present uncertainties about the most appropriate parameters applicable to Yucca Mountain and must be resolved through future field observations and laboratory measurements. However, in spite of these differences generally similar results are obtained for temperature increases and associated drying effects in the host rock surrounding the repository.

For a highly heterogeneous fractured-porous hydrogeologic system such as Yucca Mountain, water infiltration through the unsaturated zone is expected to be dominated by highly localized phenomena. These include "fast" channelized flow along preferential paths in fractures, and frequent local ponding. Current PA models focus on volume-averaged behavior and are unable to represent such effects. 
The "extended dry" repository concept proposed by the Livermore group is reviewed. The idea that a "dry" repository operation is feasible and desirable is found to be based on a rather literal interpretation of current repository performance models. These models involve many idealizations and simplifications that preclude a resolution of intrinsic variability (heterogeneity) on "small" space and time scales. In particular, the models do not address issues of channelized water flow, or the possible presence and mobilization of perched water. Because of these limitations, repository performance predictions should only be interpreted in the sense of spatial and temporal averages. Predictions of large-scale drying around the repository "on the average" for large thermal loads cannot be taken to indicate that waste packages will not be contacted by liquid water, and that aqueous-phase transport of contaminants is not possible.

A number of simple and robust estimates are developed which suggest that liquid water may contact waste packages even under conditions that are "dry on average." Specifically, we find that modest water infiltration, on the order of a few millimeters per year, would be sufficient to overwhelm the vaporization capacity of the repository heat and inundate the waste packages within a time frame of a few thousand years. A preliminary analysis indicates that channelized flow of water may persist over large vertical distances, and may cross the repository horizon without complete vaporization. The vaporization-condensation cycle has a capacity for generating huge amounts of ponded water. A small fraction of the total condensate, if ponded and then episodically released, would be sufficient to cause liquid phase to make contact with the waste packages. 


\section{Part I. Summary and Intercomparison of Recent}

Repository Performance Modeling Data and Results 9

Data Comparison 9

$\begin{array}{ll}\text { Characteristic Curves } & 12\end{array}$

Saturation Profiles 13

Sensitivity Studies $\quad 15$

Results 16

$\begin{array}{ll}\text { Evaluation } & 18\end{array}$

Part II. Interpretation of Performance Model Predictions. $\quad 21$

Livermore's Concept of an "Extended Dry" Repository 21

Critique of the "Extended Dry" Concept 23

Thermodynamic Effects 25

Coping with Infiltration $\quad 27$

Heterogeneity 31

Rainier Mesa - A Possible Analogue for Yucca Mountain 31

Stripa Site Characterization and Validation Project 33

Channelized Water Flow at Yucca Mountain 35

Models for Channelized Water Flow 35

Ponded Water $\quad 37$

Conclusions $\quad 40$

Acknowledgement $\quad 41$

References

Appendix: Effective Continuum Characteristic Curves $\quad 47$ 


\section{List of Figures}

Figure 1. Characteristic curves for Tiva Canyon. (a) capillary suction pressure, (b) liquid permeability versus matrix liquid saturation.

Figure 2. Characteristic curves for Paintbrush Tuff. (a) capillary suction pressure, (b) liquid permeability versus matrix liquid saturation.

Figure 3. Characteristic curves for Topopah Springs. (a) capillary suction pressure, (b) liquid permeability versus matrix liquid saturation.

Figure 4. Characteristic curves for Calico Hills. (a) capillary suction pressure, (b) liquid permeability versus matrix liquid saturation.

Figure 5. Equilibrium liquid saturation profiles for 1D column representation of Yucca Mountain, for different characteristic curves parameters.

Figure 6. Heat decay characteristics of 10 year old fuel and mixed fuel (average age 23 year).

Figure 7. Two-dimensional radially symmetric (R-Z) model of a high-level nuclear waste repository at Yucca Mountain (after Pruess and Tsang, 1993).

Figure 8. Repository average liquid saturation profiles for reference case with thermal loading of APD $=57 \mathrm{~kW} /$ acre and 10 year old fuel.

Figure 9. Repository average liquid saturation profiles for thermal loading of APD = $114 \mathrm{~kW} /$ acre and 10 year old fuel.

Figure 10. Repository average liquid saturation profiles for thermal loading of APD = $114 \mathrm{~kW} /$ acre and mixed fuel.

Figure 11. Repository average liquid saturation profiles for thermal loading of APD = $28.5 \mathrm{~kW} /$ acre and 10 year old fuel. 
Figure 12. Repository average temperature profiles for reference case with thermal loading of APD $=57 \mathrm{~kW} /$ acre and 10 year old fuel.

Figure 13. Repository average temperature profiles for thermal loading of APD $=114$ $\mathrm{kW} /$ acre and 10 year old fuel.

Figure 14. Repository average temperature profiles for thermal loading of APD $=114$ $\mathrm{kW} / \mathrm{acre}$ and mixed fuel.

Figure 15. Repository average temperature profiles for thermal loading of APD $=28.5$ $\mathrm{kW} / \mathrm{acre}$ and 10 year old fuel.

Figure 16. Liquid saturation and temperature history at the repository horizon, at a location midway between repository center and repository edge.

Figure 17. Total drying and rewetting times and the temperature history at $3 \mathrm{~cm}$ from the waste package surface.

Figure 18. Repository average temperature profiles for thermal loading of APD $=57$ $\mathrm{kW} / \mathrm{acre}$ and 10 year old fuel, and an enhanced gas permeability of $1.9 \times 10^{-11} \mathrm{~m}^{2}$.

Figure 19. Repository average liquid saturation profiles for thermal loading of $\mathrm{APD}=57 \mathrm{~kW} / \mathrm{acre}$ and 10 year old fuel, and an enhanced gas permeability of $1.9 \times 10^{-11} \mathrm{~m}^{2}$.

Figure 20. Dependence of saturation temperature of water on suction pressures, for different vapor pressures.

Figure 21. Areal view of waste package arrangement for analysis of the interaction between waste heat and infiltration.

Figure 22. Time dependence of heat output for a 10 year old waste package, and associated maximum vaporization rates from Eqs. $(5,6)$.

Figure 23. As Fig. 20, with logarithmic scale for heat generation and vaporization. 
Figure 24. Cumulative heat output and vaporization for a single waste package.

Figure 25. Cumulative heat output and vaporization, logarithmic scale.

Figure 26. Heat available for vaporization per waste package, and corresponding vaporization rates, for a model that accounts for heat migrating upward as well as downward from the repository, and includes conductive losses.

Figure 27. As Fig. 24, logarithmic scale.

Figure 28. Validation drift experiment at the Stripa mine (from Harding and Black, 1992).

Figure 29. Fractures mapped at the Validation Drift wall (from Olsson, 1992).

Figure 30. Computer-generated realization of a $12.5 \mathrm{~m}$ sided cube of averagely fractured rock at the Stripa Validation Drift (from Herbert et al., 1991).

Figure 31. Realization of a $7 \mathrm{~m}$ sided cube of $\mathrm{H}$-zone fracture network at Stripa (from Herbert et al., 1991).

Figure 32. Measured inflow distributions at the Validation Drift after 5,000 hours (a) and 9,500 hours (b) (from Harding and Black, 1992).

Figure 33. Areal view of waste package arrangement for analysis of channelized water flow.

Figure 34. Temperatures and liquid saturations at repository horizon in vertical water channel. 


\section{List of Tables}

Table 1. Input Data Used by Pruess and Tsang for Yucca Mountain Repository Model

Table 2. Data Comparison: Parameters for Characteristic Curves Used by Different Groups

Table 3. Cases in Sensitivity Studies.

Table 4. Buscheck and Nitao's Input Data Specifications

Table 5. Maximum Water Vaporization for Different Waste Package Designs

Table 6. Cumulative Heat and Potential Condensate Generation for Vertically Emplaced Packages of 10 Year old Fuel 


\section{Part I. Summary and Intercomparison of Recent Repository Performance Modeling Data and Results}

This section, motivated by recent discussions of thermal loading issues, presents a comparison of repository performance assessment data and calculations from different groups.

\section{Data Comparison}

Our most recent repository performance studies employed twodimensional radially symmetric ( $R Z$ ) and vertical section (XZ) models (Pruess and Tsang, 1993; Tsang et al., 1993). Thermal and hydrologic behavior was modeled with Lawrence Berkeley Laboratory's TOUGH2 simulator, a successor to the TOUGH code (Pruess, 1987, 1991). In these studies we have chosen the same reference case parameters, summarized in Table 1 , as in our previous investigations, which dealt with heat-driven flow on a waste package scale (Pruess et al., 1990a, b), large scale convective gas flow around a repository (Tsang and Pruess, 1987), and gas movement and moisture migration of the natural system at Yucca Mountain (Tsang and Pruess, 1989, 1990). The reason for retaining the same reference parameters was our desire to be able to make meaningful comparisons between model conceptualizations and calculations with different emphasis and scale. In future repository performance modeling we intend to use updated parameters, such as new data on characteristic curves for the different tuff units (Flint et al. 1993).

Table 2 shows the characteristic curve data used by different groups in modeling studies. These data had been provided for the thermal loading model exercise initiated in January 1993. In close cooperation with USGS researchers, a group at Lawrence Berkeley Laboratory is developing a 3-D sitescale model, and presented preliminary ambient saturation distributions obtained from TOUGH2 simulations (Wittwer et al., 1993). Their parameters, labeled 'LBL-USGS' in Table 2, were submitted to Russell Dyer of the Yucca Mountain Site Characterization Project Office by Larry Hayes, USGS, on February 19, 1993. Buscheck and Nitao of LLNL have presented repository performance simulations using the V-TOUGH code (Nitao, 1989), an 
Table 1. Input Data Used by Pruess and Tsang for Yucca Mountain Repository Model ${ }^{\dagger}$

\begin{tabular}{|c|c|c|c|c|c|}
\hline \multirow[t]{2}{*}{ Material Properties $(\mathrm{a})$} & \multicolumn{3}{|c|}{ Welded Units } & \multicolumn{2}{|c|}{ Non-welded Units } \\
\hline & Topopah Spring & Tiva Canyon & Prow Pass & Paintbrush & Calico Hills-Vitric \\
\hline Rock Grain Density & $2480 \mathrm{~kg} / \mathrm{m}^{3}$ & $2480 \mathrm{~kg} / \mathrm{m}^{3}$ & $2480 \mathrm{~kg} / \mathrm{m}^{3}$ & $2300 \mathrm{~kg} / \mathrm{m}^{3}$ & $2300 \mathrm{~kg} / \mathrm{m}^{3}$ \\
\hline Rock Specific Heat & $840 \mathrm{~J} / \mathrm{kg}^{\circ} \mathrm{C}$ & $840 \mathrm{~J} / \mathrm{kg}{ }^{\circ} \mathrm{C}$ & $840 \mathrm{~J} / \mathrm{kg}{ }^{\circ} \mathrm{C}$ & $840 \mathrm{~J} / \mathrm{kg}^{\circ} \mathrm{C}$ & $840 \mathrm{~J} / \mathrm{kg}^{\circ} \mathrm{C}$ \\
\hline $\begin{array}{l}\text { Matrix Continuum } \\
\text { Permeability } \\
\text { Fracture Continuum } \\
\text { Permeability }\end{array}$ & $\begin{array}{l}1.9 \mathrm{e}^{-18} \mathrm{~m}^{2} \\
1.8 \mathrm{e}^{-14} \mathrm{~m}^{2}\end{array}$ & $\begin{array}{l}1.9 \mathrm{e}^{-18} \mathrm{~m}^{2} \\
1.8 \mathrm{e}^{-14} \mathrm{~m}^{2}\end{array}$ & $\begin{array}{l}4.5 \mathrm{e}^{-16} \mathrm{~m}^{2} \\
1.8 \mathrm{e}^{-14} \mathrm{~m}^{2}\end{array}$ & $\begin{array}{c}1.8 \mathrm{e}^{-14} \mathrm{~m}^{2} \\
-\end{array}$ & $\begin{array}{c}1.8 \mathrm{e}^{-14} \mathrm{~m}^{2} \\
-\end{array}$ \\
\hline $\begin{array}{l}\text { Formation Heat Conductivity } \\
\text { (dry) (b) }\end{array}$ & $1.90 \mathrm{~W} / \mathrm{m}^{\circ} \mathrm{C}$ & $1.90 \mathrm{~W} / \mathrm{m}^{\circ} \mathrm{C}$ & $1.90 \mathrm{~W} / \mathrm{m}^{\circ} \mathrm{C}$ & $1.02 \mathrm{~W} / \mathrm{m}^{\circ} \mathrm{C}$ & $1.02 \mathrm{~W} / \mathrm{m}^{\circ} \mathrm{C}$ \\
\hline $\begin{array}{l}\text { Formation Heat Conductivity } \\
\text { (fully saturated) (b) }\end{array}$ & $2.34 \mathrm{~W} / \mathrm{m}^{\circ} \mathrm{C}$ & $2.34 \mathrm{~W} / \mathrm{m}^{\circ} \mathrm{C}$ & $2.34 \mathrm{~W} / \mathrm{m}^{\circ} \mathrm{C}$ & $1.35 \mathrm{~W} / \mathrm{m}^{\circ} \mathrm{C}$ & $1.35 \mathrm{~W} / \mathrm{m}^{\circ} \mathrm{C}$ \\
\hline Total porosity $\phi(c)$ & 0.1 & 0.1 & 0.25 & 0.4 & 0.4 \\
\hline Fracture porosity $\bar{\phi}_{\mathrm{f}}(\mathrm{c})$ & .0018 & .0018 & .0018 & - & - \\
\hline $\begin{array}{l}\text { Sample from which matrix } \\
\text { characteristic curve is } \\
\text { derived, actual parameters } \\
\text { are given in Table } 2\end{array}$ & TSw G4-6 (d) & TSw G4-6 (d) & PPw G4-18 (d) & PTn GU4-2 (d) & CHnv GU3-15 (e) \\
\hline Diffusion coefficient $D_{v a}^{o}(f)$ & $2.14 \mathrm{e}^{-5} \mathrm{~m}^{2} / \mathrm{s}$ & $2.14 \mathrm{e}^{-5} \mathrm{~m}^{2} / \mathrm{s}$ & $2.14 \mathrm{e}^{-5} \mathrm{~m}^{2} / \mathrm{s}$ & $2.14 \mathrm{e}^{-5} \mathrm{~m}^{2} / \mathrm{s}$ & $2.14 \mathrm{e}^{-5} \mathrm{~m}^{2} / \mathrm{s}$ \\
\hline Diffusion parameter $\theta(\mathrm{g})$ & 2.334 & 2.334 & 2.334 & 2.334 & 2.334 \\
\hline
\end{tabular}

$\dagger$ Pruess and Tsang, 1993.

(a) Where no specific source is given, values used are based on (RIB); for details see Tsang and Pruess (1989).

(b) At intermediate liquid saturation, heat conductivity is linearly dependent on saturation.

(c) For use in effective continuum approximation, Appendix A.

(d) Klavetter and Peters, 1986.

(e) Peters et al., 1984

(f) Langkopf, 1987.

(g) Bird et al., 1960. 
Table 2. Data Comparison: Parameters for Characteristic Curves used by Different Research Groups

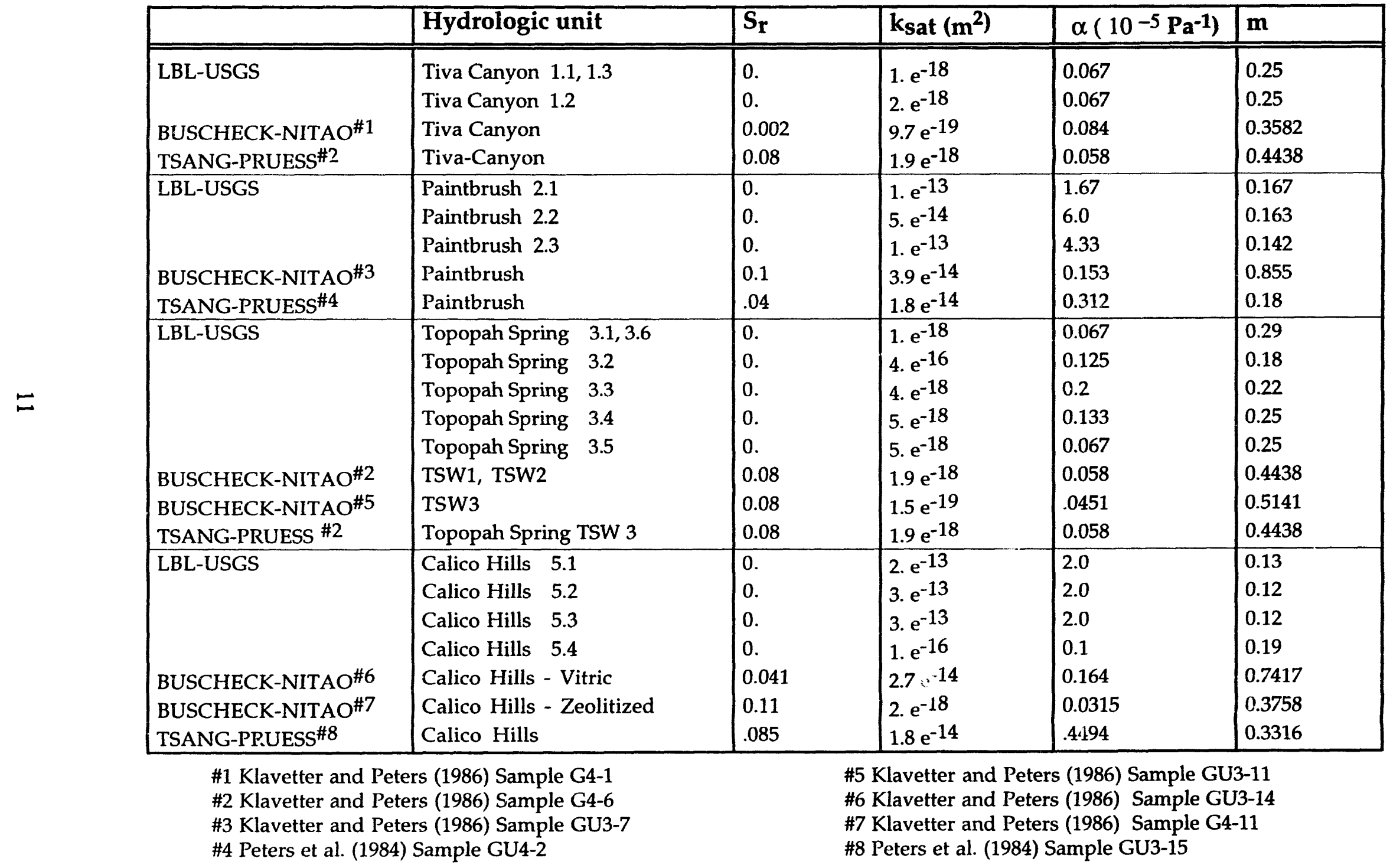


LLNL-enhanced version of TOUGH that takes advantage of vector processing capabilities on Cray computers (Nitao, 1989; Buscheck and Nitao, 1992, 1993). Their most recent calculations (1993) were forwarded to us from the office of Russell Dyer on March 1, 1993, and are labeled 'Buscheck-Nitao' in Table 2. The set of parameters which we have employed in our modeling studies (Tsang and Pruess, 1990; Pruess and Tsang, 1993) is labeled 'Tsang-Pruess'. The van-Genuchten model used in most of the modeling work expresses capillary suction $\mathrm{P}_{\text {suc }}$ and liquid relative permeability $\mathrm{k}_{\mathrm{rl}}$ as functions of liquid saturation $S_{1}$ in terms of two parameters, $\alpha$ and $m$ (van Genuchten, 1980):

$$
\begin{aligned}
& P_{\mathrm{suc}}=\frac{1}{\alpha}\left[\mathrm{S}_{\mathrm{EF}}^{-1 / m}-1\right]^{1-\mathrm{m}} \\
& \mathrm{k}_{\mathrm{rl}}=\sqrt{S_{\mathrm{EF}}}\left[1-\left(1-\mathrm{S}_{\mathrm{EF}}^{1 / \mathrm{m}}\right)^{\mathrm{m}}\right]^{2}
\end{aligned}
$$

Here $S_{E F}=\left(S_{1}-S_{r}\right) /\left(1-S_{r}\right)$ is scaled (effective) liquid saturation, $S_{1}$ and $S_{r}$ are the liquid and residual saturation, respectively. The parameter sets given in Table 2 pertain to the (unfractured) rock matrix. Ad hoc assumptions are used for capillary and relative permeability behavior of the fractures, stressing analogies to coarse porous media and utilizing effective continuum concepts (see Appendix and the discussion below).

\section{Characteristic Curves}

For comparison the curves of capillary suction pressure and effective liquid permeability versus matrix liquid saturation $\left(P_{\text {suc }}\right.$ and $k_{\text {sat }} k_{r l}$ vs. $\left.S_{1}\right)$ for the different data sets are plotted in Figures 1 through 4 . For the $T$ :va Canyon unit (Fig. 1) the capiliary suction curves have similar air-entry pressures for all three groups. The Buscheck-Nitao and Tsang-Pruess curves are also quite similar in the saturation range $S_{1}>0.1$; they are flatter than the more recent LBL-USGS data, indicating a narrower pore-size distribution. The shapes of the liquid permeability curves are similar, but the magnitudes differ by about one order of magnitude between the different groups. For the non-welded Paintbrush unit (Fig. 2) the curves used by Buscheck and Nitao stand out in their dissimilarity from those of the other groups. Their capillary pressure curve has an air-entry pressure about one order of magnitude larger than Tsang-Pruess and almost two orders of magnitude larger than LBL-USGS. The 
most striking difference is in the shape of the capillary suction curve, Buscheck's curve being very flat for most of the saturation range due to the large value of parameter $\mathrm{m}=0.855$. This large $\mathrm{m}$ also makes the liquid permeability much larger than for the LBL-USGS and Tsang-Pruess data. In Figure 3 for the Topopah Spring welded unit, all curves except LBL-USGS 2 are similar and overlap each other. The main source of the differences is the use of a much larger absolute permeability in LBL-USGS 2 (see Table 2, entry for LBL-USGS, Topopah Spring 3.2). The situation is quite different in Figure 4 for the Calico Hills unit. The LBL-USGS data for vitric and bedded media are similar, but both are different from the zeolitized tuff, which has a higher air entry pressure and much lower saturated permeability, as is to be expected. Buscheck-Nitao use two different sets of curves for the vitric and zeolitized subunits. Both their capillary suction and liquid permeability data span a broader range of values than the LBL-USGS data. Tsang-Pruess only has one set of curves for the vitric Calico Hills. Their air entry pressure is not too different from LBL-USGS, but the capillary suction curve is much flatter for a wide range of liquid saturations. Accordingly, the liquid permeability also remains higher than for LBL-USGS.

\section{Saturation Profiles}

The choice of characteristic curves determines the predicted ambient liquid saturations for the different layers. To evaluate the impact of different parametrizations, we performed calculations of gravity-capillary equilibrium in one-dimensional vertical columns, incorporating enhanced vapor diffusion effects (see below). The resulting liquid saturation profiles are shown in Figure 5. The interfaces of hydrological units are at $125 \mathrm{~m}$ (above the water table) between Calico Hills and Topopah Spring, at $450 \mathrm{~m}$ between Topopah Spring and Paintbrush, and at $500 \mathrm{~m}$ between Paintbrush and Tiva Canyon. The profile labeled 'LBL-USGS1' was obtained by using the parameters of sublayer 1.1 for the Tiva Canyon unit, sublayer 2.1 for Paintbrush, sublayer 3.1 for Topopah Spring, and sublayer 5.1 for Calico Hills bedded tuff. The profile labeled 'LBL-USGS2' was obtained by using the parameters of sublayer 1.2 for Tiva Canyon, sublayer 2.2 for Paintbrush, sublayer 3.3 for Topopah Spring, and sublayer 5.1 for bedded Calico Hills. The profile labeled 'Buscheck-Nitao' used the parameters for vitric non-welded tuff in the Calico Hills. The most significant differences among the ambient 
profiles obtained from the different sets of parameters occur in the saturation of the non-welded Paintbrush and Calico Hills units. The low liquid saturation in these units for the profile labeled 'Buscheck-Nitao' is to be expected from the very flat capillary suction curves for Buscheck-Nitao's parameters as shown in Figures $2 a$ and $4 a$. Otherwise, the different sets of parameters give comparable saturation profiles, with the more recent USGS data (Flint et al., 1993) giving rise to slightly higher liquid saturation in the Topopah Spring unit at the repository horizon than the older measurements used by Tsang-Pruess (Peters et al., 1984; Klavetter and Peters 1986) and Buscheck-Nitao (Klavetter and Peters, 1986). The ambient liquid saturation profile is sensitive to the amount of downward liquid infiltration. In the calculations shown in Figure 5, no liquid infiltration was imposed at the top of the column. Our calculations show an average downward water flux of about $.04 \mathrm{~mm} / \mathrm{yr}$, which arises from the condensation of upward vapor flux. The vapor-air diffusive gas flux $\mathbf{F}^{\mathrm{K}}$ is given by

$$
\mathbf{F}^{\mathrm{K}}=-\mathrm{D}_{\mathrm{va}} \rho_{\mathrm{g}} \nabla \chi_{\mathrm{g}}^{\mathrm{K}}
$$

where $\kappa$ is the component index for the gas phase ( $\kappa=$ air or vapor), $\chi_{g}^{\kappa}$ is the mass fraction of the $\kappa^{\text {th }}$ component in the gas phase and $D_{v a}$ is the diffusion coefficient for the vapor-air mixture in a porous medium, given by (Vargaftik, 1975; Walker et al., 1981)

$$
D_{v a}=\tau \phi S_{g} D_{v a}^{o} \frac{P_{0}}{P}\left[\frac{T}{T_{0}}\right]^{\theta}=\beta D_{v a}^{0} \frac{P_{0}}{P}\left[\frac{T}{T_{0}}\right]^{\theta}
$$

Here, $\phi$ is the porosity, $S_{g}$ is the gas saturation, $\tau$ is the tortuosity factor and $T_{0}$ and $P_{O}$ are standard conditions of $273.15 \mathrm{~K}$ and 1 bar. The parameter group $\beta$ $=\tau \phi S_{\mathrm{g}}$ represents diffusion strength in a porous medium and usually is on the order of .01. However, experimental evidence in the soil science literature indicates that vapor diffusion may be greatly enhanced from pore level phase change effects so that $\beta$ is typically in the range of 1 to 3.5 for a variety of partially saturated porous media (Jury and Letey, 1979; and references in Tsang and Pruess, 1990). We are not aware of any experimental data for effective vapor diffusion strength in tuffs. Based on the diffusion behavior 
observed in soils, we have chosen to use an enhanced value of $\beta=1$ for vapor diffusion in all our calculations.

Our simulated saturation profiles for Buscheck-Nitao's parameters are, as expected, in approximate agreement with their published results that include no vapor diffusion enhancement but apply an explicit net infiltration of $.045 \mathrm{~mm} / \mathrm{yr}$ at the top of the model (Buscheck and Nitao, 1992, 1993). Certain differences arise from their use of sub-layers within hydrologic units which are not represented in the model we used to generate the profiles shown in Fig. 5.

\section{Sensitivity Studies}

One of the issue of interest here is to investigate the effects of different thermal loadings on the performance of the repository. Our RZ and XZ repository scale calculations (Pruess and Tsang, 1993) use waste with decay characteristics of 10 year old (out of reactor) fuel and initial areal power density (APD) of $57 \mathrm{~kW} /$ acre. We have performed sensitivity studies with different thermal loading, as well as with enhanced gas permeability (Table 3).

Table 3. Cases in Sensitivity Studies

\begin{tabular}{|c|c|c|}
\hline $\begin{array}{c}\text { Areal Power } \\
\text { Density (APD) }\end{array}$ & Waste Characteristics & Gas Permeability \\
\hline \hline & 10-year-old waste & $1.8 \times 10^{-14} \mathrm{~m}^{2}$ \\
$57 \mathrm{~kW} /$ acre & $\begin{array}{c}\text { 10-year-old waste } \\
\text { mixed waste, }\end{array}$ & $1.8 \times 10^{-14} \mathrm{~m}^{2}$ \\
$114 \mathrm{~kW} /$ acre & $1.8 \times 10^{-14} \mathrm{~m}^{2}$ \\
$114 \mathrm{~kW} /$ acre & average age 22-23 years & $1.8 \times 10^{-14} \mathrm{~m}^{2}$ \\
& 10-year-old waste & $1.9 \times 10^{-11} \mathrm{~m}^{2}$ \\
\hline
\end{tabular}

The heat decay characteristics of "mixed" fuels were kindly made available to us by Peter Gottlieb of TRW-Yucca Mountain Project. The average fuel age in this mixed waste is 22 years for PWR (pressurized water reactor), and 23 years for BWR (boiling water reactor). In Figure 6 we have plotted the decay characteristics of 10 year fuel used in our previous calculations, and of 
mixed fuel, both normalized to the same initial heat per waste package of 3051 W.

We have investigated both doubling and halving of the initial APD of $57 \mathrm{~kW} /$ acre. The sensitivity studies were carried out for the radially symmetric (RZ) model (see Fig. 7). This model extends from the ground surface down to the water table and out to a distance of $5 \mathrm{~km}$ from the repository centerline. It employs fine gridding at small radii so that one centrally located waste package can be modeled explicitly. The area allotted to the central waste package is $\pi R_{w}^{2}$, where the radius $R_{w}$ is determined by equating $3051 \mathrm{~W} /\left(\pi \mathrm{R}_{\mathrm{w}}^{2}\right)$ to the appropriate areal power densities. For thermal loadings of 57,114 , and $28.5 \mathrm{~kW} /$ acre, we have $\mathrm{R}_{\mathrm{W}}=8.237,5.825$, and $11.649 \mathrm{~m}$, respectively. Beyond $R_{W}$, the appropriate areal power density is applied in an areally averaged fashion. The outer radius $R_{e}$ of the repository is also scaled so that the total heat input of emplaced waste at $t=0$ is identical for the different APDs considered. For thermal loadings of 57, 114, and $28.5 \mathrm{~kW} /$ acre the respective repository radii are 1500,1061 , and $2121 \mathrm{~m}$.

\section{Results}

Modeling results for the different thermal loadings are shown in Figs. 8 - 17 as vertical profiles of liquid saturation and temperature at selected times. The values of liquid saturation and temperature are taken at a radial distance about halfway towards the repository edge, and are therefore representative of the repository performance in an average sense.

The simulated results present no surprises. From the liquid saturation profiles, it is clear that drying around the repository increases with areal power density. The higher the APD, the larger the region of reduced liquid saturation. The heat decay characteristics affect the drying around the repository in a similar way. Heat output of the mixed wastes decays more slowly, and since the initial heat load at $t=0$ is the same for both the mixed waste and the 10 year old fuel, the liquid saturation profiles for older mixed waste (Fig. 10) show a somewhat larger volume of reduced liquid saturation than for the 10 year old waste (Fig. 9). However, it should be noted that the repository average liquid saturation does not actually go to zero in any of the cases studied, not even at the repository horizon at $-375 \mathrm{~m}$ depth. Formation dry-out is limited to a distance of a few meters from individual waste 
packages (Pruess and Tsang, 1993). Temperature rise and heated volume are larger for higher areal power density and slower decay characteristics. For an areal power density of $114 \mathrm{~kW} /$ acre, the average temperature at 500 years after waste emplacement is above $100{ }^{\circ} \mathrm{C}$ for a region of approximately $180 \mathrm{~m}$ thickness for 10 year old fuel (Fig. 13), and for a region of about $250 \mathrm{~m}$ thickness for mixed fuel. These results were obtained for a model that takes the water table at $275 \mathrm{~m}$ below the repository horizon as a constant temperature $\left(30.85^{\circ} \mathrm{C}\right)$ boundary; somewhat larger heated zones would be predicted if heat transfer in the saturated zone were modeled explicitly (Buscheck and Nitao, 1993). Figure 16 shows the liquid saturation and temperature history of the node at the repository horizon. For an APD of 114 $\mathrm{kW} / \mathrm{acre}$, the repository average temperature remains above $100^{\circ} \mathrm{C}$ from 10 to over 2000 years after waste emplacement, whereas for APDs of 57 and 28.5 $\mathrm{kW} /$ acre the temperature remains below $100{ }^{\circ} \mathrm{C}$ at all times. The repository average liquid saturation remains below ambient for over ten thousand years in all cases studied, although it never actually goes to zero.

While Figs. 8 through 16 illustrate repository performance in an average sense, the $\mathrm{RZ}$ model also resolves the behavior near a waste package. Figure 17 displays drying and rewetting times, and the temperature history in the host rock at a distance of $3 \mathrm{~cm}$ from surface of the central waste package emplacement hole. It is seen that locally the temperatures rise above $100{ }^{\circ} \mathrm{C}$ for all cases studied, and go to values in excess of $200^{\circ} \mathrm{C}$ for the high APD of $114 \mathrm{~kW} /$ acre. In all cases studied, complete drying to liquid saturation $\mathrm{Sl}=0$ occurs at approximately one year after waste emplacement. Rewetting to a mobile liquid saturation $\mathrm{S}_{1}>\mathrm{S}_{\mathrm{r}}$ takes place within 80 years or less after emplacement, and occurs when temperatures are still considerably higher than the nominal boiling point of $100{ }^{\circ} \mathrm{C}$. This effect arises from vapor pressure lowering effects due to the very strong capillary suction pressures at low liquid saturations. As illustrated in Fig. 20, the temperature at which liquid and vapor phases can coexist increases steeply when capillary suction pressures become stronger than $10^{8} \mathrm{~Pa}$ (1000 bars). Very strong suction pressures are reached for Topopah Spring tuff at low liquid saturations (Fig. 3), which explains that re-wetting takes place at temperatures above the nominal boiling point of $100^{\circ} \mathrm{C}$. 
In addition to the effects of thermal loading, we also investigated the effect of gas permeability on the performance of the repository. We simulated a case where the gas permeability was increased from $1.8 \times 10^{-14} \mathrm{~m}^{2}$ for the reference case to $1.9 \times 10^{-11} \mathrm{~m}^{2}$ throughout the mountain. The resulting average temperature and liquid saturation profiles are shown in Figs. 18 and 19 , respectively. Comparing with the results of the reference case, we note that the temperature profiles in Figs. 12 and 18 are almost identical. As for the liquid saturation, it is apparent that the condensation zone above the drying region near the repository is both larger in volume and higher in liquid saturation (Figs. 8, 19). The larger gas permeability therefore facilitates the removal of water from the vicinity of the repository, as would be anticipated.

\section{Evaluation}

Our results of substantial dry-out near the repository and a prolonged period of temperatures above the nominal boiling point are consistent with results published by the Livermore group (Buscheck and Nitao, 1992, 1993). Detailed quantitative agreement is not expected because of certain differences in input parameters such as material properties and heat decay characteristics. The input data transmitted by Buscheck to YMP for the thermal loading study are tabulated in Table 4, which has the same format as Table 1 for our reference case to facilitate comparison. The most important difference between the models as far as thermal effects is concerned is in the representation of the Topopah Spring unit. In our model this is a single unit with thermal conductivity varying from $1.9 \mathrm{~W} / \mathrm{m}{ }^{\circ} \mathrm{C}$ for dry to $2.34 \mathrm{~W} / \mathrm{m}{ }^{\circ} \mathrm{C}$ for water-saturated rock. In contrast, Buscheck and Nitao represent the Topopah Spring as three separate hydrogeologic units, of which two have considerably lower thermal conductivity. Their TSW 1 conductivities range from 1.55 (dry) to $1.65 \mathrm{~W} / \mathrm{m}{ }^{\circ} \mathrm{C}$ (wet), and TSW 3, which includes the repository level, has an even lower conductivity range of from 1.26 (dry) to $1.28 \mathrm{~W} / \mathrm{m}{ }^{\circ} \mathrm{C}$ (wet). Consequently heat is conducted away from the repository horizon somewhat less efficiently in Buscheck and Nitao's model, giving rise to higher temperatures for longer time periods. To illustrate this effect consider the case of $114 \mathrm{~kW} /$ acre thermal loading with an average fuel age of 21 years and "youngest fuel first" decay characteristics (Buscheck and Nitao, 1993). This particular scenario is similar to our case of APD of $114 \mathrm{~kW} /$ acre 
Table 4. Buscheck and Nitao's Input Data Specifications

\begin{tabular}{|c|c|c|c|c|c|}
\hline \multirow[t]{2}{*}{ Material Properties } & \multicolumn{3}{|c|}{ Welded Units } & \multicolumn{2}{|c|}{ Non-welded Units } \\
\hline & $\begin{array}{c}\text { Topopah Spring } \\
\text { TSw3 } \\
\end{array}$ & Tiva Canyon & Prow Pass & Paintbrush & Calico Hills-Vitric \\
\hline Rock Grain Density & $2580 \mathrm{~kg} / \mathrm{m}^{3}$ & $2580 \mathrm{~kg} / \mathrm{m}^{3}$ & $2580 \mathrm{~kg} / \mathrm{m}^{3}$ & $2580 \mathrm{~kg} / \mathrm{m}^{3}$ & $2580 \mathrm{~kg} / \mathrm{m}^{3}$ \\
\hline Rock Specific Heat & $948 \mathrm{~J} / \mathrm{kg}^{\circ} \mathrm{C}$ & $728 \mathrm{~J} / \mathrm{kg}^{\circ} \mathrm{C}$ & $639 \mathrm{~J} / \mathrm{kg}{ }^{\circ} \mathrm{C}$ & $422 \mathrm{~J} / \mathrm{kg}^{\circ} \mathrm{C}$ & $488 \mathrm{~J} / \mathrm{kg}^{\circ} \mathrm{C}$ \\
\hline $\begin{array}{l}\text { Matrix Continuum } \\
\text { Permeability } \\
\text { Fracture Continuum } \\
\text { Permeability }\end{array}$ & $\begin{array}{l}1.5 \mathrm{e}^{-19} \mathrm{~m}^{2} \\
8.33 \mathrm{e}^{-10} \mathrm{~m}^{2}\end{array}$ & $\begin{array}{l}9.7 \mathrm{e}^{-19} \mathrm{~m}^{2} \\
8.33 \mathrm{e}^{-10} \mathrm{~m}^{2}\end{array}$ & $\begin{array}{l}4.5 \mathrm{e}^{-16} \mathrm{~m}^{2} \\
8.33 \mathrm{e}^{-10} \mathrm{~m}^{2}\end{array}$ & $\begin{array}{l}3.9 \mathrm{e}^{-14} \mathrm{~m}^{2} \\
8.33 \mathrm{e}^{-10} \mathrm{~m}^{2}\end{array}$ & $\begin{array}{l}2.7 \mathrm{e}^{-14} \mathrm{~m}^{2} \\
8.33 \mathrm{e}^{-10} \mathrm{~m}^{2}\end{array}$ \\
\hline $\begin{array}{l}\text { Formation Heat Conductivity } \\
\text { (dry) } \\
\text { Formation Heat Conductivity } \\
\text { (fully saturated) }\end{array}$ & $\begin{array}{l}1.26 \mathrm{~W} / \mathrm{m}^{\circ} \mathrm{C} \\
1.28 \mathrm{~W} / \mathrm{m}^{\circ} \mathrm{C}\end{array}$ & $\begin{array}{l}1.60 \mathrm{~W} / \mathrm{m}^{\circ} \mathrm{C} \\
1.69 \mathrm{~W} / \mathrm{m}^{\circ} \mathrm{C}\end{array}$ & $\begin{array}{l}1.35 \mathrm{~W} / \mathrm{m}^{\circ} \mathrm{C} \\
2.00 \mathrm{~W} / \mathrm{m}^{\circ} \mathrm{C}\end{array}$ & $\begin{array}{l}0.61 \mathrm{~W} / \mathrm{m}^{\circ} \mathrm{C} \\
0.85 \mathrm{~W} / \mathrm{m}^{\circ} \mathrm{C}\end{array}$ & $\begin{array}{l}0.84 \mathrm{~W} / \mathrm{m}^{\circ} \mathrm{C} \\
1.20 \mathrm{~W} / \mathrm{m}^{\circ} \mathrm{C}\end{array}$ \\
\hline $\begin{array}{l}\text { Total porosity } \bar{\phi} \\
\text { Fracture porosity } \bar{\phi}_{\mathrm{f}}\end{array}$ & $\begin{array}{c}0.07 \\
3.33 \mathrm{e}^{-4}\end{array}$ & $\begin{array}{c}0.08 \\
3.33 e^{-4} \\
\end{array}$ & $\begin{array}{c}0.24 \\
3.33 \mathrm{e}^{-4} \\
\end{array}$ & $\begin{array}{c}0.4 \\
3.33 e^{-4} \\
\end{array}$ & $\begin{array}{c}0.46 \\
3.33 e^{-4} \\
\end{array}$ \\
\hline $\begin{array}{l}\text { Sample from which matrix } \\
\text { characteristic curve is } \\
\text { derived (actual parameters } \\
\text { are given in Table 2) }\end{array}$ & TSw GU3-11 ${ }^{* *}$ & TCw G4-1 ${ }^{* *}$ & PPw G4-18 & PTn GU4-2 & CHnv GU3-14 ${ }^{* *}$ \\
\hline
\end{tabular}

** Klavetter and Peters, 1986 
with mixed waste decay characteristics. Buscheck and Nitao's simulations (Buscheck and Nitao, 1993) show a peak temperature of $177.5^{\circ} \mathrm{C}$ occurring at 122 years after waste emplacement. Our results (Figure 16) show a slightly lower peak temperature at around the same time after waste emplacement. Buscheck and Nitao's simulation predicts that temperatures at the repository center would remain above the nominal boiling point for 7331 years, while we obtain a substantially shorter period of above-boiling conditions of about 2500 years (see Fig. 16).

We cite another example where different input parameters can give rise to quantitative differences. For some of the scenarios studied by Buscheck and Nitao (1993) the liquid saturation in fact drops to zero, while our results, for all cases studied, always register repository average liquid saturations above zero. This can be attributed to different parametrizations of the capillary suction pressure at small liquid saturations. Figs. 1 - 4 show that capillary suction pressures rise steeply and become very strong for small liquid saturations. These data also have considerable uncertainty. Slight differences in the characteristic curves can cause capillary pressure differences on the order of tens of bars at small liquid saturations, giving rise to different vapor pressure lowering factors and consequently different liquid saturations. Aside from these specific quantitative differences which result from input parameter uncertainty, published thermal modeling results appear consistent. They agree in predicting substantial dry-out of the formations around the repository in an average sense. 


\section{Part II. Interpretation of Performance Model Predictions.}

An intriguing result from recent repository performance modeling is that, in the vicinity of the repository, water saturations are predicted to decline substantially due to evaporation. Because of capillary suction effects, liquid water would flow towards the region of diminished water saturation and could not cross the repository horizon ("capillary trapping"). Near the repository, drying effects would render liquid water immobile for extended time periods, or would cause liquid to disappear altogether. These predictions from the models, if realistic, suggest that repository heating and associated (partial) formation dry-out may enhance the waste isolation capabilities of the site. Aqueous phase transport of dissolved contaminants away from the repository would only be possible after liquid saturations in the vicinity of the repository would have returned back to near-ambient values. The time scale for this resaturation is, according to the performance models, on the order of thousands of years. The partial dry-out near the repository could be enhanced and made longer-lasting through increased thermal loading.

These observations have led the Livermore group to advocate a socalled "extended dry" repository concept. In a series of papers presented at recent High-Level Radioactive Waste Management Conferences, they suggested that one could could take advantage of the waste heat and dry out a significant volume of rock around the repository to achieve favorable effects for waste isolation (Ramspott, 1991; Nitao, Buscheck, and Chesnut, 1992; Buscheck and Nitao, 1992; 1993; Wilder, 1993).

In this section we first briefly summarize Livermore's case for an "extended dry" repository operation. Subsequently we proceed to a critical examination and discussion of the underpinnings and realism of this concept.

\section{Livermore's Concept of an "Extended Dry" Repository}

Making reference to simulations by Nitao (1988) and Buscheck and Nitao (1990), Ramspott (1991) suggested that "by designing ... an unsaturated tuff repository to constructively use heat, the waste containers can be kept dry for hundreds of years." He further claimed that "... the processes ... at 
temperatures greater than $90^{\circ} \mathrm{C}$ are either favorable or benign to waste isolation", and "... modeling of processes involved in drying the rock ... is easier than modeling sub-boiling processes." Nitao, Buscheck and Chesnut (1992) did acknowledged that "boiling of pore water near the waste package could lead to significant condensate fluxes all the way to the water table." However, they asserted nonetheless that "in an unsaturated environment, waste heat will dry the host rock which benefits performance by (1) removing water as a possible transport mechanism, and (2) providing a favorable environment that will reduce the likelihood of waste package corrosion."

This view was echoed by Wilder (1993). Citing simulation results of Buscheck and Nitao (1992), he suggested that "the dry-out approach would ell. inate not only container corrosion failures but also transport by water for thousands of years." He further suggested that "the need for extensive tests and analyses to assess flux is minimized for the extended dry-out approach," and "if above boiling conditions exist, perched water has little impact on performance since all water boils as it enters the dry-out zone, and thus cannot contact the waste." Further elaborating this line of reasoning, Buscheck and Nitao (1993) stated that "licensing of a sub-boiling or marginalboiling repository will be critically dependent on characterizing the highly heterogeneous distribution of fracture and matrix properties as well as the highly spatially and temporally variable distribution of net recharge flux." In contrast, licensing of an "extended-dry repository" was seen as a much simpler matter which "can be based on three fundamental considerations: (1) the spatial and temporal extent of above-boiling conditions, (2) how closely the dry-out zone corresponds to the zone of above-boiling conditions, and (3) how long it takes the dry-out zone to rewet back to ambient saturation."

The views expressed by the Livermore group can be summarized as follows. (1) The vicinity of the repository will boil dry from heat released by the waste packages. (2) The dried volume will increase with increasing heat load. (3) Drying is a beneficial effect that adds to the waste isolation capability of the site by removing potential aqueous phase transport paths for contaminants. (4) The task of site characterization is made easier and cheaper because "the need for extensive tests and analyses to assess flux is minimized for the extended dry-out approach" (Wilder, 1993). Consistent with this view, 
Buscheck et al. (1993) suggested that site characterization efforts should place major emphasis on large-scale in situ heater tests.

\section{Critique of the "Extended Dry" Concept}

Is "extended dry" a realistic outlook? Do the performance assessment models cited in support of this concept in fact support these interpretations? The comparison between thermal modeling efforts by different groups presented in Part I has not revealed any obvious inconsistencies. Differences between model predictions are generally minor and can be attributed to somewhat different choices for hydrologic and thermal parameters. It appears, therefore, that current repository performance modeling does provide consistent predictions for the conceptual and mathematical models used. The all-important question is then whether these models do or do not capture the essential aspects of site hydrology as far as dry-out and water flow behavior is concerned.

We believe that there are compelling reasons why the model predictions cannot be interpreted to suggest that an "extended dry" concept is feasible, or even desirable. The main reason why model predictions have to be viewed with caution is the internal variability and heterogeneity of the fractured-porous formations at Yucca Mountain. The present crop of performance assessment models does not begin to resolve the kind of smallscale variability that, in our view, will invariably lead to localized ponding of water, and will cause water flow to be channelized in "seeps and weeps," as opposed to uniformly averaged flow and saturation patterns on the scale of typical model grid blocks (1-10 m or more). We agree with Chesnut (1992) who emphatically stated that "since flow is probably highly heterogeneous, calculations based upon average flux may be completely wrong." None of the current repository performance models resolves fractures explicitly, much less the possibly very significant heterogeneity of the pore space within individual fractures. Instead, Yucca Mountain is represented as consisting of intrinsically homogeneous hydrogeologic units, with fracture-matrix behavior approximated by means of effective continuum concepts.

The effective continuum concept, originally proposed by Pruess et al. $(1984,1985)$, and subsequently elaborated by Peters and Klavetter (1988), Nitao 
(1988), and Pruess et al. (1988, 1990a, b), is an approximate method for modeling averaged fluid and heat flow in fractured-porous media. Such media are conceptualized as consisting of two interacting continua which are in approximate thermodynamic equilibrium locally: one continuum represents the rock matrix, the other, the network of fractures. Each continuum is viewed as being intrinsically homogeneous. The averaging implied in the effective continuum approximation entails both a spatial and a temporal component. The spatial averaging involves a number of matri: blocks and fractures, and a typical length scale of the order of several meters (Pruess et al., 1990b). Temporal averaging relates to characteristic times for equilibration of thermodynamic conditions between fractures and rock matrix. Depending on applicable thermal and hydrologic parameters, typical time scales at Yucca Mountain may range from days to months (Pruess et al., 1990b). Clearly, then, the effective continuum concept involves approximations which preclude any representation of processes with smallscale spatial and temporal variability. Dry-out "on average" as seen in performance assessment models cannot and must not be taken literally to suggest that liquid water cannot be present near the waste packages. Indeed, as will be discussed below, it appears likely that "some" of the waste packages will experience wet conditions "some" of the time, even and possibly more so for high thermal loading.

The prediction of (partial) dry-out near the repository may be realistic in an average sense. The associated tendency of "capillary trapping" of liquid phase in the region of reduced water saturation would contribute favorably to waste isolation. However, complete drying of the repository environment is, in our view, not feasible. Increased thermal loading would be expected not only to increase vaporization rates and drying on average, it would also increase the rates at which condensate would form. This would tend to promote non-equilibrium matrix-fracture flow effects, and could well result in an increase of localized and intermittent water flow near waste packages for high thermal loads.

Present performance assessment models have additional limitations. External forcings such as infiltration with climatic variability are either neglected or represented only in highly simplified fashion. There is 
considerable uncertainty about some of the important hydrologic parameters, such as relative permeability and capillary pressure data, especially for fractures. In fact, one may well question to what extent "continuum concepts" such as capillary pressure and relative permeability may even be relevant to water flow at Yucca Mountain. Note also that the performance models are not calibrated, let alone validated, against observations on meaningful space and time scales.

In the following sections we present a number of simple estimates to show that (i) liquid water can be present and flowing even if high thermal loading would be employed to achieve formation temperatures above the nominal boiling point of water; (ii) relatively minor amounts of infiltration will begin to exceed the vaporization capacity of waste heat within a time frame of a few thousand years; and (iii) modest discharges of ponded water would be sufficient to overcome the vaporization capability of individual waste packages. We also note that thermal modeling work by Ryder (1993) has shown strong "edge effects," which would greatly complicate the achievement of dry conditions even in a homogeneous hydrogeologic setting. All these effects and phenomena suggest that it is not possible to design and operate the repository in a manner that would assure dry waste package environments for a 10,000 year time frame. The concept of "extended dry", while intuitively appealing, appears viable only for the idealizations and simplifications made in computer modeling.

\section{Thermodynamic Effects}

As water boils in response to repository heating, vapor is generated inside porous matrix rocks. Due to its much smaller density in comparison to liquid water (e.g., at a temperature of $100{ }^{\circ} \mathrm{C}$, vapor and liquid densities are, respectively, .598 and $958.3 \mathrm{~kg} / \mathrm{m}^{3}$; Keenan et al., 1969), the vapor will pressurize and will subsequently flow away from the boiling region, towards cooler and more permeable zones (e.g., fractures), where it condenses. Pressures and temperatures will increase, depending on the rate of heating and the "ease" with which vapor can flow away from the boiling regions (i.e., sizes and permeabilities of matrix blocks). 
In addition to this "dynamic" temperature rise there will be another "static" effect, that would occur even if matrix permeabilities were large enough (or fracture spacing small enough) to minimize pressurization of vapor during boiling. Inside porous media, suction pressures from capillary and phase adsorption effects reduce vapor pressures below the "saturated vapor pressures" that would be present above a free plane surface of bulk water. As a consequence it is possible for water to exist in liquid form, even under conditions of thermodynamic equilibrium, at temperatures well in excess of saturation temperatures for ambient pressures. The vapor pressure lowering effect is expressed by Kelvin's equation:

$$
P_{v}\left(T, P_{\text {suc }}\right)=P_{\text {sat }}(T) \bullet \exp \left\{\frac{m_{1} P_{\text {suc }}}{\rho_{1} R(T+273.15)}\right\}
$$

Here $\mathrm{T}$ is temperature in ${ }^{\circ} \mathrm{C}, \mathrm{P}_{\text {sat }}$ is saturated vapor pressure of "free" liquid, $P_{\text {suc }} \leq 0$ is capillary and phase-adsorptive suction pressure, $\rho_{l}$ is liquid density, $\mathrm{m}_{1}$ the molecular weight of the fluid, and $\mathrm{R}$ is the universal gas constant. By solving Eq. (4) for $T$, we can determine the temperatures that would be required to generate a certain vapor pressure as a function of applied suction. Using water properties from the steam table equations recommended by the International Formulation Committee (1967), we have calculated boiling temperatures as a function of suction pressures (Fig. 20). It is seen that the temperatures at which vapor-liquid mixtures are in thermodynamic equilibrium increase very significantly as suction pressure approach and exceed $10^{8} \mathrm{~Pa}$ (1000 bars). Suction pressures of such magnitude do occur at low (non-zero) liquid saturations (Pruess and O'Sullivan, 1992), suggesting that dry-out with complete removal of aqueous phase will only take place when temperatures rise substantially above the nominal boiling point. Additional vapor pressure lowering can arise from salinity. For example, the vapor pressure of saturated $\mathrm{NaCl}$ solutions is only about $2 / 3$ that of pure water (Battistelli et al., 1993). Although ambient waters at Yucca Mountain have low salinity, they may become highly concentrated from vapor-liquid counterflow (heat pipe) effects, and reach saturated levels in boiling zones near the waste packages. 


\section{Coping with Infiltration}

The rate of net infiltration at Yucca Mountain under present climatic conditions is not well known but is believed to be small, of order $1 \mathrm{~mm} / \mathrm{yr}$ or less, and quite possibly near zero. It might even be negative, as there appears to be some evidence that the entire mountain is slowly drying (water table falling). Even if net infiltration were zero or negative overall, we expect some spatial variability with localized downflows, balanced by drying in other parts of the mountain. The natural geothermal gradient has been estimated to cause upward vapor diffusion at a liquid water-equivalent rate of approximately .03 - .04 mm/yr (Ross, 1984; Tsang and Pruess, 1990). The condensate formed from the vapor at shallower depths may flow downward partially through preferential pathways with locally larger rates and velocities. Substantially larger net infiltration, perhaps of order $10 \mathrm{~mm} / \mathrm{yr}$ on average, may occur in response to more pluvial climatic conditions in a 500 10,000 year time frame.

How would infiltrating water interact with the heat released from the high-level waste packages? As water flows towards the waste packages it may partially vaporize. One may inquire as to the capacity of the waste heat to vaporize incoming water: what is the maximum rate of water flow that can be completely vaporized? Water infiltration from the surface could be partially buffered by the large rock mass and pore volume between land surface and repository horizon. Therefore, if infiltrating flux exceeds the vaporization capacity of the waste heat there may be a considerable lag time before such infiltration would be felt at the repository horizon. An effect opposite to buffering is also possible, namely, the heterogeneity of the rock mass may cause downward water fluxes to be highly non-uniform. Even if areallyaveraged water fluxes were small, highly-focused localized flow may occur at large rates and velocities. Such water flow along "fast paths" may expose a portion of the waste packages to wet conditions with fast travel times.

Models of different levels of complexity and realism can be developed to estimate the various effects. Interaction with the waste heat can be estimated from instantanəous heat release rates, or from heat output 
integrated over time. The latter approach implicitly acknowledges the buffering action of the formations overlying the repository horizon in smoothing out variations of infiltration rates over time. One may allocate all available heat to vaporization or, less conservatively, allow for the fact that waste heat transferred to the formation must partition between rocks and fluids. In this section we focus on waste heat and estimations of vaporization rates. Subsequently we proceed to discussing effects of formation heterogeneity on spatial distribution of infiltration.

For a given time-dependent heat output $G(t)$ (units: $W$ ), an absolute limit for the mass rate $Q(\mathrm{~kg} / \mathrm{s})$ at which liquid water can be vaporized is given by

$$
\mathrm{Q} \leq \frac{\mathrm{G}}{\mathrm{h}_{\mathrm{vl}}}
$$

Here $h_{v l}=h_{v}-h_{l}$ is the specific heat of vaporization (units: J/kg), i.e., the difference in specific enthalpies for vapor and liquid phases. In order to derive limits on the amount of infiltrating flux that can be vaporized, consider vertical emplacement of waste packages on a regular square pattern, as shown in Fig. 21. If infiltration occurs at an average volumetric rate $q$ (units of $\mathrm{m}^{3} / \mathrm{m}^{2} \mathrm{~s}$, or $\mathrm{mm} /$ year), the mass rate of liquid water infiltrating over the area $A$ per waste package is $Q=A q \rho_{l}$. The maximum volumetric infiltration rate that could be completely vaporized by waste heat is then, from Eq. (5),

$$
\mathrm{q}=\frac{\mathrm{G}}{\mathrm{A} \rho_{1} \mathrm{~h}_{\mathrm{vl}}}
$$

For a thermal loading of $57 \mathrm{~kW} /$ acre at an initial power level of $3.051 \mathrm{~kW}$ per package for 10 year old high-level wastes, the area per waste package is $\mathrm{A}=$ $213.2 \mathrm{~m}^{2}$. Using steam table equations for thermophysical properties of water (IFC, 1967), and assuming that infiltrating water has a temperature of $13{ }^{\circ} \mathrm{C}$ and vapor is generated at $100{ }^{\circ} \mathrm{C}$, we have calculated time-dependent water rates from Eqs. (5) and (6). Figs. (22) and (23) show that initially heat generation rates are large, and equivalent water infiltration rates in excess of 
$100 \mathrm{~mm} / \mathrm{yr}$ could be completely vaporized. As heat output declines, potential vaporization rates drop below $10 \mathrm{~mm} / \mathrm{yr}$ after 700 years, and to below 3 $\mathrm{mm} / \mathrm{yr}$ after 3,000 years. Note that, for different thermal loading, the vaporization rates would scale proportional to the areal power density.

We have examined several variations of the above simple model for waste heat interaction with infiltration. A less stringent infiltration limit can be defined by considering total cumulative heat output instead of the instantaneous heat generation:

$$
\hat{\mathrm{G}}=\int_{0}^{\mathrm{t}} \mathrm{G}\left(\mathrm{t}^{\prime}\right) \mathrm{dt^{ \prime }}
$$

Defining an average infiltration rate $\hat{q}=\int q d t^{\prime} / t$, the vaporization limit on infiltration for the cumulative heating model becomes

$$
\hat{\mathrm{q}}=\frac{\hat{\mathrm{G}}}{\operatorname{At} \rho_{1} h_{\mathrm{vl}}}
$$

Estimates obtained by using Eq. (8) are plotted in Figs. 24 and 25. Comparing with Figs. 22 and 23, it is seen that infiltration limits derived from cumulative heat generation are larger by only a modest factor of $2-3$ in the time frame from 1,000 to 10,000 years.

More stringent limits can be obtained by allowing for the fact that (i) only approximately half of total heat output goes upward where it would impact incoming infiltration, and (ii) heat is lost from the system at the land surface at a rate which can be estimated as $G_{\text {cond }}=\lambda A \partial T / \partial Z$. Here, $\lambda$ is thermal conductivity, and the average temperature gradient at "sufficiently" late time is approximately (Trep - Tl.s.) $/ 375 \approx(100-13) / 375=.232^{\circ} \mathrm{C} / \mathrm{m}$. Using $\mathrm{G} \rightarrow \mathrm{G}^{\prime}=\mathrm{G} / 2-\mathrm{G}_{\mathrm{c} \sim \text { nd }}$ in Eqs. $(5,6)$ we obtain the estimates plotted in Figs. 26 and 27.

Further refinement of the vaporization models is achieved by allowing for the fact that, as heat is transferred to the formation, it must partition between the pore fluid and the porous medium. Let $G_{i \rightarrow f}$ denote the amount 
of heat required to raise a unit volume of formation from initial temperature $T_{i}$ to final temperature $T_{f}$, and to completely vaporize all liquid at temperature $\mathrm{T}_{\mathrm{f}}$. We have

$$
\begin{aligned}
G_{i \rightarrow f}= & \phi S_{1} \rho_{1}\left[h_{v}\left(T_{f}\right)-h_{l}\left(T_{i}\right)\right] \\
& +(1-\phi) \rho_{R} c_{R}\left(T_{f}-T_{i}\right)
\end{aligned}
$$

Here $\phi$ is formation porosity, $h_{v}\left(T_{f}\right)$ is vapor enthalpy at temperature $T_{f}$, $h_{1}\left(T_{i}\right)$ is liquid enthalpy at temperature $T_{i}$, and $\rho_{R}$ and $c_{R}$ are, respectively, the density and specific heat of the rock grains. The first term in Eq. (9) represents the heat transferred to the fluid, while the second term represents the heat transferred to the rock. The fraction $\gamma$ of total heat transfer available for vaporization is given by

$$
\gamma=\frac{\phi S_{1} \rho_{1} h_{v l}}{G_{i \rightarrow f}}
$$

where $h_{\mathrm{vl}}$ is the vaporization enthalpy at temperature $T_{f}$. Using typical parameter values of $\phi=0.1, \mathrm{~S}_{\mathrm{l}}=0.8,\left(\rho_{\mathrm{R}} \mathrm{C}_{\mathrm{R}}\right)=2.6 \times 10^{6} \mathrm{~J} / \mathrm{m}^{3}{ }^{\circ} \mathrm{C}, \mathrm{T}_{\mathrm{i}}=20{ }^{\circ} \mathrm{C}, \mathrm{T}_{\mathrm{f}}=$ $100{ }^{\circ} \mathrm{C}$, we obtain $\gamma \approx 0.50$. Thus only approximately half of the heat transferred to the formation is available for vaporization, the other half is used up to heat the porous medium and the pore water to the vaporization temperature. Allowing for this partitioning of total heat transfer, the quantities $G$ and $\hat{G}$ in Eqs. (5) - (8) should be multiplied by a factor $\gamma \approx 0.50$, and the estimates given in Figs. $22-27$ for infiltrating water flux that can be vaporized should be reduced by the same factor.

The estimates presented above are approximate and are not meant to rigorously define the operating envelope for "dry" repository conditions. Indeed, not all infiltrating water would need to be vaporized in order that dry conditions could be maintained at the waste packages. We have performed numerical simulation studies in which infiltration at different rates was initiated 1,000 years after waste emplacement. Our results for $57 \mathrm{~kW} /$ acre thermal loading with $10 \mathrm{yr}$ old fuel indicate that a rate of $10 \mathrm{~mm} / \mathrm{yr}$ will obliterate the partially dried out zone around the repository within a 2,000 year time frame, while for infiltration at a rate of $1 \mathrm{~mm} / \mathrm{yr}$ this zone persists 
for $>10,000$ years (Pruess and Tsang, 1993). These simulation results are consistent with the estimates given above, suggesting that the simple approximation Eq. (6) can indeed be used as a rough indication of infiltration conditions that would be compatible with a "dry" repository concept.

We conclude that estimates from very simple and robust models indicate that a zone of average partial dry-out around the repository can be maintained for several thousand years only if net infiltration remains below a few $\mathrm{mm}$ per year. These estimates were confirmed by means of detailed numerical simulation studies (Pruess and Tsang, 1993).

\section{Heterogeneity}

In agreement with Chesnut (1992), we believe that an understanding of heterogeneity holds the key to evaluating repository performance and site suitability. At Yucca Mountain formation heterogeneity is present in different geometric patterns and spatial scales. On the largest scale we have layering of welded and non-welded units, and major fractures and faults that may extend beyond lithologic units. Within each of the units there are fracture networks embedded in permeable matrix rocks. Within the fractures there are variations in aperture, surface roughness, coatings, and fill.

Water flow under partially saturated conditions in this hydrologic setting is likely to be highly heterogeneous. In addition to matrix flow we expect sparse channelized flow ("seeps and weeps") in the fractures. Substantial amounts of ponded water may be present naturally in regions of small permeability. Ponded water may be released and become available for downward flow virtually instantaneously as fractures open, perhaps from thermally induced stress. Vaporization from thermal loading, and subsequent condensation, may cause channelized downflow of water, and may accumulate additional pools of ponded water.

\section{Rainier Mesa - A Possible Analogue for Yucca Mountain}

Useful insight into possible modes of water flow at Yucca Mountain may be gained from existing studies of the hydrogeology at Rainier Mesa (Thordarson, 1965; Cook et al., 1991). "Rainier Mesa ... is the highest of a group of ridges and mesas within the Nevada Test Site. The mesa is about 9.5 square 
miles in area and reaches a maximum altitude of 7,679 feet. The mesa is underlain by welded tuff, friable-bedded tuff, and zeolitized-bedded tuff ... 2,000 to 5,000 feet thick..." (Thordarson, 1965). Cook et al. (1991) discussed Thordarson's study with a view on evaluating the appropriateness of Rainier Mesa as an analogue for Yucca Mountain. As chief differences with respect to Yucca Mountain they note that (i) net infiltration is larger, estimated at $8 \%$ of average annual precipitation of 7.5 inches, or approximately $15 \mathrm{~mm} / \mathrm{yr}$; and (ii) the tuff formations at Rainier Mesa have matrix permeabilities that appear to be larger than those of their Yucca Mountain counterparts by as much as a few orders of magnitude. The unsaturated zone at Yucca Mountain extends to a depth of approximately $600 \mathrm{~m}$ below land surface, while "the water table at Rainier Mesa is located about 1,000 m below the surface in the dolomite, which is overlain by some $550 \mathrm{~m}$ of bedded tuffs resembling those at Yucca Mountain..." (Cook et al., 1991). Observations in the extensive system of tunnels beneath Rainier Mesa showed many localized water inflows from joints and faults. From studies of stable isotopes and tritium content it was determined that the inflow was much less saline than water extracted from the tuff matrix, and that it was of recent meteoric origin (1 - 6 years old; Clebsch, 1961, as cited by Thordarson). These observations strongly suggest that water traveled along "fast paths", which is surprising to many because straightforward application of capillary theory would suggest that water flow should be restricted to the rock matrix at prevailing partially saturated conditions (Wang and Narasimhan, 1985). Cook (1991) remarks "At this stage, it is not known how fractures could remain sutficiently saturated to act as fast paths in the face of high matrix suction."

The observations at Rainier Mesa are tantalizing and challenging. They suggest that great caution should be exercised when applying theoreticallybased concepts and predictions to multiphase flows in highly heterogeneous media. The implications of capillary suction effects for matrix and fracture flow may appear irrefutable to the theoretician, yet field observations show ubiquitous fast path flow in fractures. It appears as though formation heterogeneities make strong spatial focussing of flow not only possible but likely. This concept is supported by experimental studies of unsaturated flow (Glass et al., 1991; Nicholl et al., 1993) and recent theoretical models of partially saturated flow in fracture networks (Kwicklis and Healy, 1993; 
Karasaki et al., 1994). Temporal flow focussing (intermittent "on-off" flow) may also be important (Thunvik and Braester, 1990; Persoff and Pruess, 1993), as may be the frequent presence of ponded water. The experience at Rainier Mesa suggests that reliable information on water travel at Yucca Mountain can only be obtained through direct observations underground.

For the time being we consider it highly likely that channelized fast water flow beneath Yucca Mountain is the rule rather than the exception. Accordingly, we propose to investigate how channelized liquid flow would interact with the repository heat. We begin by briefly summarizing some of the information on fractured rock heterogeneity collected in the recent "validation drift" experiments at the Stripa Mine, Sweden. Being located in the saturated zone, Stripa is only of limited value as an analogue to Yucca Mountain. However, it provides a useful context for the discussion of flow effects from heterogeneity of fractured rock masses.

\section{Stripa Site Characterization and Validation Project.}

An intensive program of detailed geologic mapping, inflow measurements, and modeling was carried out at Stripa, an abandoned iron ore mine in central Sweden (Olsson, 1992; Long et al., 1992). A "validation drift" of $50 \mathrm{~m}$ length and $3 \mathrm{~m}$ diameter was excavated at a depth of $385 \mathrm{~m}$ beneath the ground surface (Fig. 28). Drift wall mapping indicated approximate fracture densities of 4 fractures $/ \mathrm{m}^{3}$ in "average" rock, and 30 fractures $/ \mathrm{m}^{3}$ in the so-called H-zone (Fig. 29; Hodgkinson and Cooper, 1992). Average permeabilities are approximately $20 \mu \mathrm{d}$ in the average rock, and 150 $\mu \mathrm{d}$ in the H-zone (Herbert et al., 1991). As can be seen from Figs. $29-31$, fractures are ubiquitous and have numerous intersections. It may appear surprising, then, that of the many hundred fractures mapped on the drift walls, only a limited number in two major sets were found to contribute to inflow (Fig. 32; Harding and Black, 1992). $99 \%$ of all inflow occurred in the Hzone, which covers $14 \%$ of the drift wall area. $57 \%$ of inflow occurred in an area of $1 \mathrm{~m}^{2}$, corresponding to $0.2 \%$ of drift wall area; thus, water flux in the preferred inflow region is larger than average flux in the remainder of the drift by a factor of approximately $660 ! 38 \%$ of the H-zone has no inflow at all, while another $13 \%$ of the $\mathrm{H}$-zone contributes $6 \%$ of inflow. 
The validation drift data suggest that water flow in fractured rock is highly heterogeneous and channelized. Fractures appear to conduct significant amounts of fluid only over a small fraction of their area, which is in agreement with general observations made in tracer tests (Tsang and Tsang, 1987). Heterogeneity of flow is very pronounced, with little or no flow occurring over most of the fracture areas. The customary depictions of fracture networks as intersecting planes (see Figs. 30,31) tend to suggest a much higher degree of network connectivity than is actually present. Under partially saturated conditions one may expect that water flow in fractures could be even more focused and localized in small portions of the entire fracture areas.

An intriguing analysis of earlier inflow measurements at Stripa was presented by Chesnut (1992). He showed that the spatial distribution of flux was log-normal, consistent with a large body of evidence from water-flooding of heterogeneous petroleum reservoirs. The log-normal model is attractive because of its simplicity. It also has considerable empirical support from analyses of permeability distributions in heterogeneous media. Whether or not the model is applicable to water flux distributions and ground water travel time at Yucca Mountain remains to be seen. It is a feature of the lognromal distribution that a considerable fraction of flow will occur at high flux rates, or fast travel times. This again emphasizes the crucial role of heterogeneity for site suitability at Yucca Mountain.

Based on the observations at Stripa, and on much additional qualitative and circumstantial evidence from other mines, we believe that water flow at Yucca Mountain should be expected to be highly heterogeneous. Downflow is likely to be highly localized in channels of small cross-sectional area, with little or no flow present over much of the area. Even if net infiltration at Yucca Mountain were near zero, or possibly negative (overall drying of the mountain), it is to be expected that episodic or persistent downflow of water may be present in localized areas. Observations in the experimental studies facility (ESF) currently under construction will hopefully provide a basis for more detailed and quantitative assessments in the future. 


\section{Channelized Water Flow at Yucca Mountain}

Even if highly focused, channelized, and possibly rather rapid water movement along preferential paths at Yucca Mountain occurs in the "natural state," this does not necessarily imply that such flow can persist in the presence of a repository with significant heat generation. We have performed preliminary modeling studies to examine whether channelized water flow over "large" depth intervals is possible in the presence of thermal loading with formation temperatures above the nominal boiling point, and allowing for imbibition into a rock matrix of low permeability but strong capillary suction. We have also examined some aspects of possible behavior of ponded water. An important question relates to the amount of ponded water that would need to be discharged so that it could flood a waste package without being completely vaporized. Further we are interested to examine whether ponded water, once released due to changing fracture permeability, could flow all the way to the water table without being (entirely) adsorbed by matrix imbibition.

\section{Models for Channelized Water Flow}

Under natural conditions, preferential flow channels for water will emerge from the heterogeneity of pore spaces and wall rock permeability of individual fractures and fracture networks. Ideally, performance assessment models should represent such heterogeneity in sufficient detail and realism so that preferential flow channels would arise in a natural way. Calculational demands of models with sufficiently detailed heterogeneity are very large, however, especially when considering that very complex coupled fluid and heat flow processes from the thermal load of the repository need to be accounted for. Therefore, we have in our preliminary scoping studies pursued a much more simplified approach. Instead of working with fracture heterogeneity detailed enough to permit flow channels to emerge naturally, we specify such channels explicitly as high-permeability regions of small cross-sectional area and large vertical extent. The most likely regions where water flow channels could persist is away from the heat generating waste packages. For modeling purposes we choose a regular geometric pattern of waste emplacement as shown in Fig. 33, and model one symmetry element. 
We further simplify the model by approximating the three-dimensional flow geometry with a 2-D axisymmetric grid centered about the presumed flow channel. As a consequence, the four discrete heat sources surrounding the channel will be smeared out over the mantle of the cylinder drawn around the channel. This approximation is expected to be adequate, especially in the most important region near the channel.

For the reference case of $57 \mathrm{~kW} /$ acre loading with waste packages containing 10 year old fuel, the area per waste package is $213.2 \mathrm{~m}^{2}$. Accordingly, the cylindrical symmetry element shown in Fig. 33 is modeled as having an outer radius of $8.237 \mathrm{~m}$. Vertical stratigraphy was assumed identical to our repository-scale R-Z model (see Table 1). Rather arbitrarily, the channel was specified as a high-permeability region with $20 \%$ porosity, having a radius of $1 \mathrm{~cm}$ and extending from $150 \mathrm{~m}$ depth all the way down to the water table. Two alternative models for permeability were employed. In model 1, channel walls are assumed impermeable, while in model 2 channel walls are permeable, with permeabilities equal to the unfractured rock in the appropriate stratigraphic layers (see Table 1). Effective continuum descriptions are employed beyond the channel walls. In model 1 , channel permeability is assumed as 9 darcies, while in model 2 it is 100 darcies. Water is infiltrating at $225 \mathrm{~m}$ depth at modest rates of $3 \times 10^{-6} \mathrm{~kg} / \mathrm{s}$ (approximately $0.251 /$ day) for model $1,250 \times 10^{-6} \mathrm{~kg} / \mathrm{s}$ (approximately $22 \mathrm{l} /$ day) for model 2 .

The parameters chosen here for channel geometry, permeability, and flow rate are admittedly speculative, as we have no data from Yucca Mountain to constrain them. The intent in the present study was to select what appeared to be "modest" values for channel permeability and flow rate, and to then examine whether a scenario without "extreme" assumptions would yield water flow across the repository horizon.

Results of TOUGH2 simulations for channel temperatures and water saturations at the repository horizon are given in Fig. 34. For both models, maximum channel temperatures in response to repository heating peak near $100{ }^{\circ} \mathrm{C}$. Water saturations decline at early times, then rise again as heat output from the wastes decline. Downflow of water across the repository horizon is found to persist throughout. 
Data on preferential water flow at Yucca Mountain are presently unavailable, and the models for channelized water flow discussed here are highly schematic and artificial. Simulation results should not be taken as providing a quantitatively realistic outlook at flow processes at Yucca Mountain; however, they demonstrate that persistent downflow of water appears possible across a repository horizon where average temperatures would be predicted to be above the nominal boiling point.

\section{Ponded Water}

The geometry, frequency, and amount of water ponding at Yucca Mountain has not yet been characterized. We also lack information on details of the permeability structure that could induce ponding of condensing vapor as a consequence of repository heating. Such information is expected to become available from the Experimental Studies Facility (ESF). Ponded water could significantly impact repository performance. Ponds of water present naturally, or accumulated from vapor condensate, could discharge more or less instantaneously, e.g., as fractures open in response to thermal or tectonic stress. After ponded water is released into permeable pathways it would begin to flow downward. On approaching the repository horizon it would partially vaporize due to heat transfer from the rock. If a "sufficient" quantity of ponded water were released into "sufficiently" permeable pathways, some of it could escape vaporization and matrix imbibition, contact the waste packages, pick up some water-soluble radionuclides, and continue to flow downward to the water table.

Obviously, the potential hazard posed by ponded water or condensate and its sudden release depends on an interplay of many processes and parameters. In an effort to get some basic insight into whether or not water ponding may pose significant hazards, we have examined one simple aspect of the problem. Namely, we estimate the amount of water that, if instantaneously released, would be needed to overcome the vaporization capability of the waste package. More specifically, we assume that a waste package is instantaneously flooded by an as yet undetermined quantity of water. Conservatively we assume that the entire waste package is at a uniform temperature of $350{ }^{\circ} \mathrm{C}$ at the time it is flooded. The liquid water is 
assumed to have a temperature of $100{ }^{\circ} \mathrm{C}$, and to be vaporized from heat transfer by the package into steam at $100{ }^{\circ} \mathrm{C}$. We determine the amount of water that could be so vaporized if the waste package is cooled to uniform 100 ${ }^{\circ} \mathrm{C}$. This will give a conservative (large) estimate of the amount of water that would be needed to overcome the vaporization capability of the waste package. Clearly, if the waste package temperature is lower initially, or if water contacts and cools only a portion of the waste package, smaller amounts of water could survive waste package contact without complete vaporization. Using heat capacity data that were kindly provided to us by G. Johnson of LLNL (1993, private communication), we obtain the vaporization capabilities shown in Table 5 for three current alternative waste package designs.

Table 5. Maximum Water Vaporization for Different Waste Package Designs

\begin{tabular}{|c|c|c|c|}
\hline Waste form & $\begin{array}{c}\text { Total heat } \\
\text { capacity }\left(\mathrm{MJ} /{ }^{\circ} \mathrm{C}\right)\end{array}$ & $\begin{array}{l}\text { Vaporizatic } \\
\qquad(\mathrm{kg})\end{array}$ & $\begin{array}{l}\text { capability } \\
\left(\mathrm{m}^{3}\right)\end{array}$ \\
\hline (1) & 15.85 & 1754.5 & 1.83 \\
\hline (2) & 5.85 & 646.9 & 0.68 \\
\hline (3) & 3.27 & 362.2 & 0.38 \\
\hline
\end{tabular}

\# Data from Gary Johnson, LLNL, private communication

(1) package for drift emplacement, with 21 PWR spent fuel assemblies

(2) package for vertical emplacement, with consolidated fuel from 3 PWR or 4 BWR assemblies

(3) package for vertical emplacement, with unconsolidated fuel (intact assemblies)

These estimates indicate that the amount of ponded water that would be required to partially survive a waste package contact in liquid form is not large. Very conservatively it is of the order of $1 \mathrm{~m}^{3}$, and is most likely 
considerably less. We expect water ponds of this magnitude to be numerous, suggesting that repeated episodic flooding of waste packages may be quite likely. To further place the vaporization estimates in perspective, we have calculated the total cumulative amounts of condensate that could be generated from the waste heat.

Table 6. Cumulative Heat and Corresponding Condensate Generation for a Vertically Emplaced Package of 10 Year old Fuel

\begin{tabular}{|c|c|c|c|}
\hline $\begin{array}{l}\text { time after } \\
\text { emplacement } \\
\text { (years) }\end{array}$ & $\begin{array}{c}\text { cumulative } \\
\text { heat generation } \\
\left(10^{12} \text { Joules }\right)\end{array}$ & $\begin{array}{l}\text { maximun } \\
\text { condensa } \\
\left(10^{6} \mathrm{~kg}\right)\end{array}$ & $\begin{array}{l}\text { cumulative } \\
\left(10^{3} \mathrm{~m}^{3}\right)^{\ddagger}\end{array}$ \\
\hline 10 & .8658 & .3303 & .3447 \\
\hline $10^{2}$ & 4.488 & 1.712 & 1.786 \\
\hline $10^{3}$ & 12.39 & 4.726 & 4.932 \\
\hline $10^{4}$ & 27.59 & 10.52 & 10.98 \\
\hline $10^{5}$ & 51.05 & 19.47 & 20.32 \\
\hline
\end{tabular}

$\dagger$ Based on converting water at $13^{\circ} \mathrm{C}$ to $100^{\circ} \mathrm{C}$ vapor; heat of vaporization is $\mathrm{h}_{\mathrm{vl}}=2621.5 \mathrm{~kJ} / \mathrm{kg}$.

$\ddagger$ Based on water density of $958.3 \mathrm{~kg} / \mathrm{m}^{3}$ at $100^{\circ} \mathrm{C}$.

As shown in Table 6, the amount of condensate that could be potentially generated from the heat output of a single waste package is huge, of the order of thousands of $\mathrm{m}^{3}$. Comparing this with the previous estimates of vaporization capabilities suggests that vapor condensate could easily generate many water ponds of a magnitude that could induce liquid phase flow past a waste package. In conclusion, then, ponding and releases of water ponds appear to be credible occurrences with potentially significant impact on waste package and repository performance and design. The issue clearly deserves further detailed study. 


\section{Conclusions}

The main conclusions reached from the studies presented here are as follows.

(1) Hydrologic and thermal data used by different groups active in repository performance assessment modeling are generally in agreement. Some significant differences exist which should not be surprising in view of the fact that new data for Yucca Mountain are coming in all the time, and that much uncertainty remains.

(2) Thermal modeling results from different groups appear consistent. Existing differences are minor and can be traced to somewhat different data or assumptions used. The existing differences do not materially affect the evaluation of alternative thermal loading strategies.

(3) Present repository thermal performance models are conceptually similar. They employ fairly large-scale averaging, such as effective continuum approximations, homogeneous hydrostratigraphic units, and typical grid block dimensions of order $1-100 \mathrm{~m}$. Such models can only provide insight into large-scale average thermal and hydrologic behavior, but cannot be used to resolve issues relating to small-scale heterogeneity.

(4) Present performance assessment models predict formation of an extensive zone of partial dry-out around the repository, which is surrounded by a condensation halo. It is important to note that this prediction pertains only to large-scale averages. In no way can it be taken to imply that liquid water will be absent from the vicinity of the waste packages. On the contrary, thermodynamic effects, external forcings (climatic variability), and internal heterogeneities all make it likely that some and quite possibly most of the waste packages will experience wet conditions some of the time.

(5) Simple robust estimates suggest that, even for large thermal loadings, water infiltration in excess of a few millimeters per year will lead to widespread wet conditions in the repository within a few thousand years.

(6) Experience with fractured rock systems suggests that water flow at Yucca Mountain is likely to be channelized in highly localized preferential pathways. However, data required to determine the behavior of water in the unsaturated zone at Yucca Mountain are not presently available.

(7) We have performed simulation studies using modest (albeit hypothetical) assumptions about preferential water flow paths. Our results 
indicate that channelized water flow across the repository horizon can persist even if average repository temperatures are well above the nominal boiling point.

(8) Ponding of water and its episodic release due to changing stress and permeability conditions is another mechanism that is capable of inducing numerous instances of transient wet conditions at waste packages. The amount of ponded water that would need to be discharged to escape complete vaporization from direct waste package contact is modest, typically of order 1 $\mathrm{m}^{3}$ or less. By comparison, the amount of condensate that can be generated from the heat of a single waste package is huge, of order of thousands of cubic meters.

(9) Increased thermal loading will not necessarily increase the likelihood of dry waste package environments. Indeed, it would cause both vaporization and condensation to occur at higher rates, which may promote fast water flow due to non-equilibrium fracture-matrix flow effects.

\section{Acknowledgement}

The authors are grateful to Peter Gottlieb of TRW and Gary Johnson of LLNL for making data available to us prior to publication. Thanks are due to G. Bodvarsson and J. Wang for a critical review of the manuscript and suggestions for improvements. This work was supported by the Director, Office of Civilian Radioactive Waste Management, Yucca Mountain Site Characterization Project Office, Regulatory and Site Evaluation Division, through U.S. Department of Energy Contract No. DE-AC03-76SF00098.

\section{References}

Battistelli, A., C. Calore and K. Pruess, 1993. A fluid property module for the TOUGH2 simulator for saline brines with non-condensible gas, presented at the 18th Workshop on Geothermal Reservoir Engineering, Stanford University, January 26-28.

Bird, R. B., W. E. Stewart and E. N. Lightfoot, 1960. Transport Phenomena, J. Wiley and Sons, New York, NY.

Buscheck, T.A. and J. J. Nitao, 1992. The impact of thermal loading on repository performance at Yucca Mountain, Proceedings, Third High Level Radioactive Waste Management International Conference, Las Vegas, NV, April 12-16. 
Buscheck, T.A. and J. J. Nitao, 1993. The analysis of repository-heat-driven hydrothermal flow at Yucca Mountain, Proceedings, Fourth High Level Radioactive Waste Management International Conference, Las Vegas, NV, April 26-30.

Buscheck, T.A., Wilder, D.G. and J. J. Nitao, 1993. Large-scale in situ heater tests for hydrothermal characterization at Yucca Mountain, Proceedings, Fourth High Level Radioactive Waste Management International Conference, Las Vegas, NV, April 26-30.

Chesnut, D.A., 1992. Characterizing the Altered Zone at Yucca Mountain: The Beginning of a Testing Strategy, Proceedings, Third High Level Radioactive Waste Management International Conference, Las Vegas, NV, April 12-16.

Clebsch, A., 1961. Tritium Age of Groundwater at the Nevada Test Site, Nye County, Nevada, U.S. Geological Survey, Professional Paper 424-C.

Cook, N.G.W., I. Javandel, J.S.Y. Wang, H.A. Wollenberg, C.L. Carnahan, K.H. Lee, 1991. A review of Rainer Mesa tunnel and borehole data and their possible implications to Yucca Mountain study plans, Lawrence Berkeley Laboratory Report LBL-32068, December.

Flint A. L., L. E. Flint, and J. A. Hevesi, 1993. The influence of long term climate change on net infiltration at Yucca Mountain, Nevada, Proceedings, Fourth High Level Radioactive Waste Management International Conference, Las Vegas, Nevada, April 26-30.

Glass, R. J. , J. Y. Parlange and T. S. Steenhuis, 1991. Immiscible displacement in porous media: stability analysis of three-dimensional, axisymmetric disturbances with application to gravity-driven wetting front instability, Water Resour. Res., 27 (8), 1947-1956.

Harding, W. and J. Black, 1992. Site characterization and validation - inflow to the validation drift, SKB, Stripa Project Report 92-14, Stockholm, Sweden.

Herbert, A., J. Gale, G. Lanyon, and R. MacLeod, 1991. Modeling for the Stripa site characterization and validation drift inflow: prediction of flow through fractured rock, SKB, Stripa Project Report 91-35, Stockholm, Sweden.

Hodgkinson, D. and N. Cooper, 1992. A comparison of measurements and calculations for the Stripa validation drift inflow experiment, SKB, Stripa Project Report 92-07, Stockholm, Sweden. 
International Formulation Committee, 1967. A formulation of the thermodynamic properties of ordinary water substance, IFC Secretariat, Düsseldorf, Germany.

Jury W. A. and J. Letey, Jr., 1979. Water vapor movement in soil:

Reconciliation of theory and experiment, Jour. Soil Sci. Am., 43(5), 823827.

Karasaki, K., S. Segan, K. Pruess and S. Vomyoris, 1994. A study of two-phase flow in fracture networks, Lawrence Berkeley Laboratory Report LBL34706, presented at International High Level Radioactive Waste Management Conference, Las Vegas, NV, May.

Keenan, J. S., F. G. Keyes, P. G. Hill and J. G. Moore, 1969. Steam Tables Thermodynamic Properties of Water Including Vapor, Liquid, and Solid Phases, John Wiley \& Sons, New York.

Klavetter, E. A., and R. R. Peters, 1986. Estimation of hydrologic properties of an unsaturated fractured rock mass, Report SAND84-2642, Sandia Nat. Lab., Albuquerque, N. M.

Kwicklis, E.M. and R.W. Healy, 1993. Numerical investigation of steady liquid water flow in a variably saturated fracture network, Water Resour. Res., Vol. 29, No. 12, pp. 4091-4102.

Langkopf, B., 1987. Problem definition memo for COVE3a benchmarking problem, Sandia Nat. Lab., Albuquerque, N. M., March 26.

Long, J., A. Mauldon, K. Nelson, S. Martel, P. Fuller, and K. Karasaki, 1992. Prediction of flow and drawdown for the site characterization and validation site in the stripa mine, SKB Technical Report 92-05, Stockholm, Sweden, January.

Nicholl, M.J., R.J. Glass, and H.A. Nguyen, 1993. Wetting front instability in an initially wet unsaturated fracture, Proceedings, Fourth High Level Radioactive Waste Management International Conference, Las Vegas, Nevada, April 26-30.

Nitao, J.J., 1988. Numerical modeling of the thermal and hydrological environment around a nuclear waste package using the equivalent continuum approximation: horizontal emplacement, Lawrence Livermore National Laboratory Report UCID - 21444.

Nitao, J.J., 1989. V-TOUGH, an enhanced version of the TOUGH code for the thermal and hydrologic simulation of large-scale problems in nuclear 
waste isolation, Lawrence Livermore National Laboratory Report UCID 21954.

Nitao, J.J., T.A. Buscheck, and D.A. Chesnut, 1992. The implications of episodic nonequilibrium fracture-matrix flow on site suitability and total system performance, Proceedings, Third High Level Radioactive Waste Management International Conference, Las Vegas, NV, April 26-30.

Olsson, O., 1992. Site characterization and validation - final report, SKB, Stripa Project Report 92-22, Stockholm, Sweden.

Persoff, P. and K. Pruess, 1993. Flow visualization and relative permeability measurements in rough-walled fractures, in: Proceedings, Fourth Annual High-Level Radioactive Waste Management International Conference, Las Vegas, Nevada, April 1993, Vol. 2, pp. 2033-2041, American Nuclear Society, La Grange Park, Ill.

Peters R. R., E. A. Klavetter, I. J. Hall, S. C. Blair, P. R. Heller, and G. W. Gee, 1984. Fracture and matrix hydrologic characteristics of tuffaceous materials from Yucca Mountain, Nye County, Nevada, Report SAND841471, Sandia Nat. Lab. Albuquerque, NM, 188 PP.

Peters, R. R. and E. A. Klavetter, 1988. A continuum model for water movement in an unsaturated fractured rock mass, Water Resour. Res., 24(3), 416-430.

Pruess, K., 1987. TOUGH user's guide, Nuclear Regulatory Commission Report NUREG/CR-4645; also Lawrence Berkeley Laboratory Report No. LBL-20700.

Pruess, K., 1991. TOUGH2 - A general purpose numerical simulator for multiphase fluid and heat flow, Report No. LBL-29400, Lawrence Berkeley Laboratory, Berkeley, CA, May.

Pruess, K. and M. O'Sullivan, 1992. Effects of capillarity and vapor adsorption in the depletion of vapor-dominated geothermal reservoirs, Lawrence Berkeley Laboratory Report LBL-31692, presented at Seventeenth Workshop on Geothermal Reservoir Engineering, Stanford University, Stanford, CA, January.

Pruess K. and Y. Tsang, 1993. Modeling of strongly heat-driven flow processes at a potential high-level nuclear waste repository at Yucca Mountain, Nevada, Proceedings, Fourth High Level Radioactive Waste Management International Conference, Las Vegas, Nevada, April 26-30. 
Pruess, K., Y. W. Tsang and J. S. Y. Wang, 1984. Numerical studies of fluid and heat flow near high-level nuclear waste packages emplaced in partially saturated fractured tuff, Lawrence Berkeley Laboratory Report No. LBL18552, Berkeley, CA, November.

Pruess, K., Y. W. Tsang and J. S. Y. Wang, 1985. Modeling of strongly heat driven flow in partially saturated fractured porous media, International Association of Hydrologists (ed.), Memoires, XVII, 486-497.

Pruess, K., J. S. Y. Wang and Y. W. Tsang, 1988. Effective continuum approximation for modeling fluid and heat flow in fractured porous tuff, Report No. SAND86-7000, Sandia National Laboratories, Albuquerque, NM.

Pruess K., J. S. Y. Wang and Y.W.Tsang, 1990a. On thermohydrologic conditions near high-level nuclear wastes emplaced in partially saturated fractured tuff, Part 1. Simulation studies with explicit consideration of fracture effects, Water Resour. Res., 26(6), 1235-1248.

Pruess K., J. S. Y. Wang and Y.W.Tsang, 1990b. On thermohydrologic conditions near high-level nuclear wastes emplaced in partially saturated fractured tuff, Part 2. Effective continuum approximation, Water Resour. Res., 26(6), 1249-1261.

Ramspott, L.D., 1991. The constructive use of heat in an unsaturated tuff repository, Proceedings, Second High Level Radioactive Waste Management International Conference, Las Vegas, Nevada, April 28 May 2.

Ross, B. A., 1984. Conceptual model of deep unsaturated zones with negligible recharge, Water Resour. Research, 20 (11), 1627-1629, November.

Ryder, E., 1993. Comparison of predicted far-field temperatures for discrete and smeared heat sources, Proceedings, Fourth High Level Radioactive Waste Management International Conference, Las Vegas, Nevada, April 26-30.

Thordarson, W, 1965. Perched groundwater in zeolitized-bedded tuff, Rainier Mesa and vicinity, Nevada Test Site, Nevada, U.S. Geological Survey Report TEI-862, 93 pp.

Thunvik, R. and C. Braester, 1990. Gas migration in discrete fracture networks, Water Resour. Res., Vol. 26, No. 10, pp. 2425-2434. 
Tsang, Y. W. and K. Pruess, 1987. A study of thermally induced convection near a high-level nuclear waste repository in partially saturated fractured tuff, Water Resour. Res., 23 (10), 1958-1966.

Tsang, Y. W., and K. Pruess, 1989. Preliminary studies of gas phase flow effects and moisture migration at Yucca Mountain, Nevada, Lawrence Berkeley Laboratory Report LBL-28819, Berkeley, California.

Tsang and Pruess, 1990. Further modeling studies of gas movement and moisture migration at Yucca Mountain, Nevada, Lawrence Berkeley Laboratory Report LBL-29127, Berkeley, California.

Tsang Y.W., K. Pruess, and J. S. Y. Wang, 1993. The role of fault zone in affecting multiphase flow at Yucca Mountain, Proceedings, Fourth High Level Radioactive Waste Management International Conference, Las Vegas, Nevada, April 26-30.

Tsang, Y.W. and C. F. Tsang, 1987. Channel model of flow through fractured media, Water Resour. Res., 23 (3), 467-479, March.

van Genuchten, M. Th., 1980. A closed-form equation for predicting the hydraulic conductivity of unsaturated soils, Soil Sci. Soc. Am. J., Vol. 44, pp. 892-898.

Vargaftik, N. B., 1975. Tables on the thermophysical properties of liquids and gases, 2nd ed., John Wiley, NY.

Walker, W. R., J. D. Sabey, and D. R. Hampton, 1981. Studies of heat transfer and water migration in soils, final report, Department of Agricultural and Chemical Engineering, Colorado University, Fort Collins, CO, April.

Wang, J.S.Y. and T.N. Narasimhan, 1985. Hydrologic mechanisms governing fluid flow in a partially saturated, fractured, porous medium, Water Resour. Res., 21 (12), 1861-1874, December.

Wilder, D.G., 1993. Alternative strategies - a means for saving money and time on the Yucca Mountain project, Proceedings, Fourth High Level Radioactive Waste Management International Conference, Las Vegas, Nevada, April 26-30.

Wittwer C. S., G. Chen and G. S. Bodvarsson, 1993. Studies of the role of fault zones on fluid flow using the site-scale numerical model of Yucca Mountain, Proceedings, Fourth High Level Radioactive Waste Management International Conference, Las Vegas, Nevada, April 26-30. 


\section{Appendix. Effective Continuum Characteristic Curves}

In the effective continuum approximation, the suction pressure $\mathrm{P}_{\text {suc }}$ and the equivalent continuum permeabilities to the liquid and gas phase, $\mathrm{k}_{1}$ and $\mathrm{k}_{\mathrm{g}}$ are expressed in terms of the continuum liquid saturation, $\mathrm{S}_{\mathrm{l}}$. For reference we give here the equations relating the effective continuum parameters to the corresponding matrix and fracture parameters, denoted by subscript $m$ and $f$, respectively. The material properties and the characteristic curves for the matrix and fracture media are tabulated in Tables 1 and 2.

\section{(1) Threshold liquid saturation}

Let $S_{1}$ be the liquid saturation of the effective continuum. It is expressed in terms of the matrix and fracture saturations as follows (Pruess et al., 1988):

$$
S_{1}=\frac{S_{1 m} \bar{\phi}_{m}+S_{1 f} \bar{\phi}_{f}}{\bar{\phi}_{m}+\bar{\phi}_{f}}
$$

where both $\bar{\phi}_{\mathrm{m}}$ and $\bar{\phi}_{\mathrm{f}}$ are void fractions defined in terms of the total volume,

$$
\mathrm{V}_{\text {tot }}=\mathrm{V}_{\mathrm{m}}+\mathrm{V}_{\mathrm{f}}
$$

Employing a 'sequential saturation' model in which the matrix gets saturated first, then the fractures, we introduce a threshold saturation $S_{\text {th }}$ as the continuum liquid saturation at the juncture when the matrix is fully saturated and the fracture is dry. $S_{\text {th }}$ corresponds to the value of $S_{1}$ in Equation (A-1) where $S_{I m}$ is 1 and $S_{1 f}$ is 0 ,

$$
\mathrm{S}_{\mathrm{th}}=\frac{\bar{\phi}_{\mathrm{m}}}{\bar{\phi}_{\mathrm{m}}+\bar{\phi}_{\mathrm{f}}}=1-\frac{\bar{\phi}_{\mathrm{f}}}{\bar{\phi}}
$$

The reasoning behind the sequential saturation model is as follows. An effective continuum concept is only applicable when approximate local thermodynamic equilibrium exists between matrix and fractures. Because the capillary suction in the matrix is much stronger then that in the fracture, local equilibrium implies that the liquid saturation in the fracture will remain near zero until matrix saturation approaches $100 \%$. The concept of a threshold continuum saturation as defined by Equation (A-3) is based on the 
approximation that the enormous disparity of the strength of capillary suction in the matrix and fractures will cause the fractures to remain dry until the matrix becomes fully saturated during imbibition; and for the fractures to be completely drained before the matrix begins to desaturate during drainage. We have found the above approximation of local equilibrium to be an excellent one from running 2-D simulations of discrete fracture and matrix systems with infiltration.

From Equation (A-1), given the liquid saturation of the effective continuum, $\mathrm{S}_{1}$, the matrix and fracture liquid saturation are as follows:

$$
\begin{array}{ll}
S_{l m}=S_{1} / S_{t h}, S_{1 f}=0 ; & \text { for } S_{1} \leq S_{t h} \\
S_{I m}=1, S_{I f}=\frac{S_{1}-S_{t h}}{1-S_{t h}} ; & \text { for } S_{1}>S_{t h}
\end{array}
$$

\section{(2) Capillary suction}

The capillary suction for the effective continuum in terms of the continuum saturation $S_{1}$ is

$$
\begin{aligned}
P_{\text {suc }}\left(S_{1}\right) & =P_{\text {suc }}\left(S_{\text {lm }}-\delta\right) & & \text { for } S_{1}<S_{\text {th }} \\
& =P_{\text {suc }}(1-\delta) \cdot \frac{1-S_{1}}{1-S_{\text {th }}} & & \text { for } S_{1} \geq S_{\text {th }}
\end{aligned}
$$

The matrix characteristic curve as tabulated in Table 2 is used for $P_{\text {suc. The }}$ formulation in Equation (A-5) gives a continuous curve as the continuum liquid saturation passes through the threshold value. Below the threshold, it follows the suction curve for the matrix; above the threshold, the capillary suction in the fracture varies linearly with $S_{1}$. The parameter $\delta$ is introduced to represent air entry effects; i.e., a finite suction is required to reduce the matrix saturation from $S_{1 \mathrm{~m}}=1$. It gives the added advantage that the slope of $\mathrm{dP}_{\text {suc }} / \mathrm{dS}_{\mathrm{lm}}$ remains finite at $\mathrm{S}_{\mathrm{th}}$. The infinite slope of $\mathrm{dP}_{\text {suc }} / \mathrm{dS}_{\mathrm{lm}}$ at $\mathrm{S}_{\mathrm{lm}}=1$ would have made the transition across the threshold impossible physically and numerically. A choice of $\delta$ corresponding to a suction pressure of a couple 
of thousands of Pascals $\left(.2 \mathrm{~m}\right.$ of $\left.\mathrm{H}_{2} \mathrm{O}\right)$ is sufficient to render the numerical computation possible.

\section{(3) Effective continuum liquid and gas permeability}

The effective continuum liquid and gas permeabilities as functions of the effective continuum liquid saturation are defined in terms of the permeabilities in the matrix and fracture continua.

$$
\begin{aligned}
\mathrm{k}_{1}\left(\mathrm{~S}_{\mathrm{l}}\right) & =\bar{k}_{\mathrm{m}}\left(1-\bar{\phi}_{\mathrm{f}}\right) \mathrm{k}_{\mathrm{rm}}\left(\mathrm{S}_{\mathrm{lm}}\right) \quad \text { for } S_{1} \leq S_{\mathrm{th}} \\
& =\bar{k}_{\mathrm{m}}\left(1-\bar{\phi}_{\mathrm{f}}\right)+\overline{\mathrm{k}}_{\mathrm{f}} \mathrm{k}_{\mathrm{rf}}\left(\mathrm{S}_{\mathrm{lf}}\right) \text { for } S_{1}>S_{\mathrm{th}}
\end{aligned}
$$

Equation (A-6) makes use of the fact that below $S_{t h}$, the liquid saturation in the fracture continuum is 0 and therefore the relative permeability to the liquid in the fracture is zero; whereas above $S_{t h}$, the matrix continuum is fully saturated with relative permeability equal to 1 . The $\overline{\mathrm{k}}_{\mathrm{m}}$ and $\overline{\mathrm{k}}_{\mathrm{f}}$ are the saturated matrix and fracture continuum permeabilities in Table 1. Assuming that gas and liquid relative permeabilities sum to 1 , the effective continuum gas permeability may be expressed as the difference between the saturated permeability of the effective continuum and the permeability to the liquid phase,

$$
k_{g}\left(S_{1}\right)=\left[\bar{k}_{m}\left(1-\bar{\phi}_{f}\right)+\bar{k}_{f}\right]-k_{1}\left(S_{1}\right)
$$

where the expression in the square bracket is the saturated permeability of the effective continuum. 

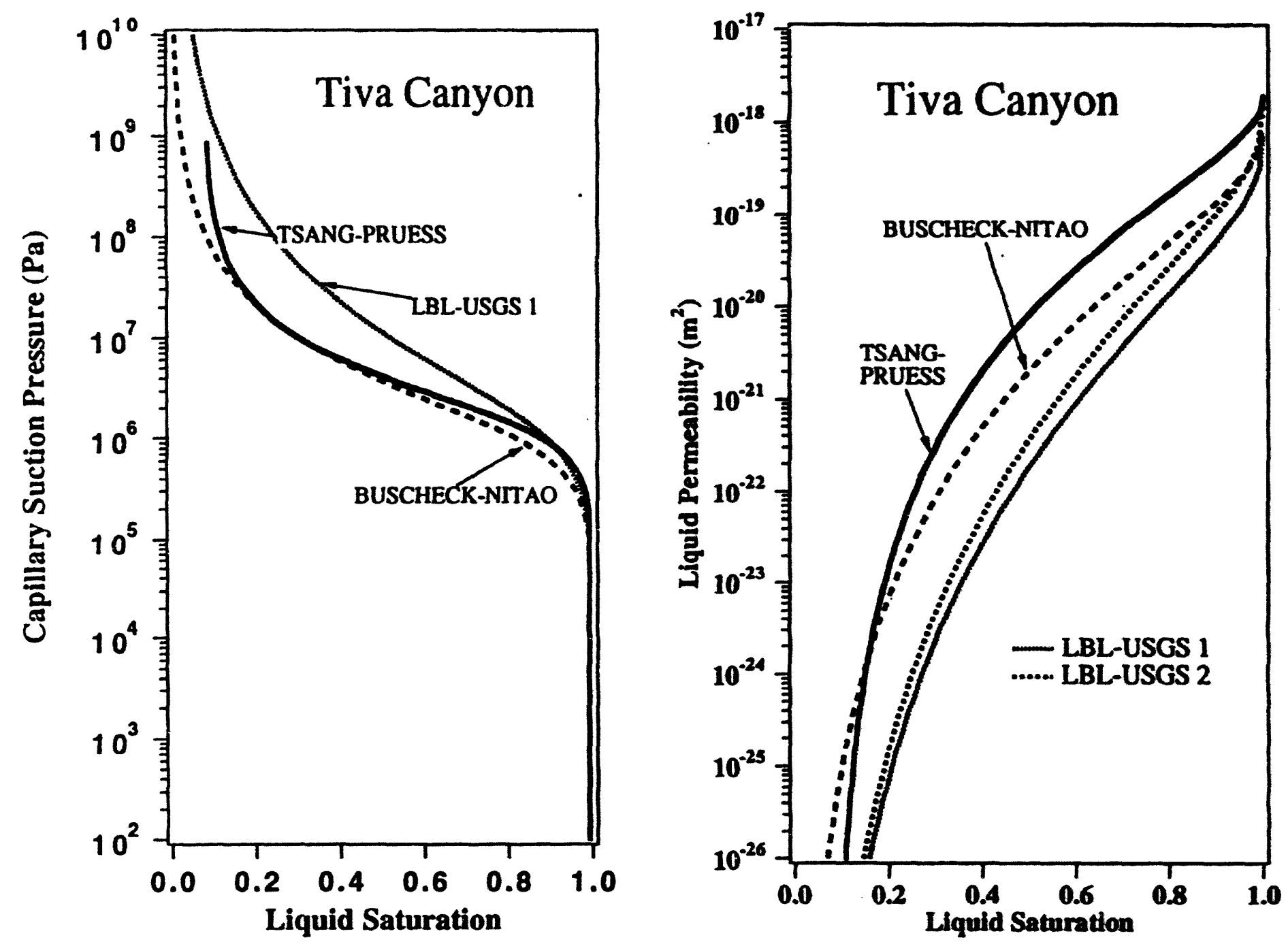

Figure 1. Characteristic curves for Tiva Canyon. (a) capillary suction pressure,

(b) liquid permeability versus matrix liquid saturation. 

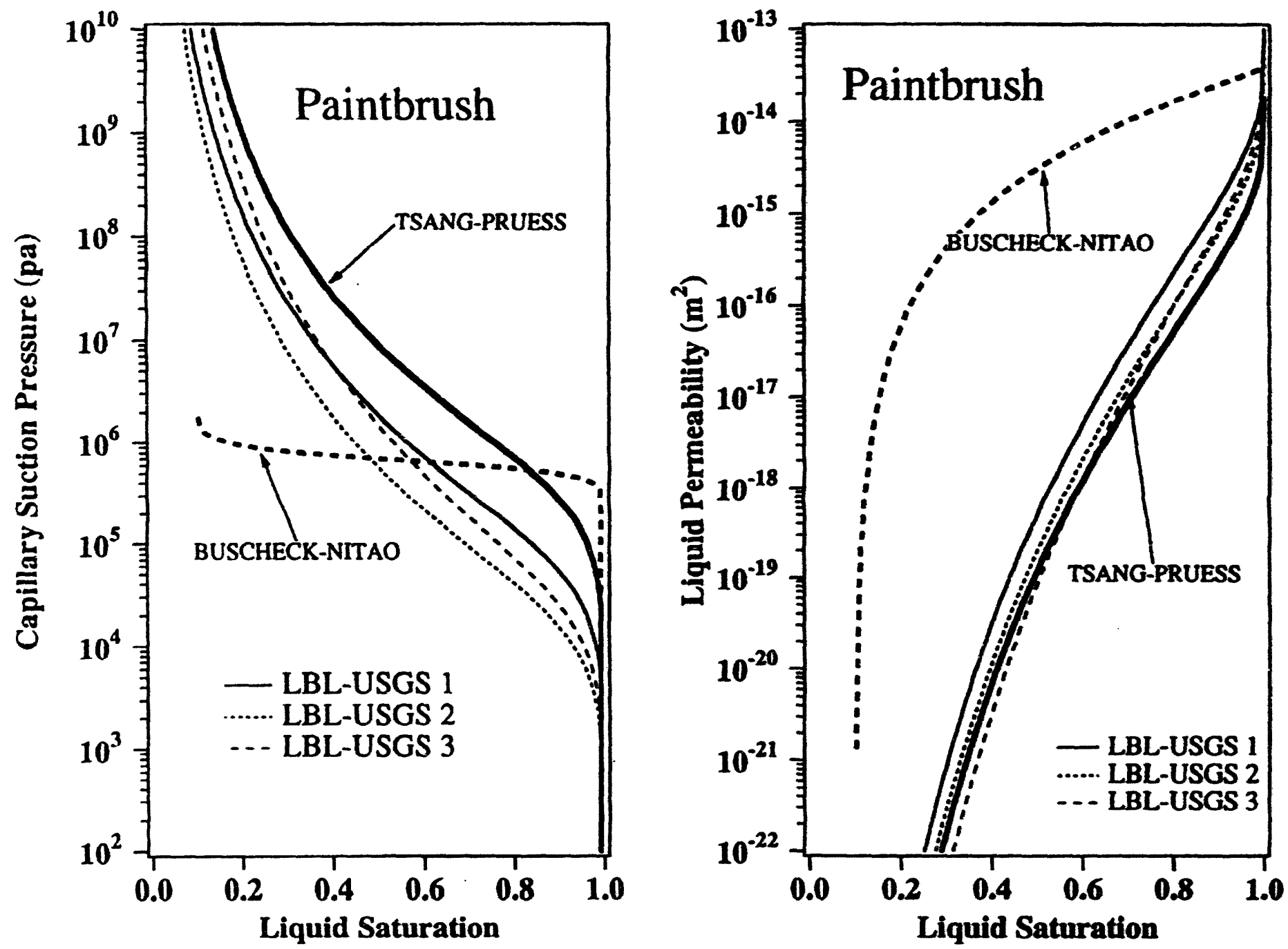

Figure 2. Characteristic curves for Paintbrush Tuff. (a) capillary suction pressure, (b) liquid permeability versus matrix liquid saturation. 

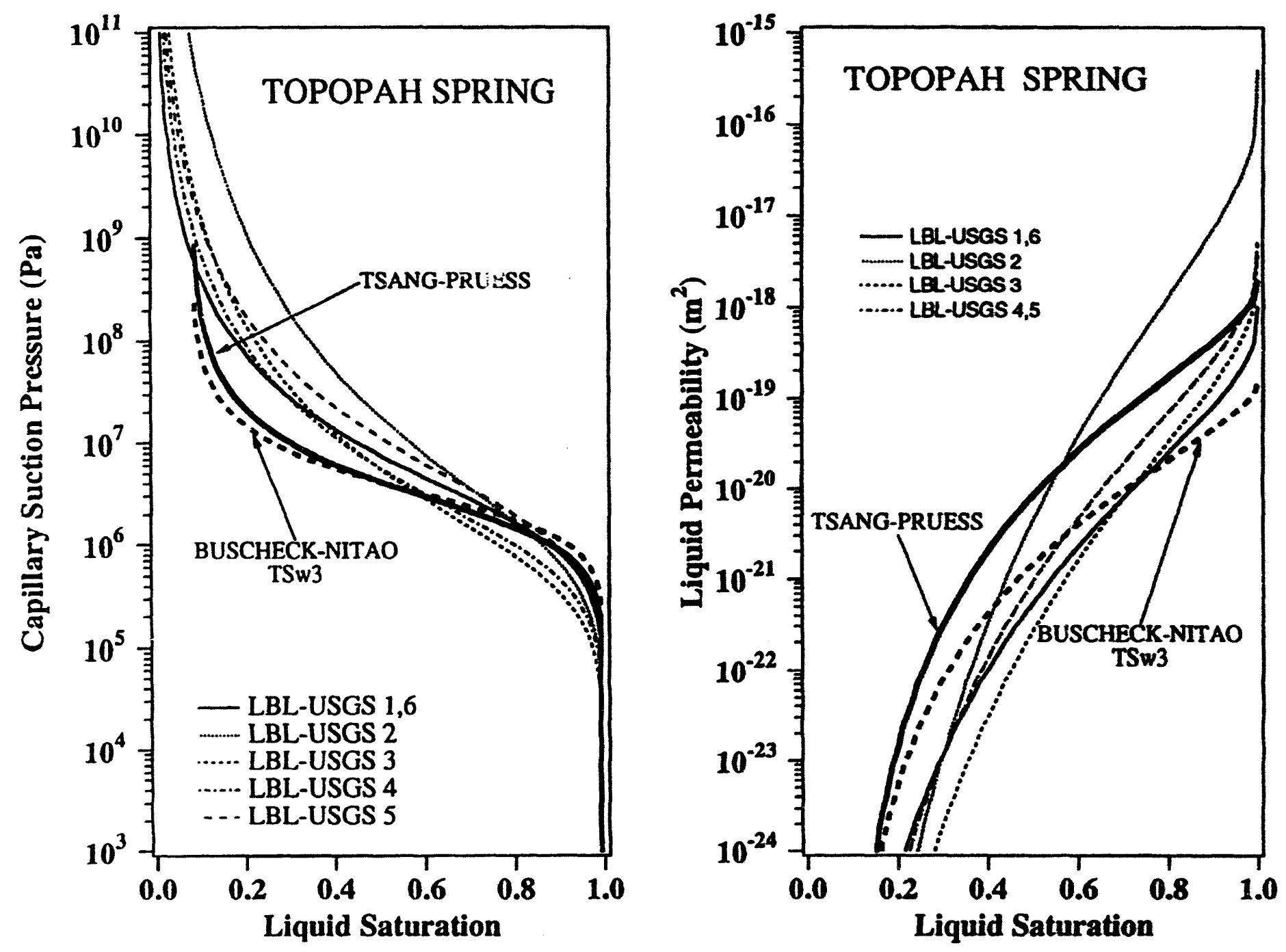

Figure 3. Characteristic curves for Topopah Springs. (a) capillary suction pressure, (b) liquid permeability versus matrix liquid saturation. 

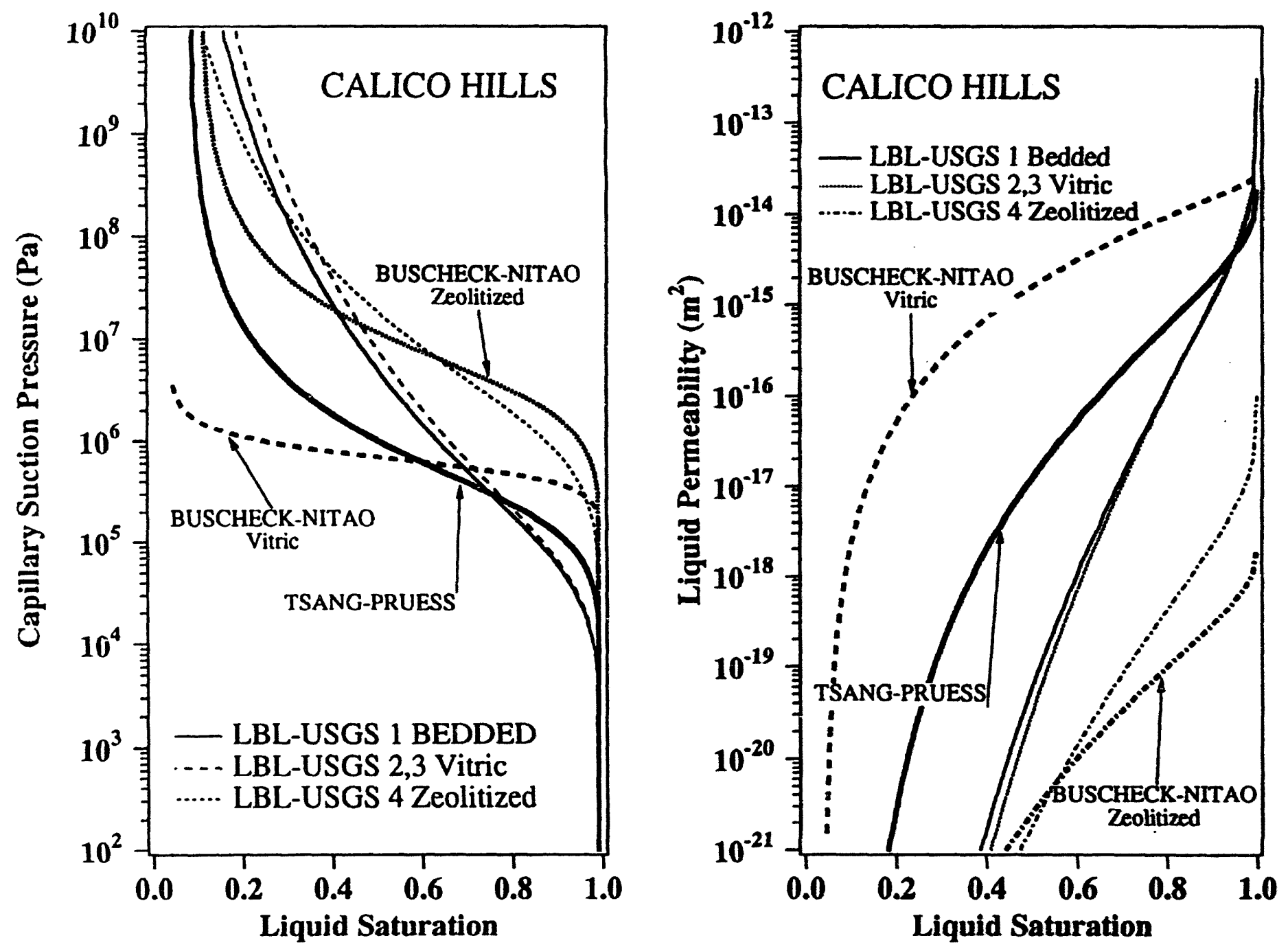

Figure 4. Characteristic curves for Calico Hills. (a) capillary suction pressure, (b) liquid permeability versus matrix liquid saturation. 
Ambient Liquid Saturation Profiles - All With Enhanced Vapor Diffusion

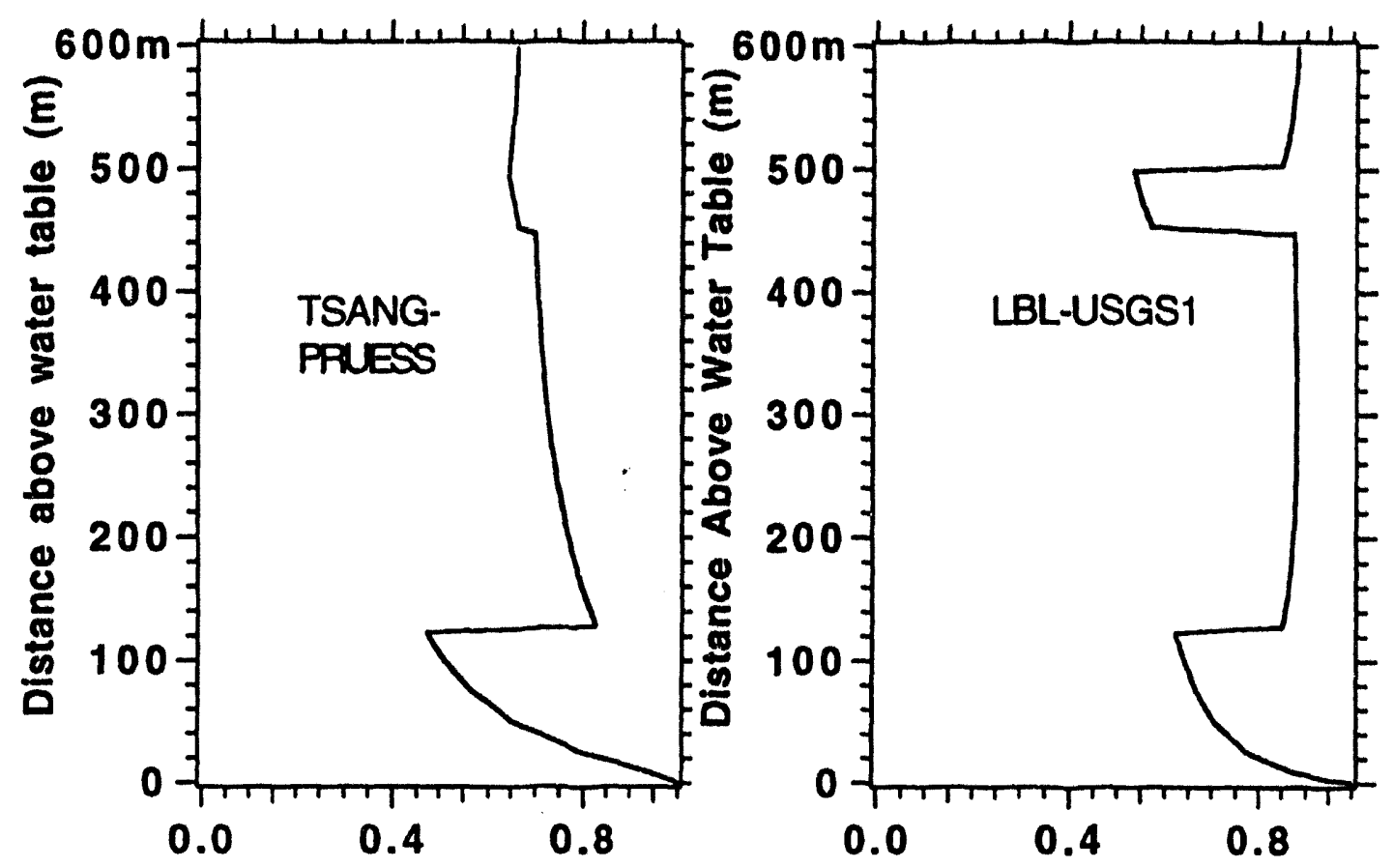

Liquid Saturation

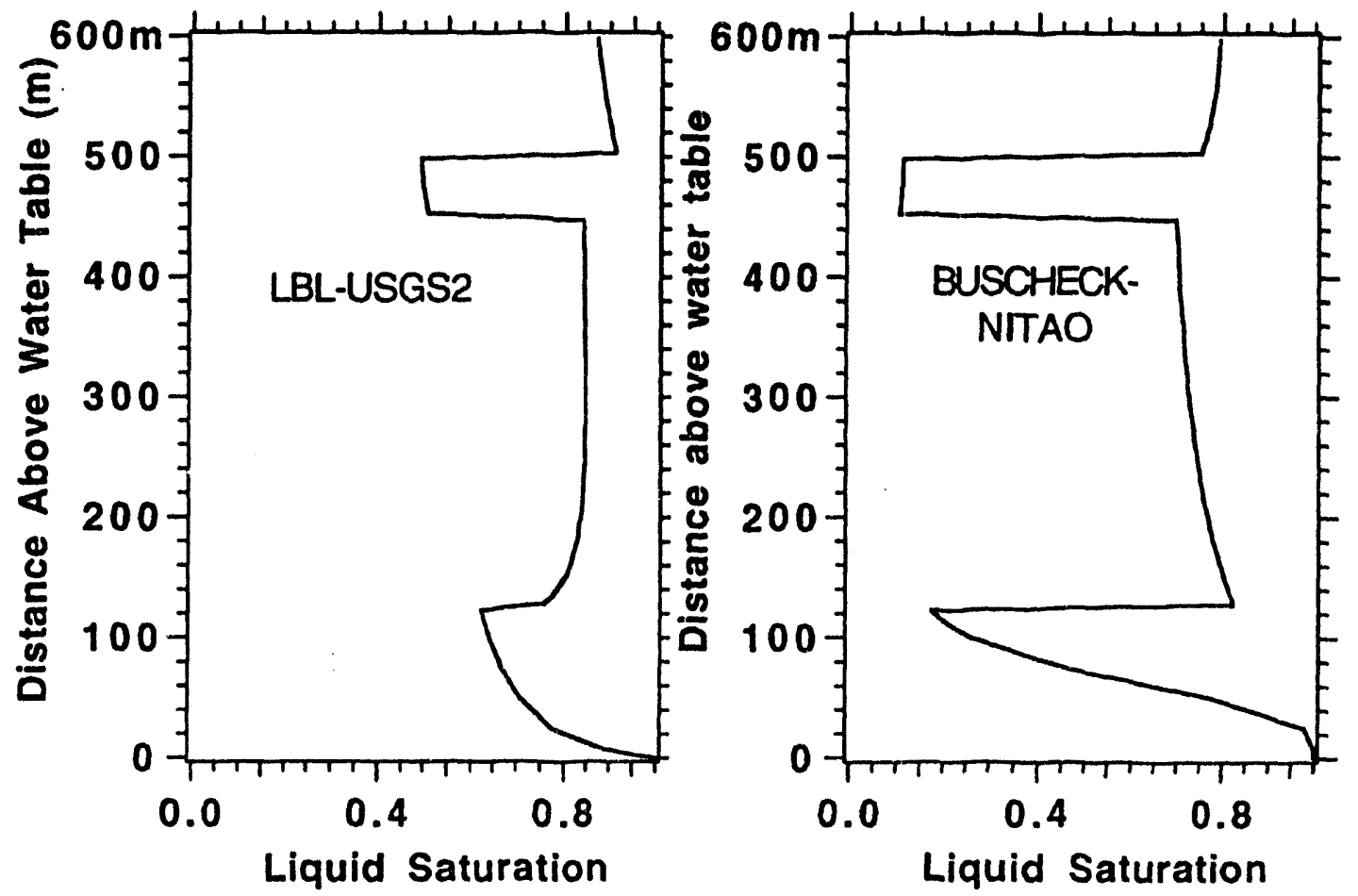

Figure 5. Equilibrium liquid saturation profiles for 1D column representation of Yucca Mountain, for different characteristic curves parameters. 
Heat Decay Characteristics of a Mixed Waste of Average Age 22 Years, and a 10-Year-Old Waste
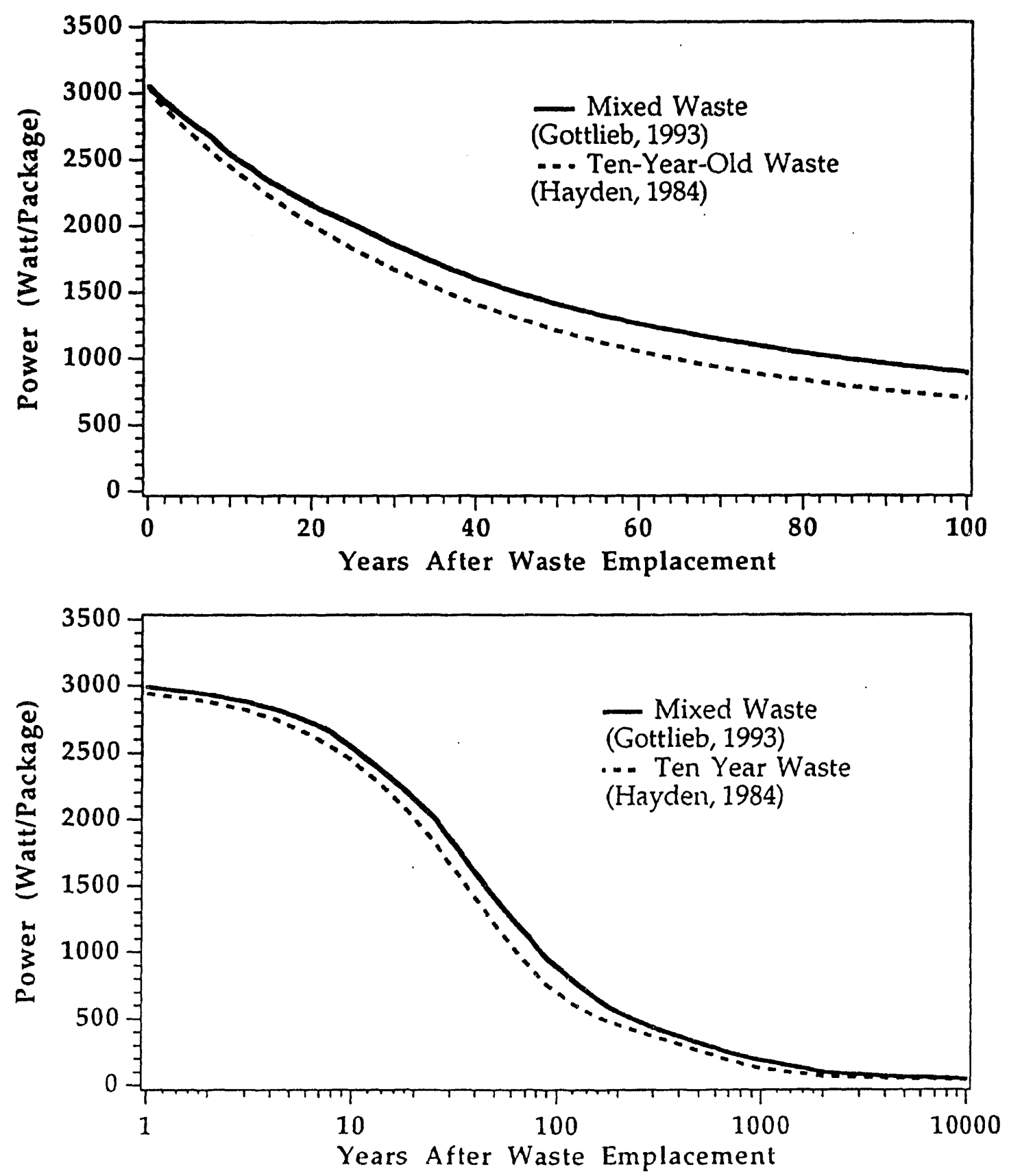

Figure 6. Heat decay characteristics of 10 year old fuel and mixed fuel (average age 23 year). 


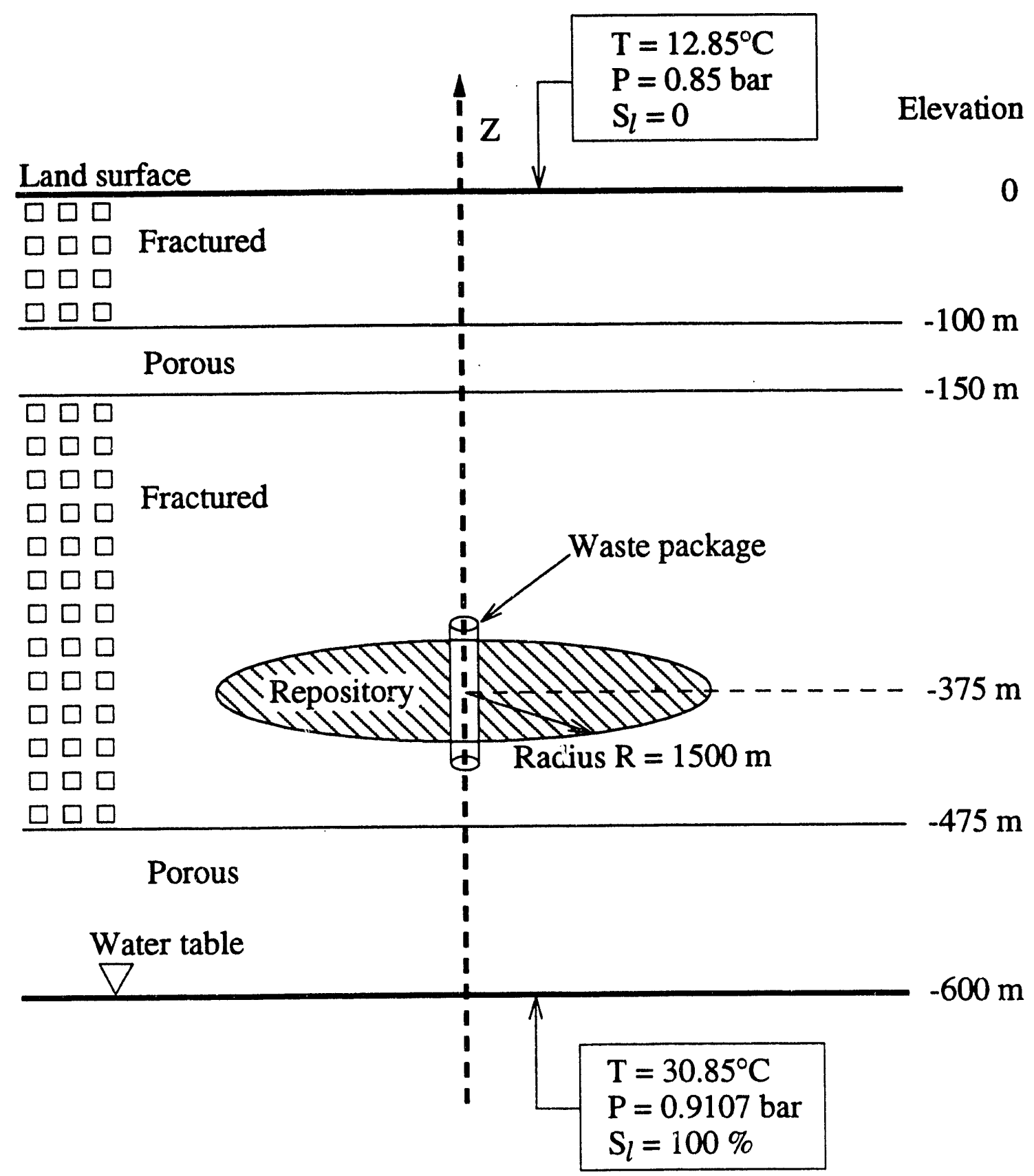

ESD-906-0009

Figure 7. Two-dimensional radially symmetric (R-Z) model of a high-level nuclear waste repository at Yucca Mountain (after Pruess and Tsang, 1993). 
Reference Case APD $57 \mathrm{~kW} /$ Acre, 10 Year old fuel

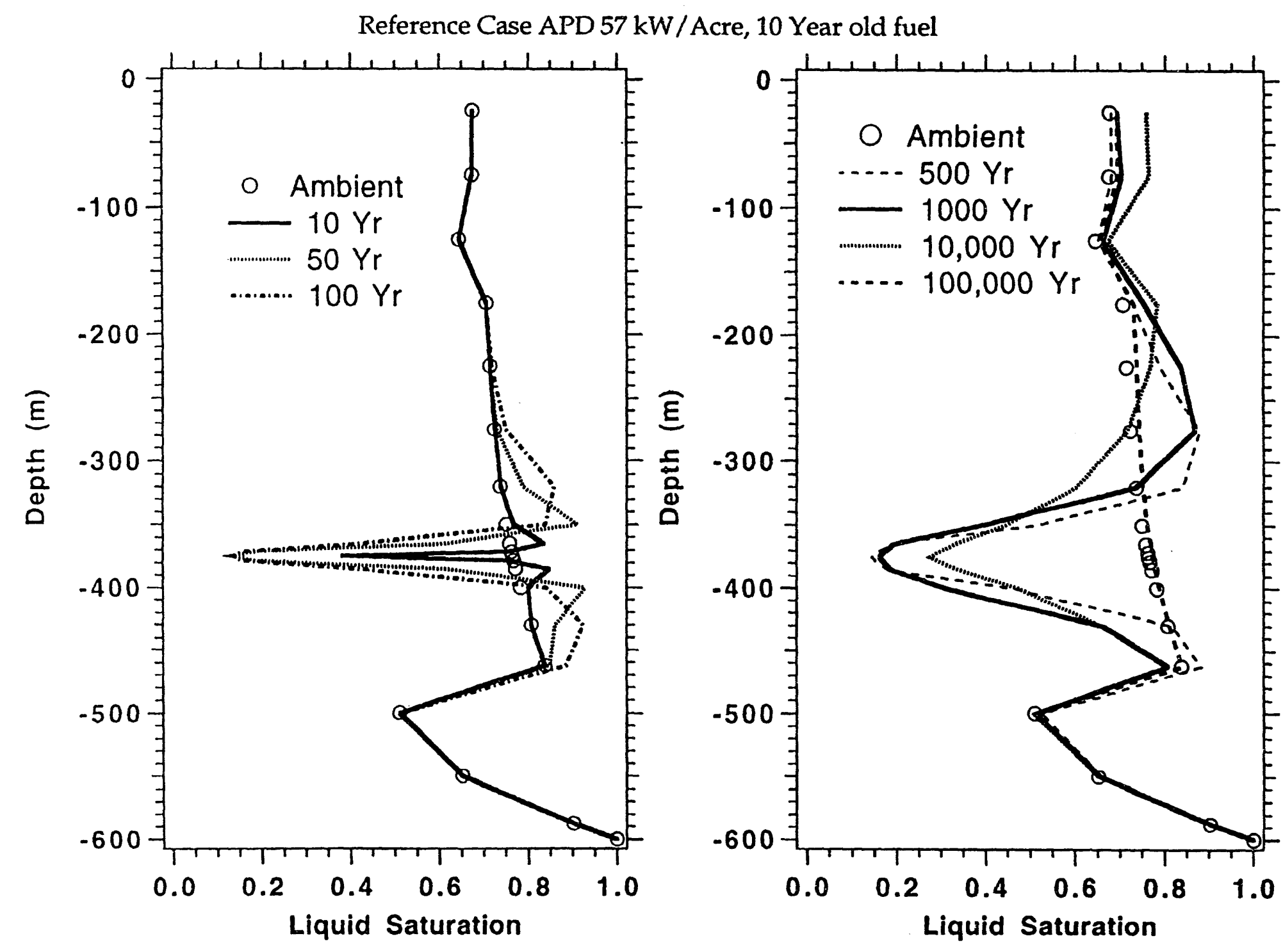

Figure 8. Repository average liquid saturation profiles for reference case with thermal loading of $\mathrm{APD}=57 \mathrm{~kW} / \mathrm{acre}$ and 10 year old fuel. 
APD $114 \mathrm{~kW} /$ acre, 10 Year old fuel
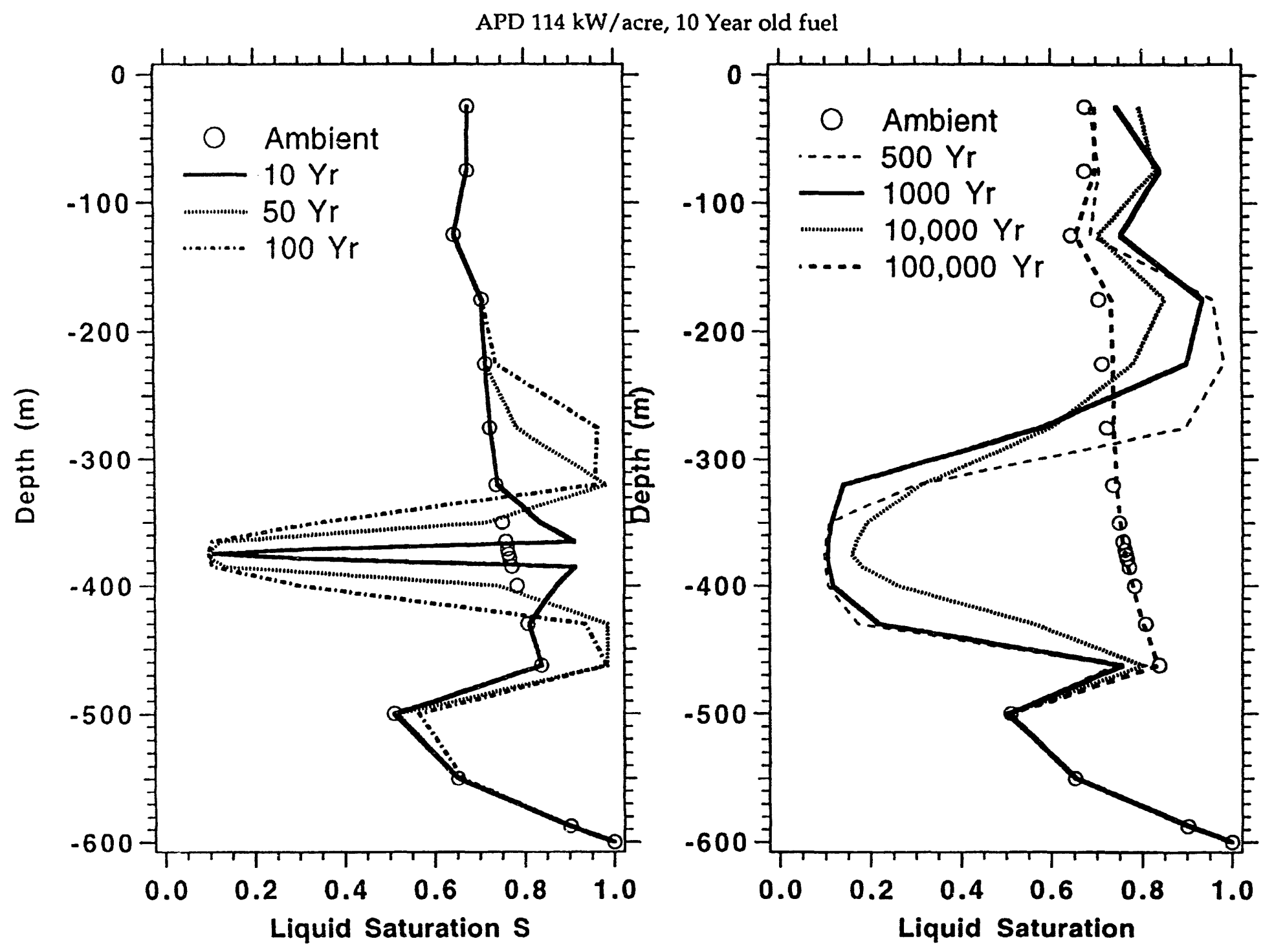

Figure 9. Repository average liquid saturation profiles for thermal loading of APD = $114 \mathrm{~kW} /$ acre and 10 year old fuel. 
APD $114 \mathrm{~kW} /$ acre, Mixed fuel, Youngest first, Average age 22-23 Yr
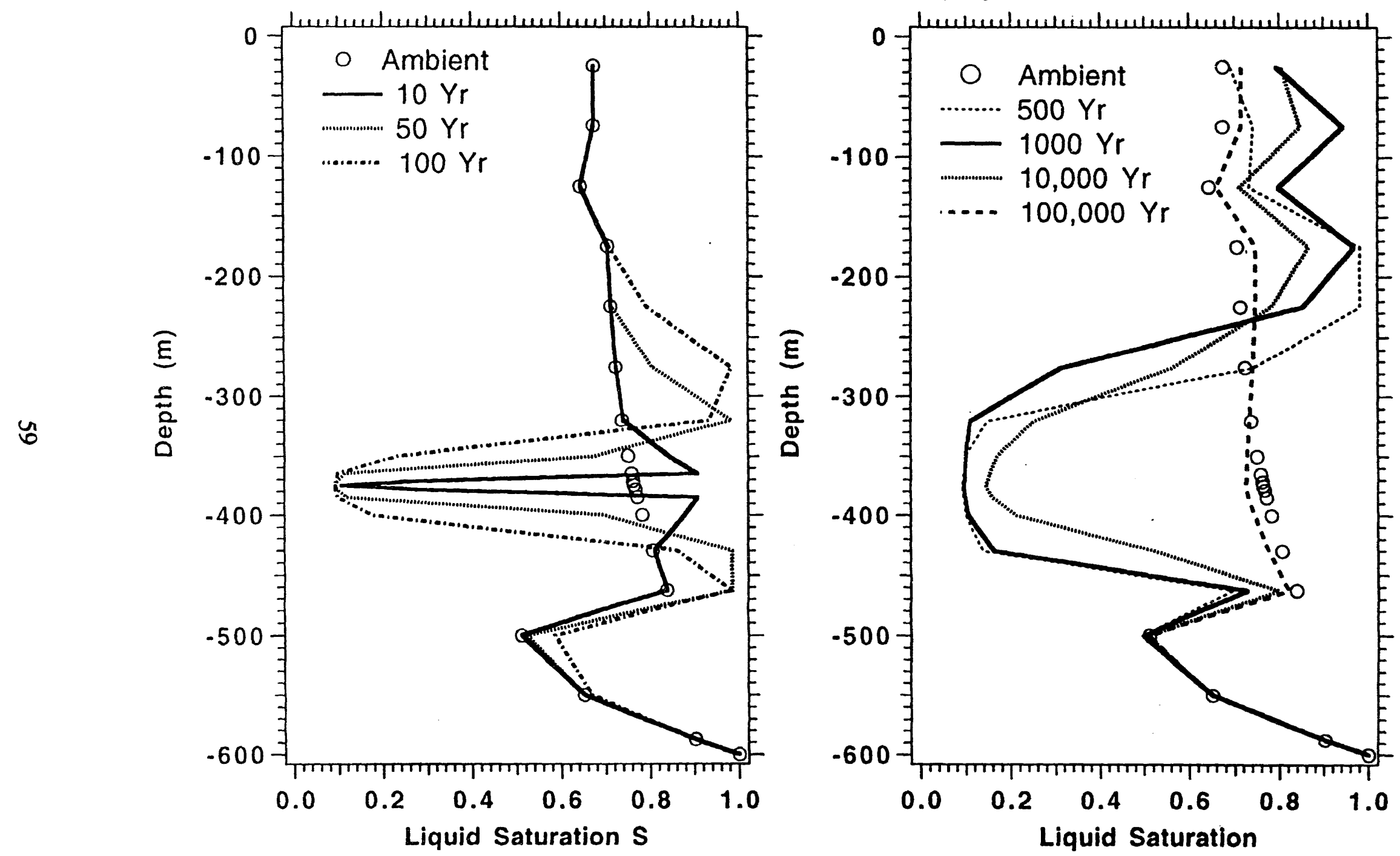

Figure 10. Repository average liquid saturation profiles for thermal loading of APD = $114 \mathrm{~kW} /$ acre and mixed fuel. 
APD $28.5 \mathrm{~kW} /$ acre, 10 Year Old Fuel
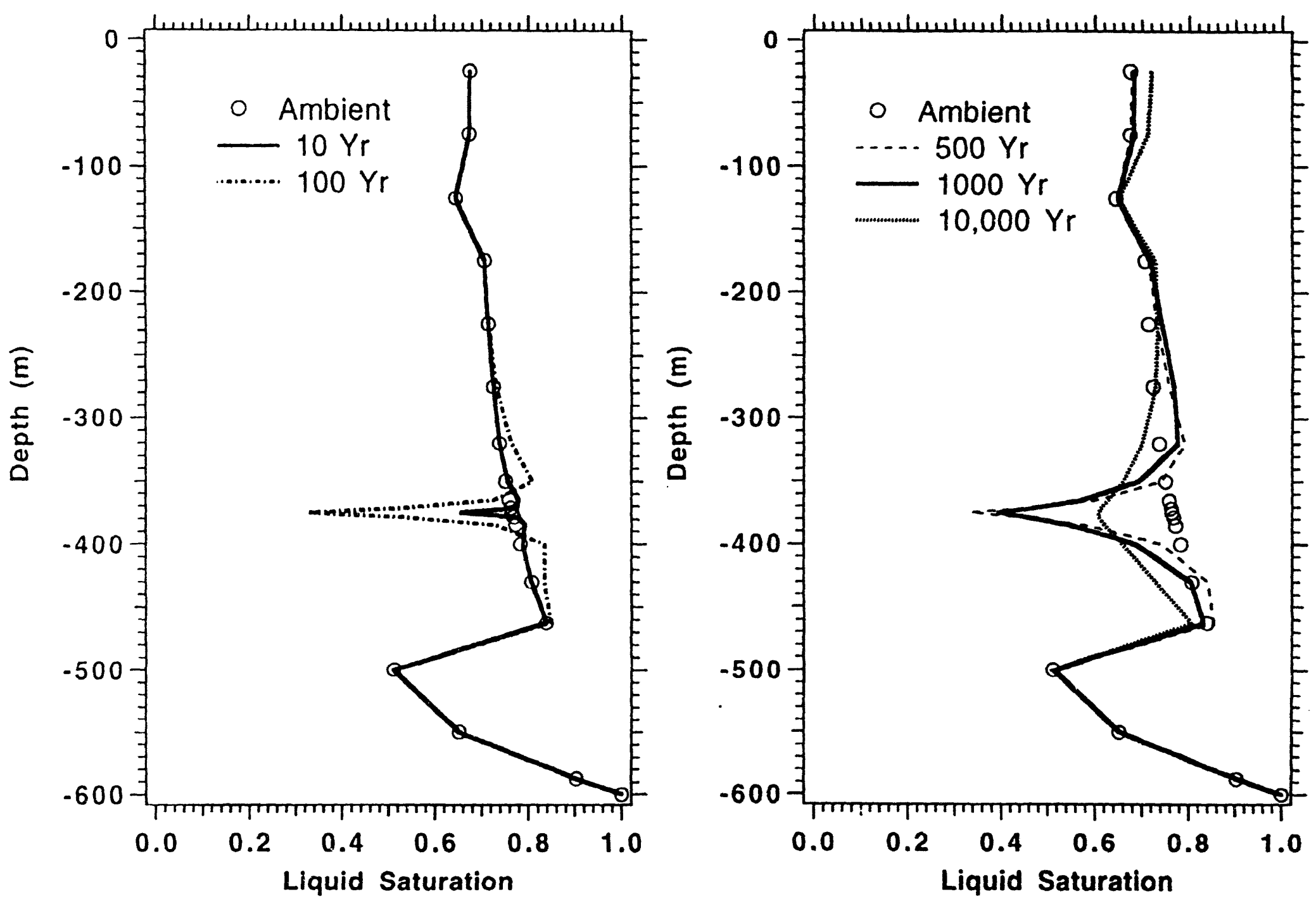

Figure 11. Repository average liquid saturation profiles for thermal loading of APD = $28.5 \mathrm{~kW} /$ acre and 10 year old fuel. 


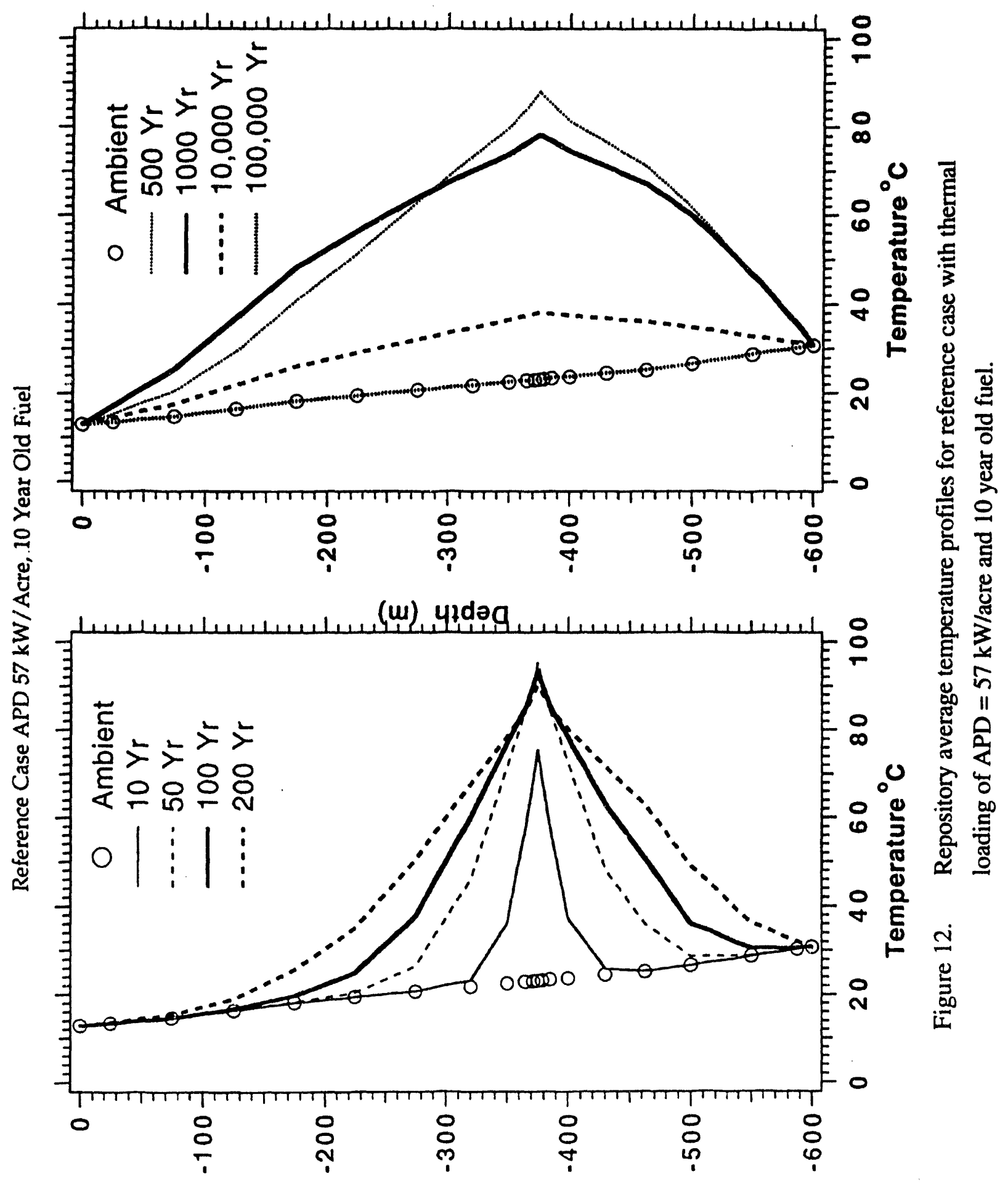

(w) yldao 
APD $114 \mathrm{~kW} /$ Acre, 10 Year old fuel
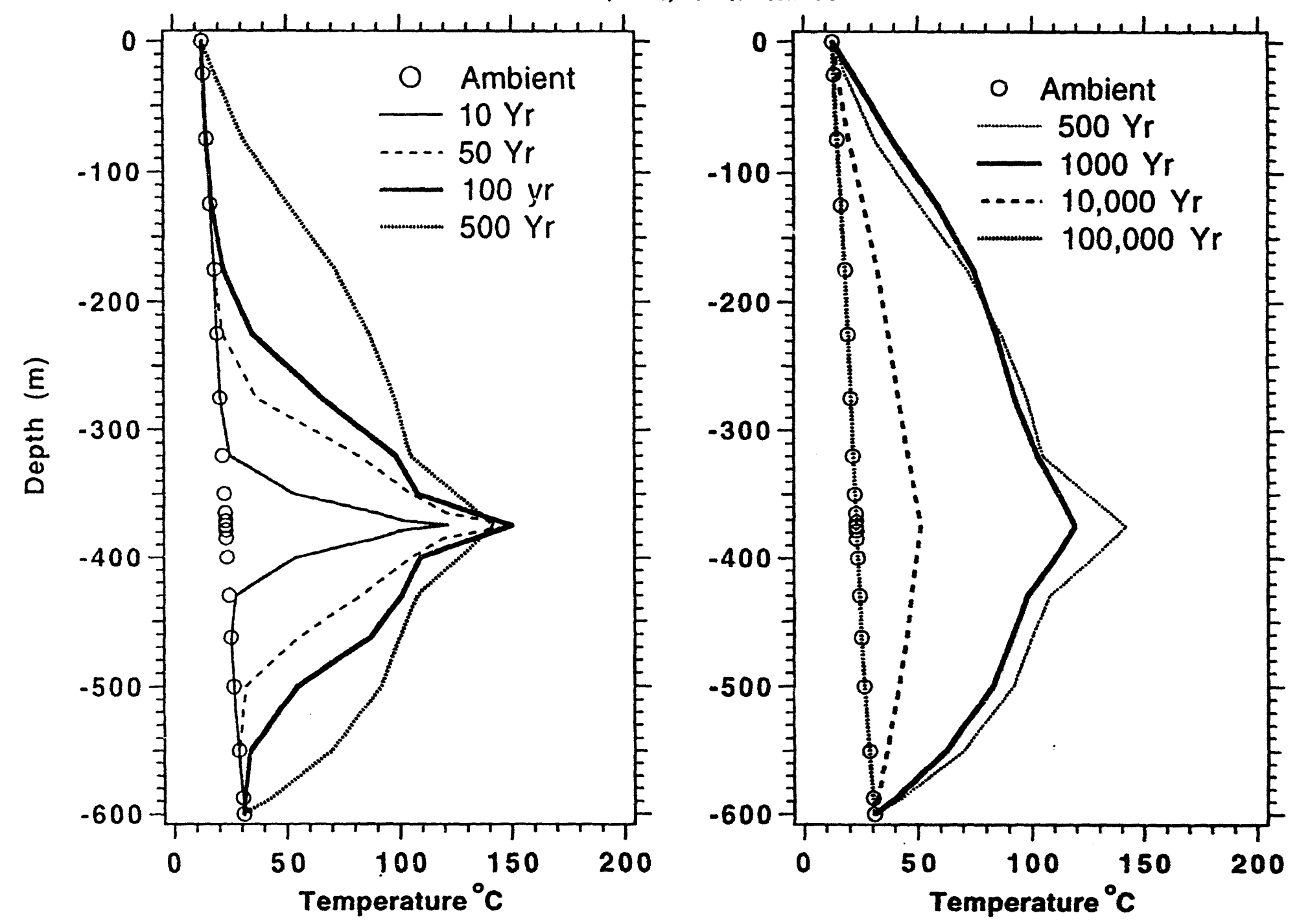

Figure 13. Repository average temperature profiles for thermal loading of APD $=114$ $\mathrm{kW} / \mathrm{acre}$ and 10 year old fuel. 
APD $114 \mathrm{~kW} /$ acre, Mixed fuel, Youngest first, Average Age 22-23 Yr
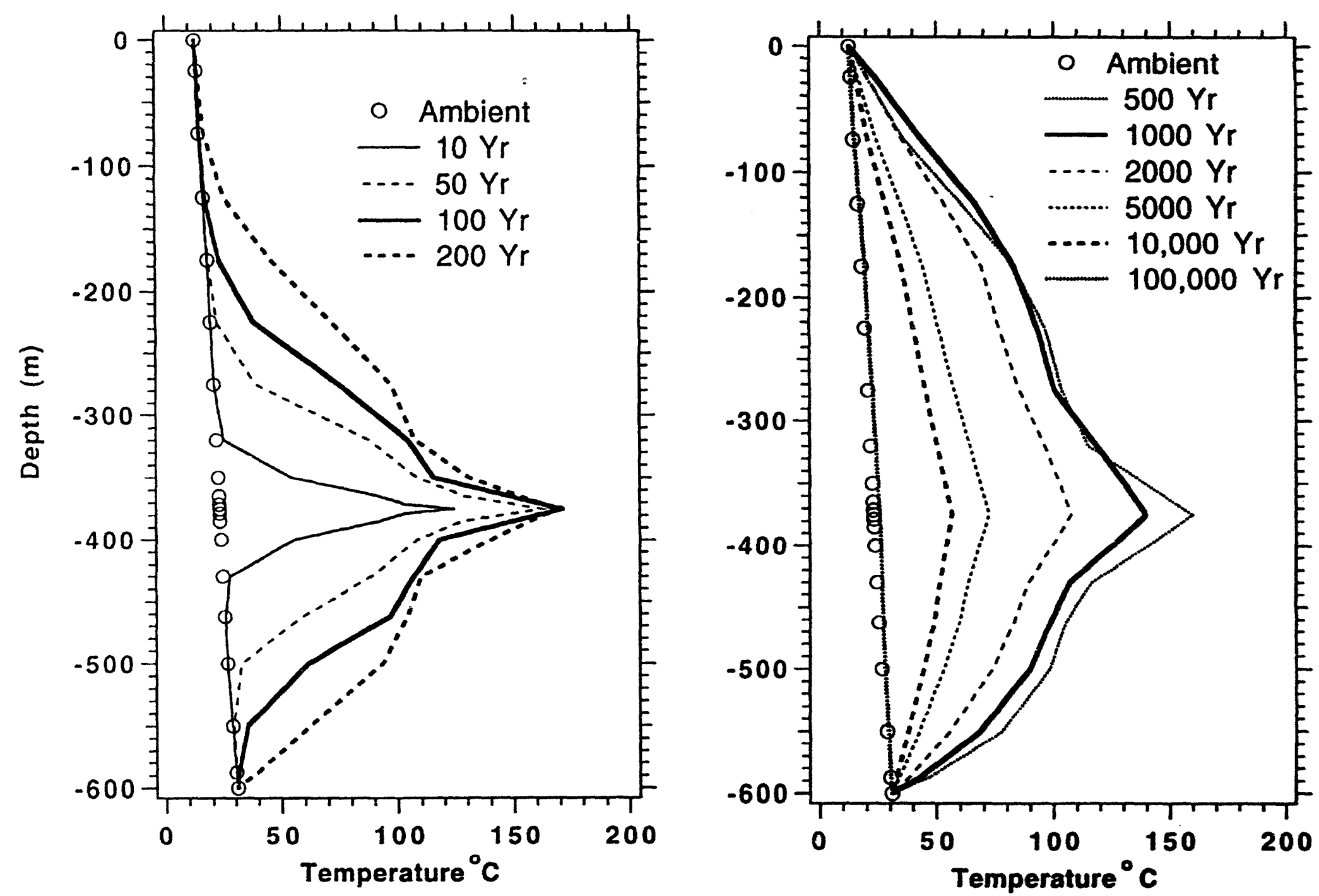

Figure 14. Repository average temperature profiles for thermal loading of APD $=114$ $\mathrm{kW} / \mathrm{acre}$ and mixed fuel. 


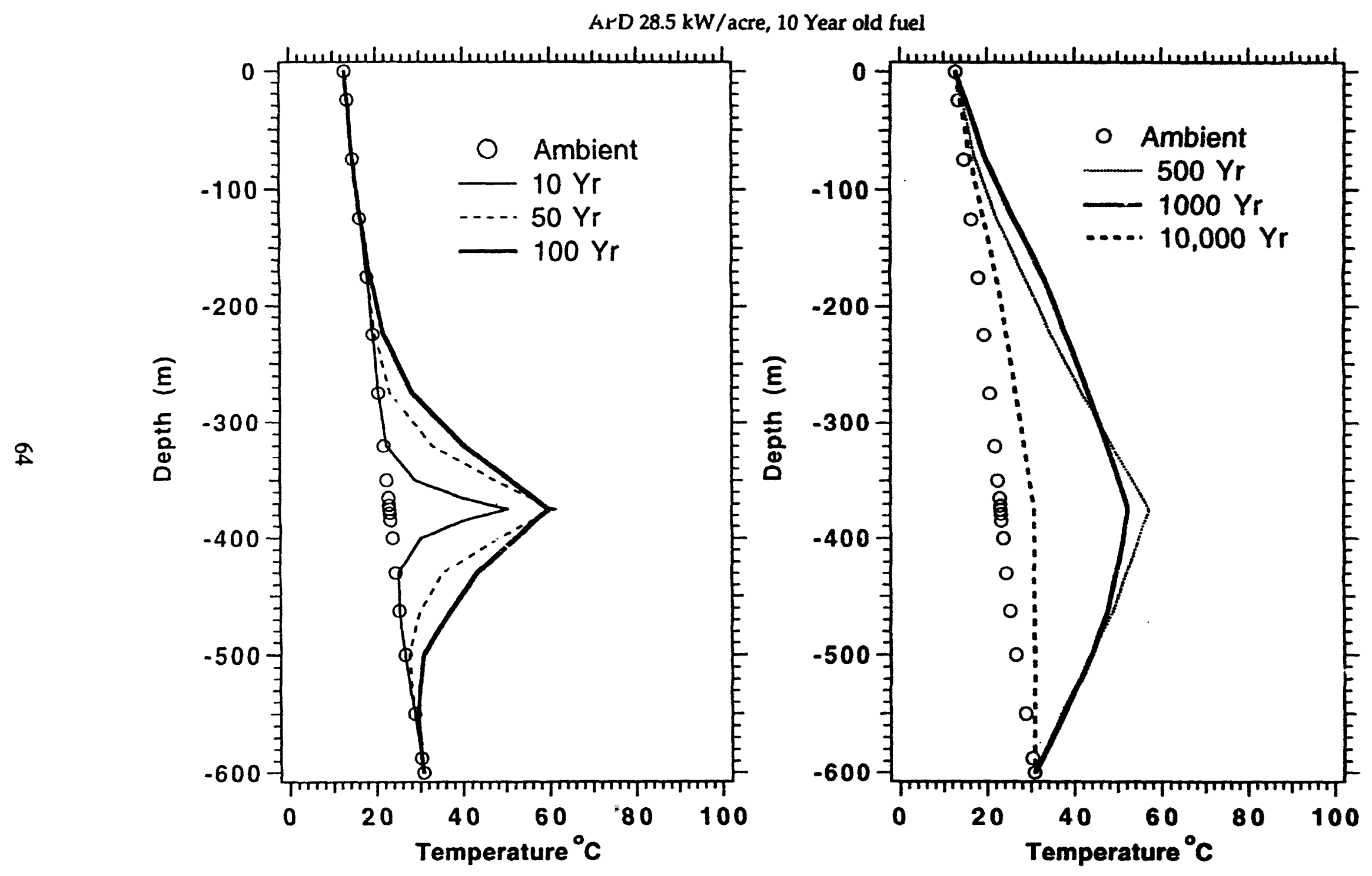

Figure 15. Repository average temperature profiles for thermal loading of APD $=28.5$ $\mathrm{kW} / \mathrm{acre}$ and 10 year old fuel. 
Repository Average Liquid Saturation and Temperature History
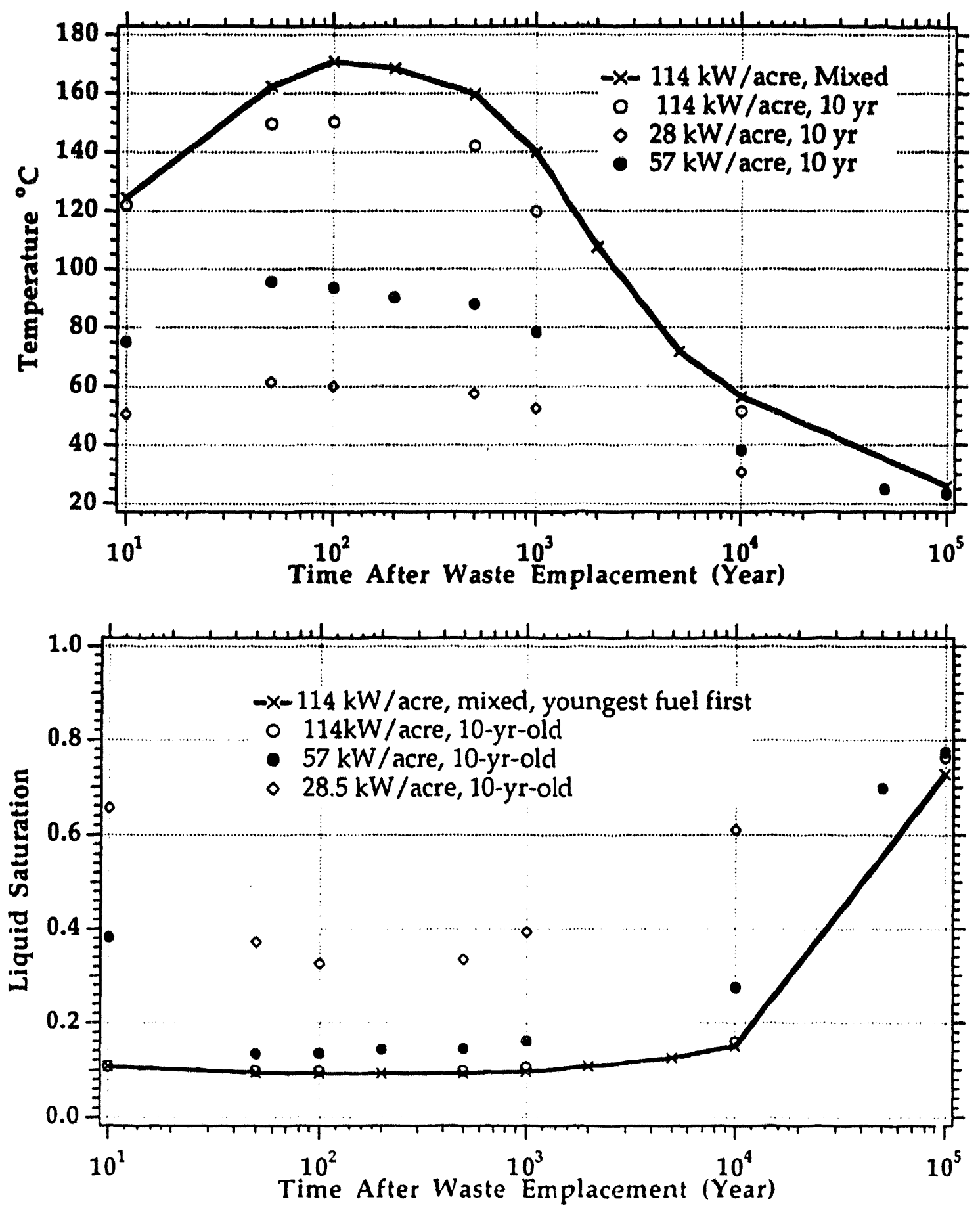

Figure 16. Liquid saturation and temperature history at the repository horizon, at a location midway between repository center and repository edge. 
Temperature History, Drying and Rewetting Times at Node $A C 2,3 \mathrm{~cm}$ from Waste Package surface

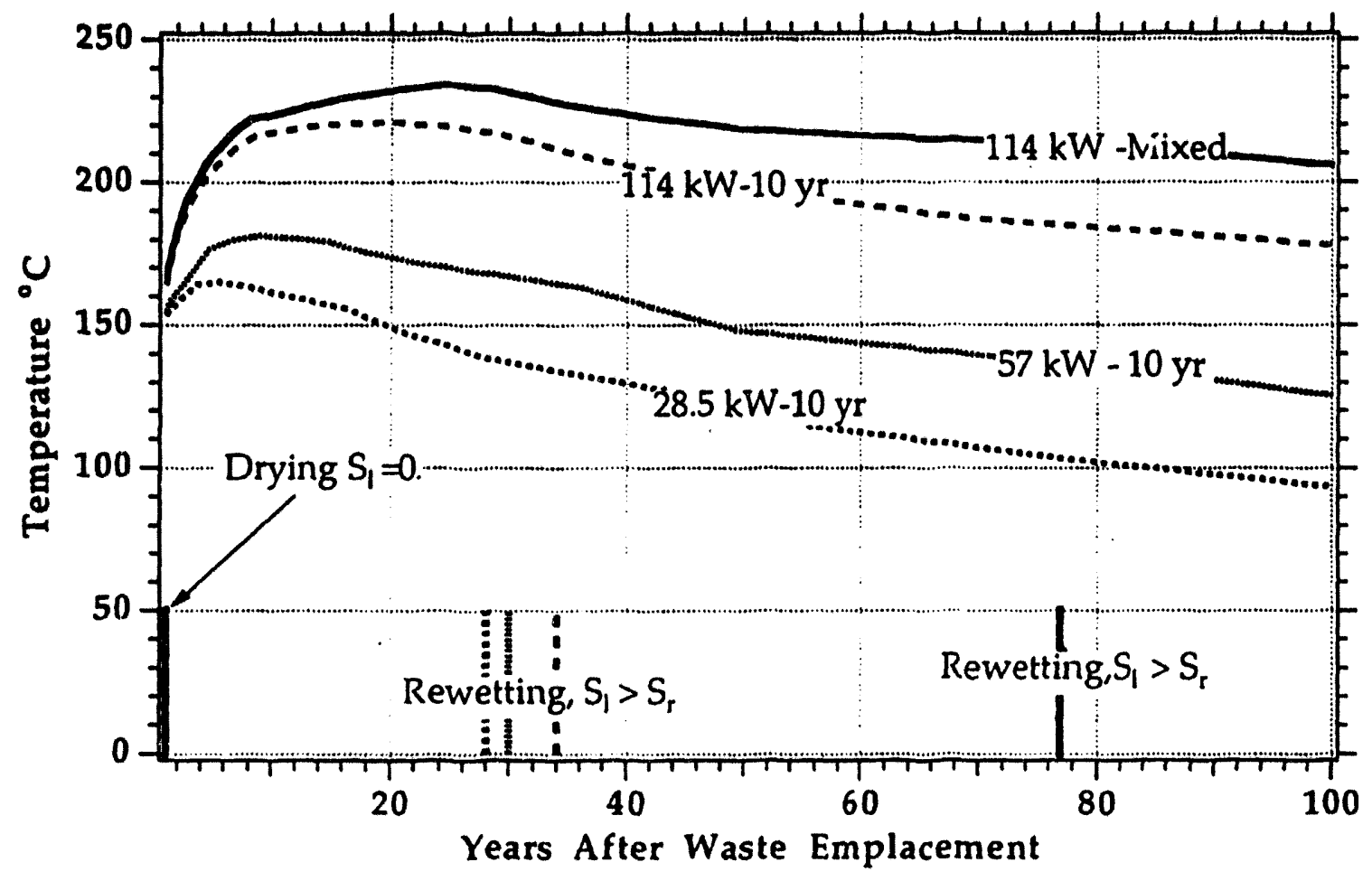

Figure 17. Total drying and rewetting times and the temperature history at $3 \mathrm{~cm}$ from the waste package surface. 
APW $57 \mathrm{~kW} / \mathrm{kcre}, 10$ Yr fuel, Large gas permeability: 19 darcies

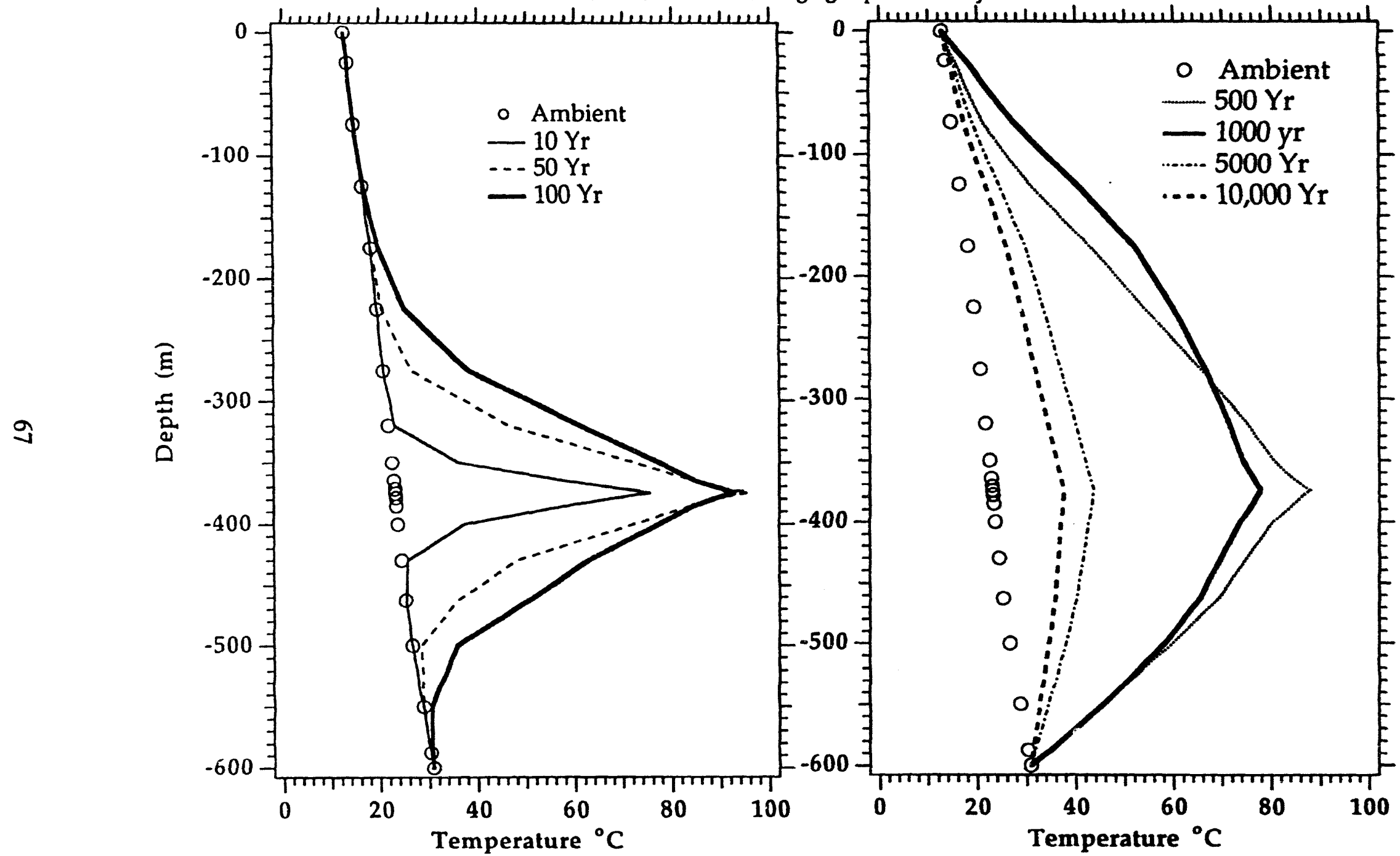

Figure 18. Repository average temperature profiles for thermal loading of APD $=57$

$\mathrm{kW} / \mathrm{acre}$ and 10 year old fuel, and an enhanced gas permeability of $1.9 \times 10^{-11} \mathrm{~m}^{2}$. 
APD $57 \mathrm{~kW} /$ acre, 10 Yr Fuel, Large gas permeability: 19 darcies
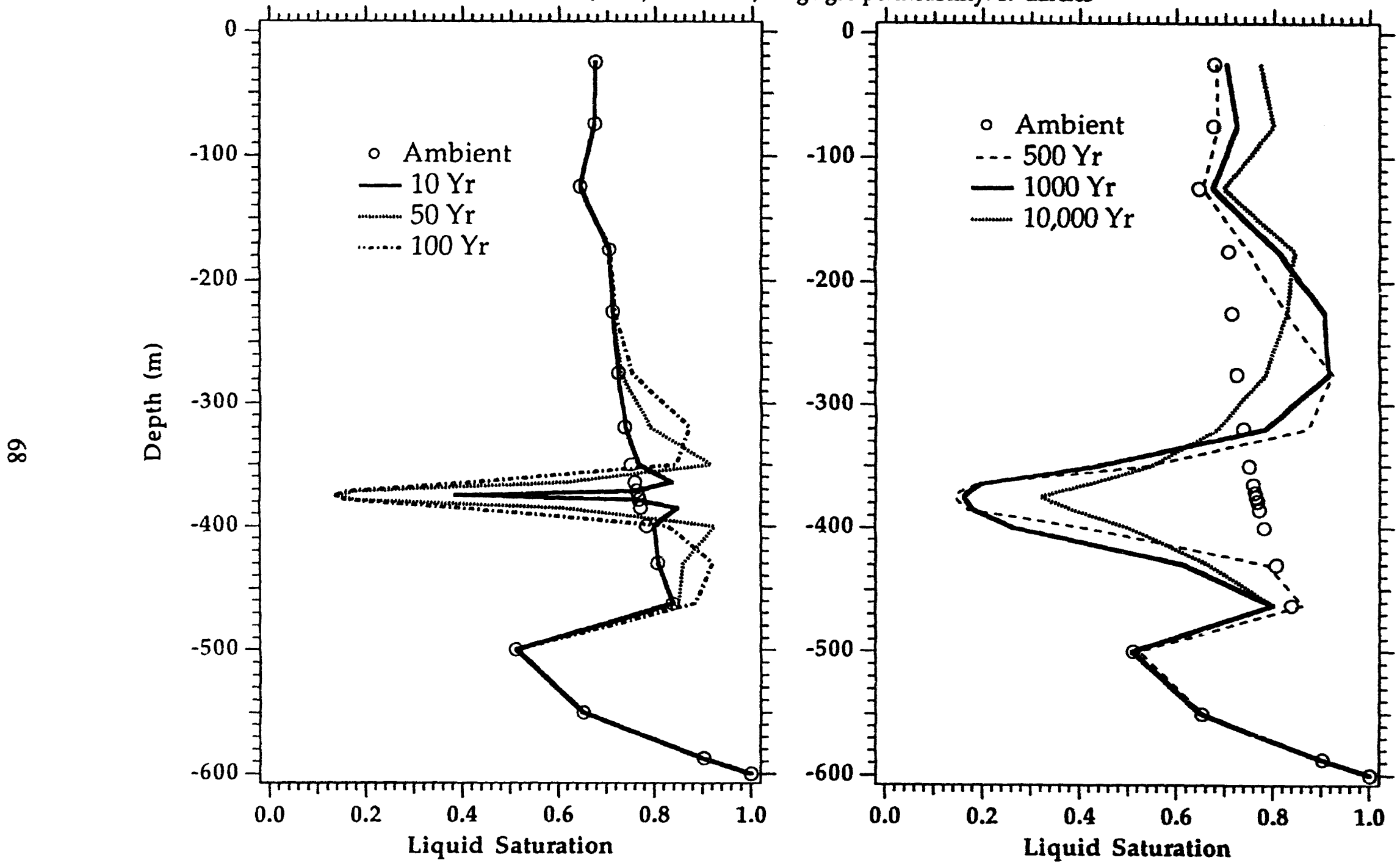

Figure 19. Repository average liquid saturation profiles for thermal loading of $\mathrm{APD}=57 \mathrm{~kW} /$ acre and 10 year old fuel, and an enhanced gas permeability of $1.9 \times 10^{-11} \mathrm{~m}^{2}$. 


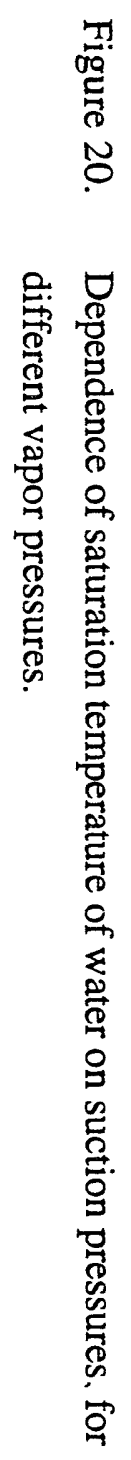

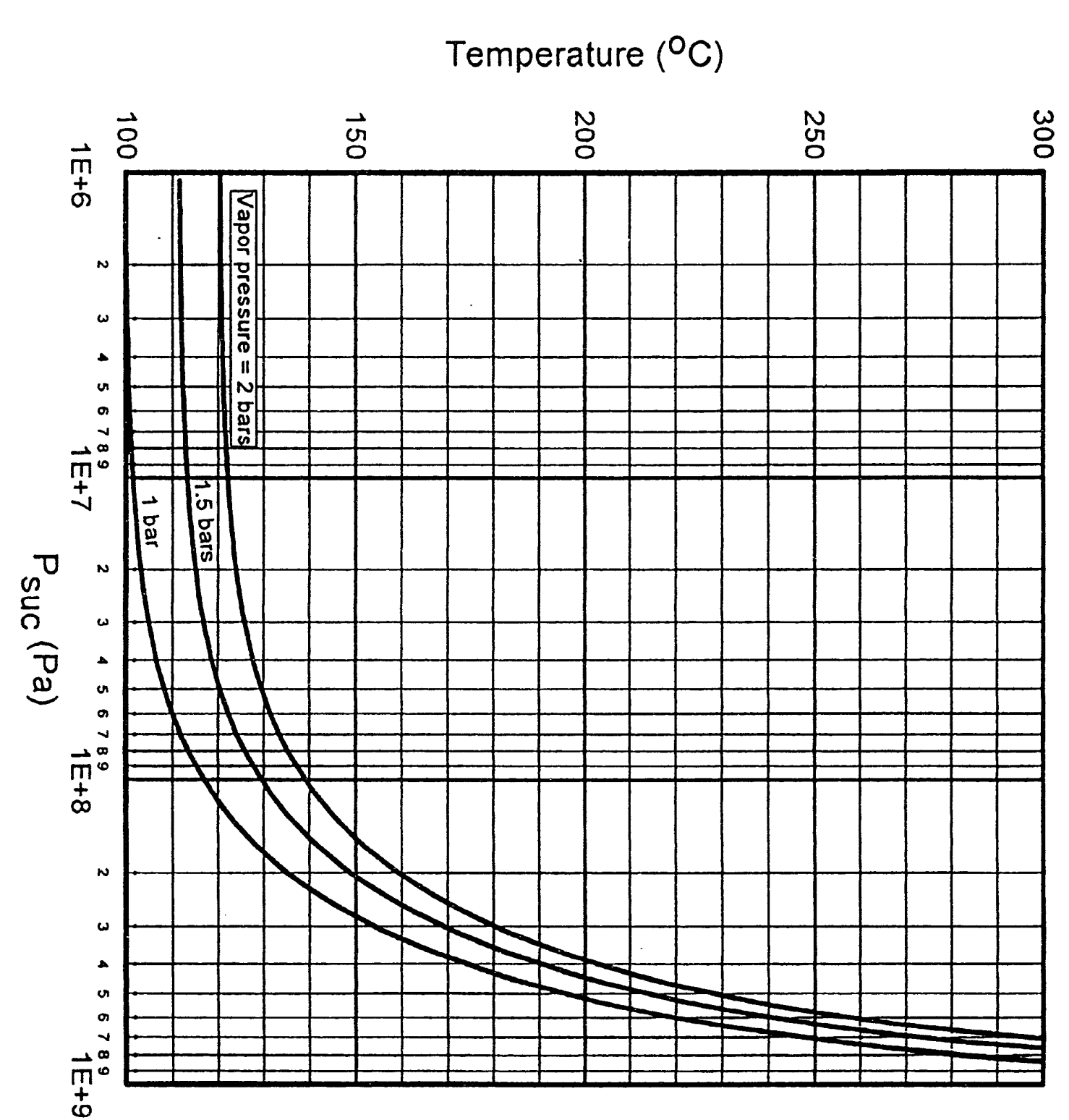




\section{WASTE HEAT $\Leftrightarrow$ INFILTRATION}

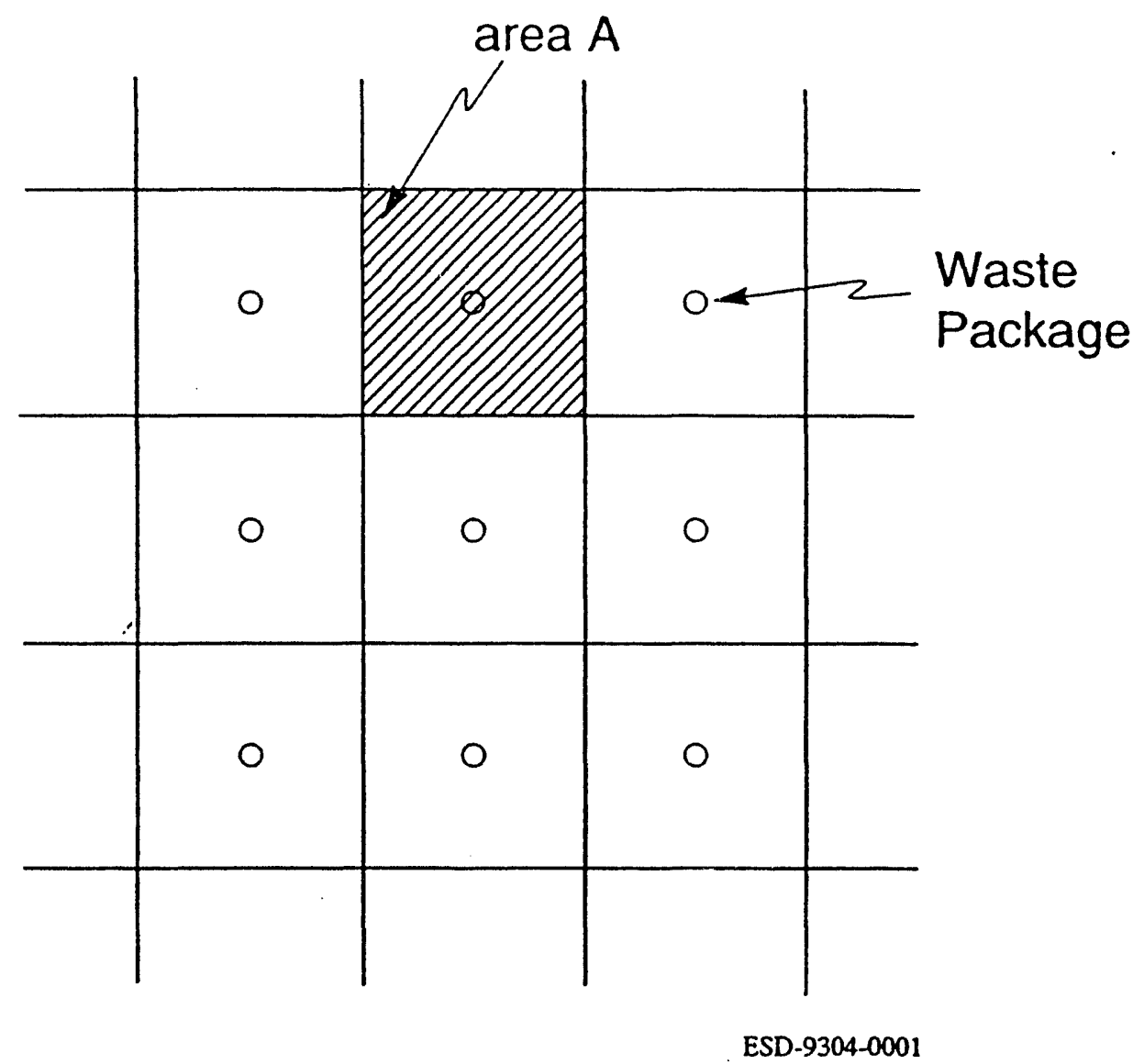

Heat rate per waste package, $G(W)$

Area per waste package, $\mathrm{A}\left(\mathrm{m}^{2}\right)$

Net infiltration, q (mm/yr)

Net infiltration per waste package, Q $(\mathrm{kg} / \mathrm{s})$

$$
\mathrm{Q}=\mathrm{Aq} \rho_{\mathrm{w}}
$$

Heat requirement for vaporization

$$
\mathrm{Q}\left(\mathrm{h}_{\mathrm{v}}-\mathrm{h}_{l}\right) \leq \mathrm{G}
$$

Figure 21. Areal view of waste package arrangement for analysis of the interaction between waste heat and infiltration. 


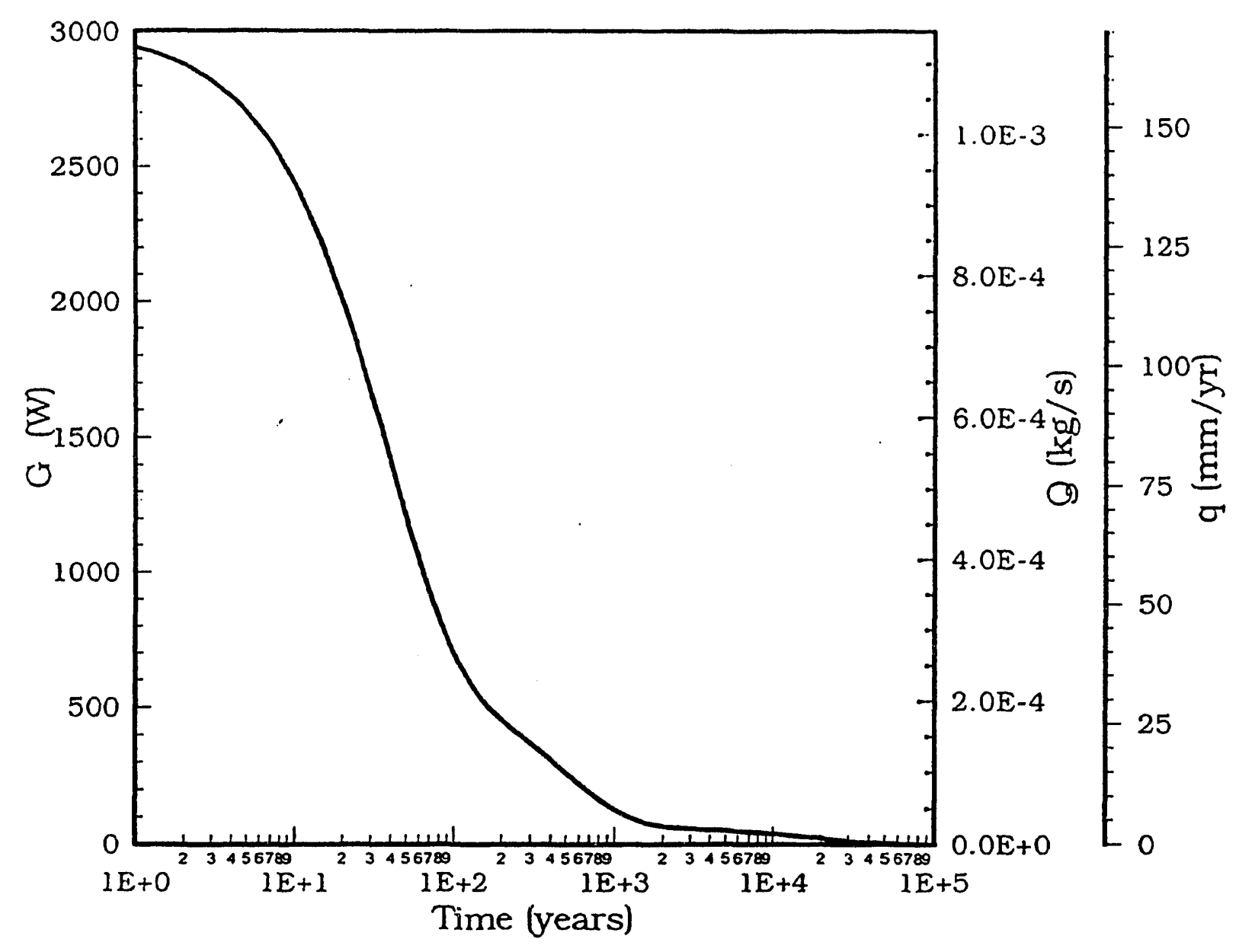

Figure 22. Time dependence of heat output for a 10 year old waste package, and associated maximum vaporization rates from Eqs. $(5,6)$. 


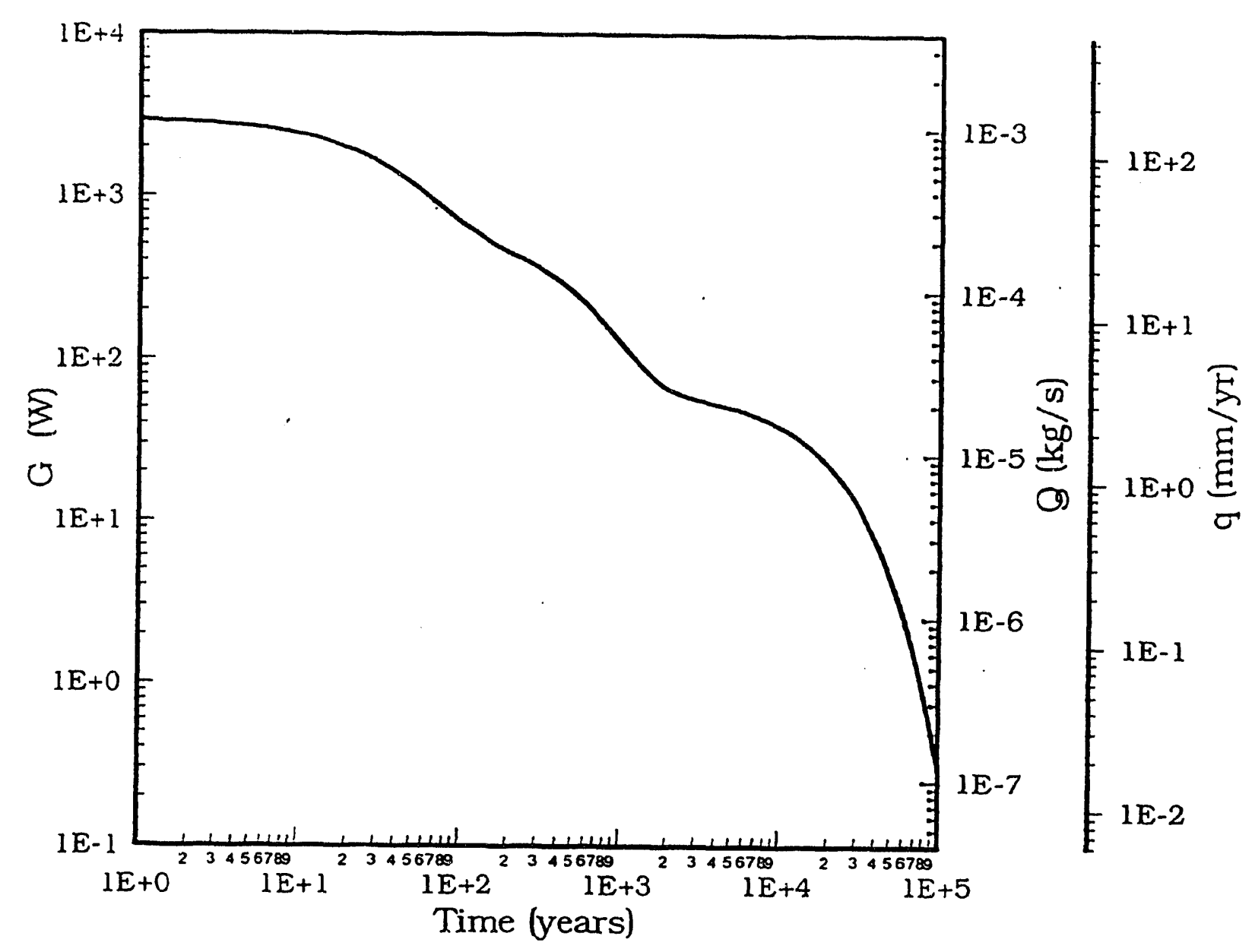

Figure 23. As Fig. 20, with logarithmic scale for heat generation and vaporization. 


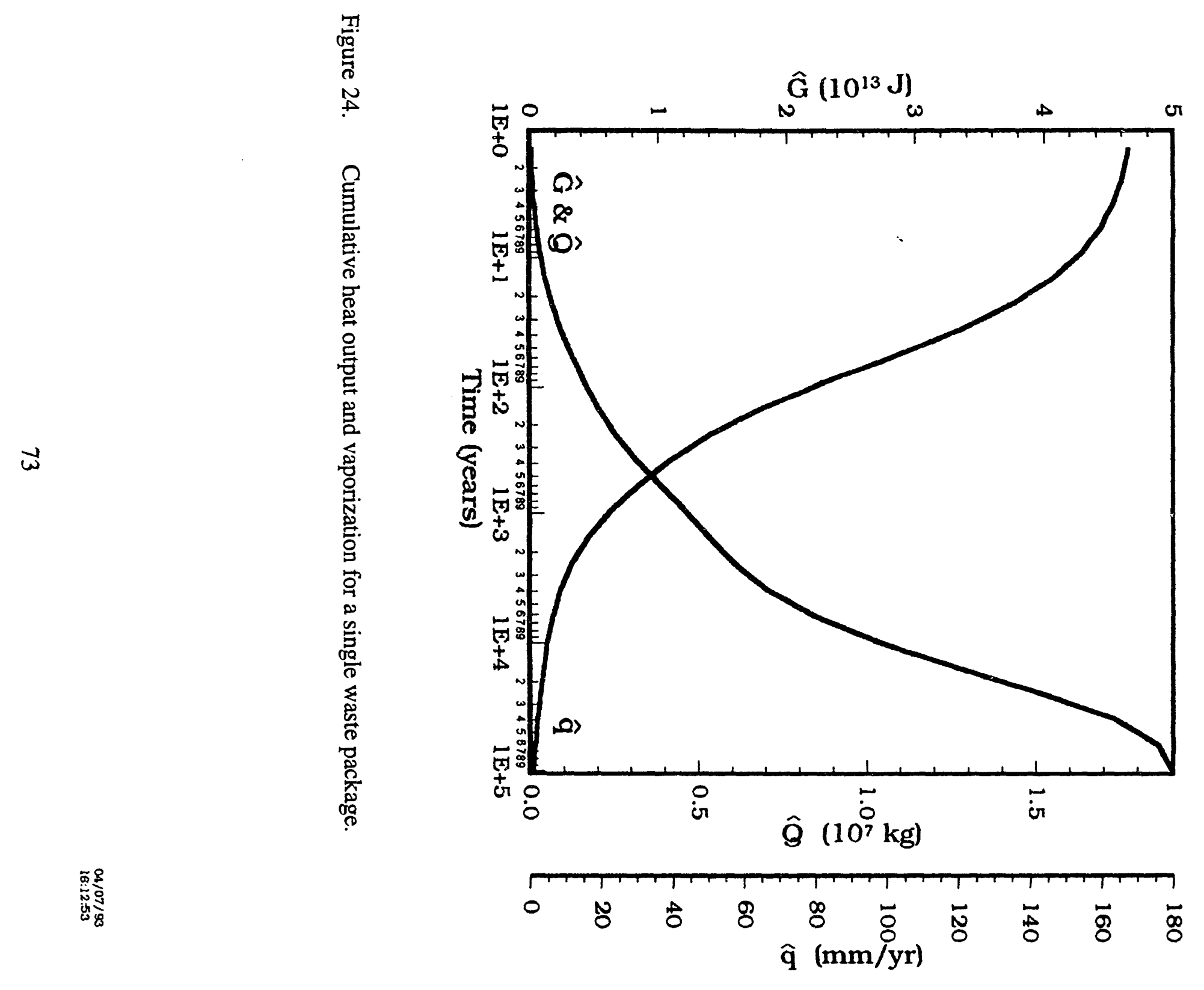




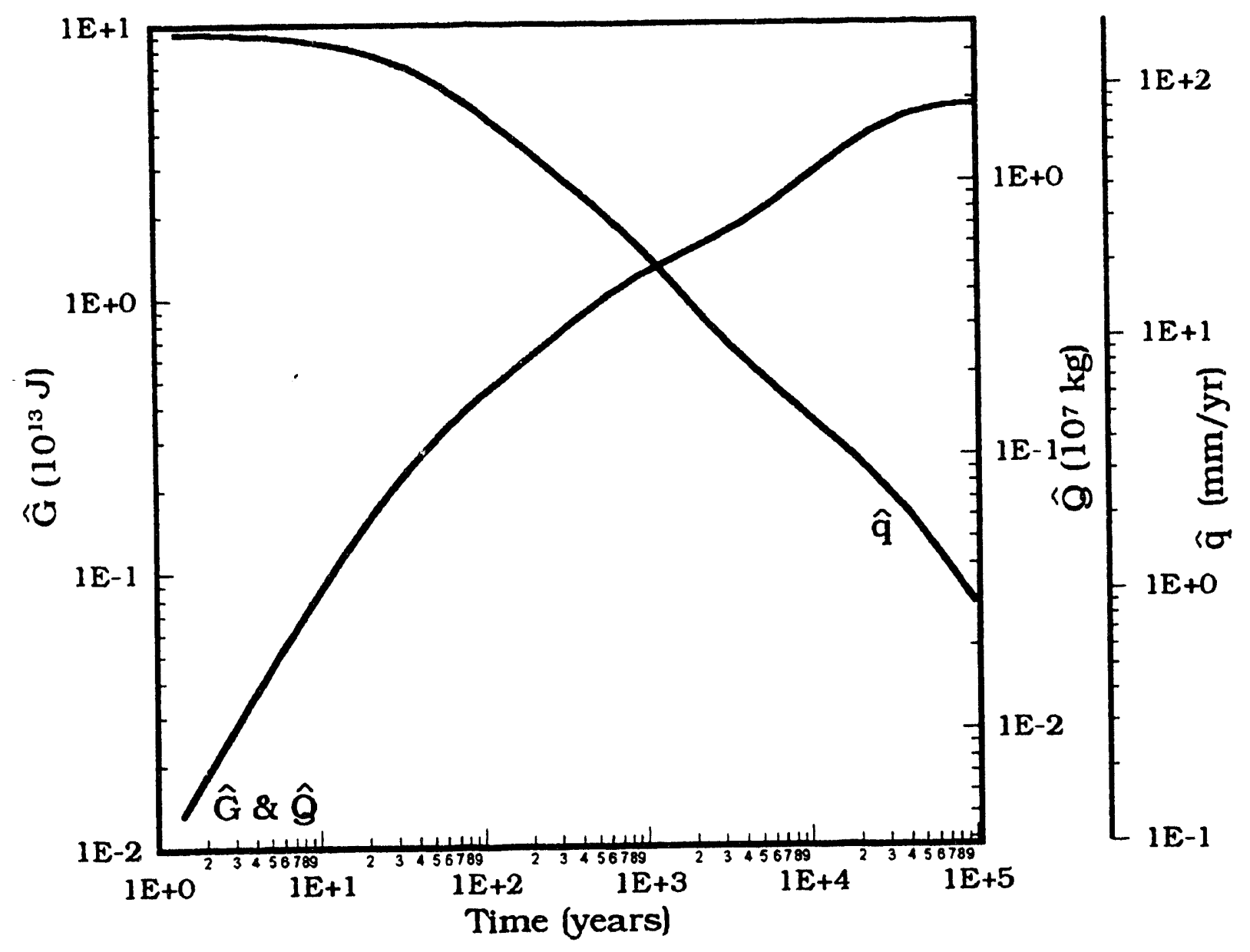

Figure 25. Cumulative heat output and vaporization, logarithmic scale. 


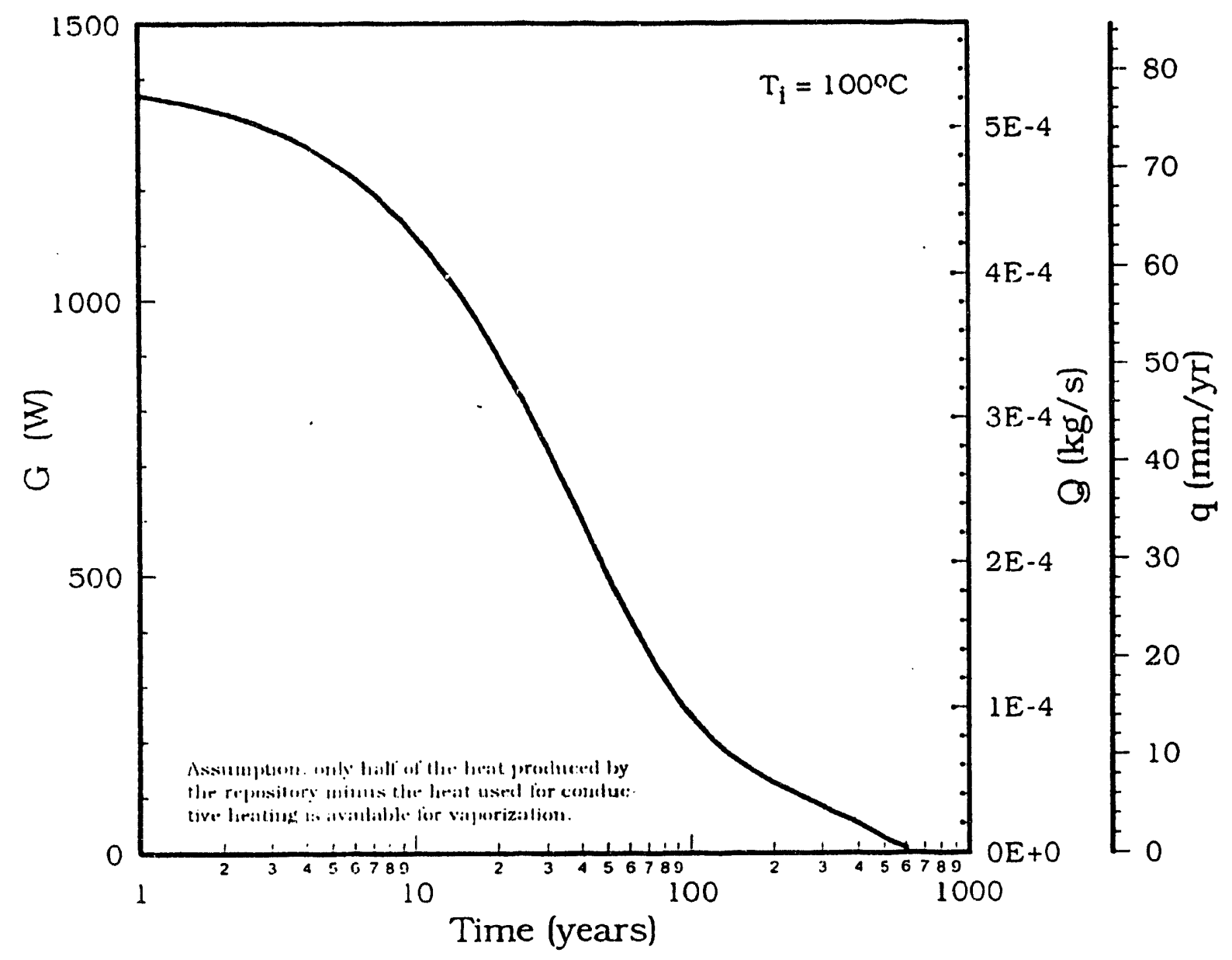

Figure 26. Heat available for vaporization per waste package, and corresponding vaporization rates, for a model that accounts for heat migrating upward as well as downward from the repository, and includes conductive losses. 


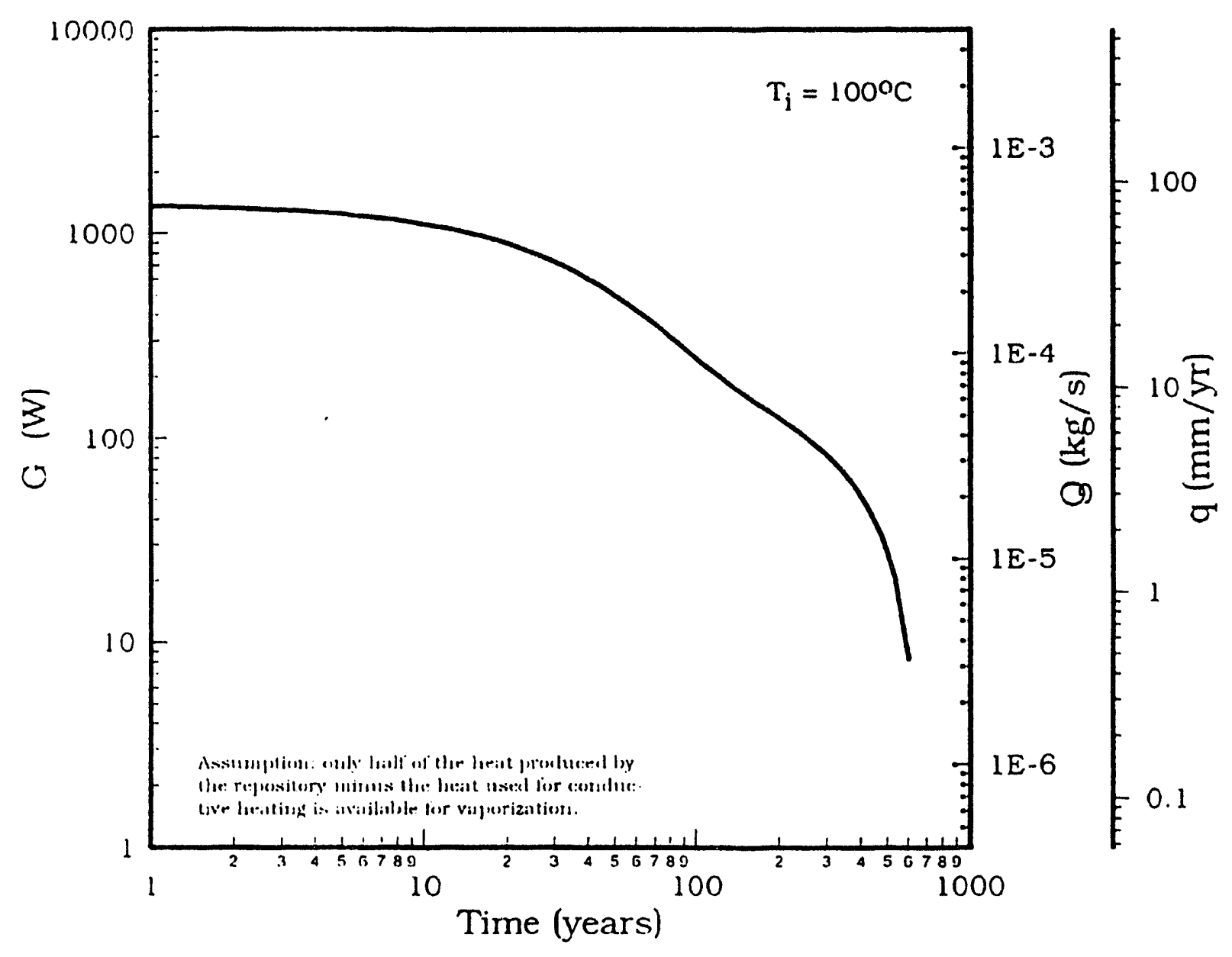

Figure 27. As Fig. 24, logarithmic scale. 


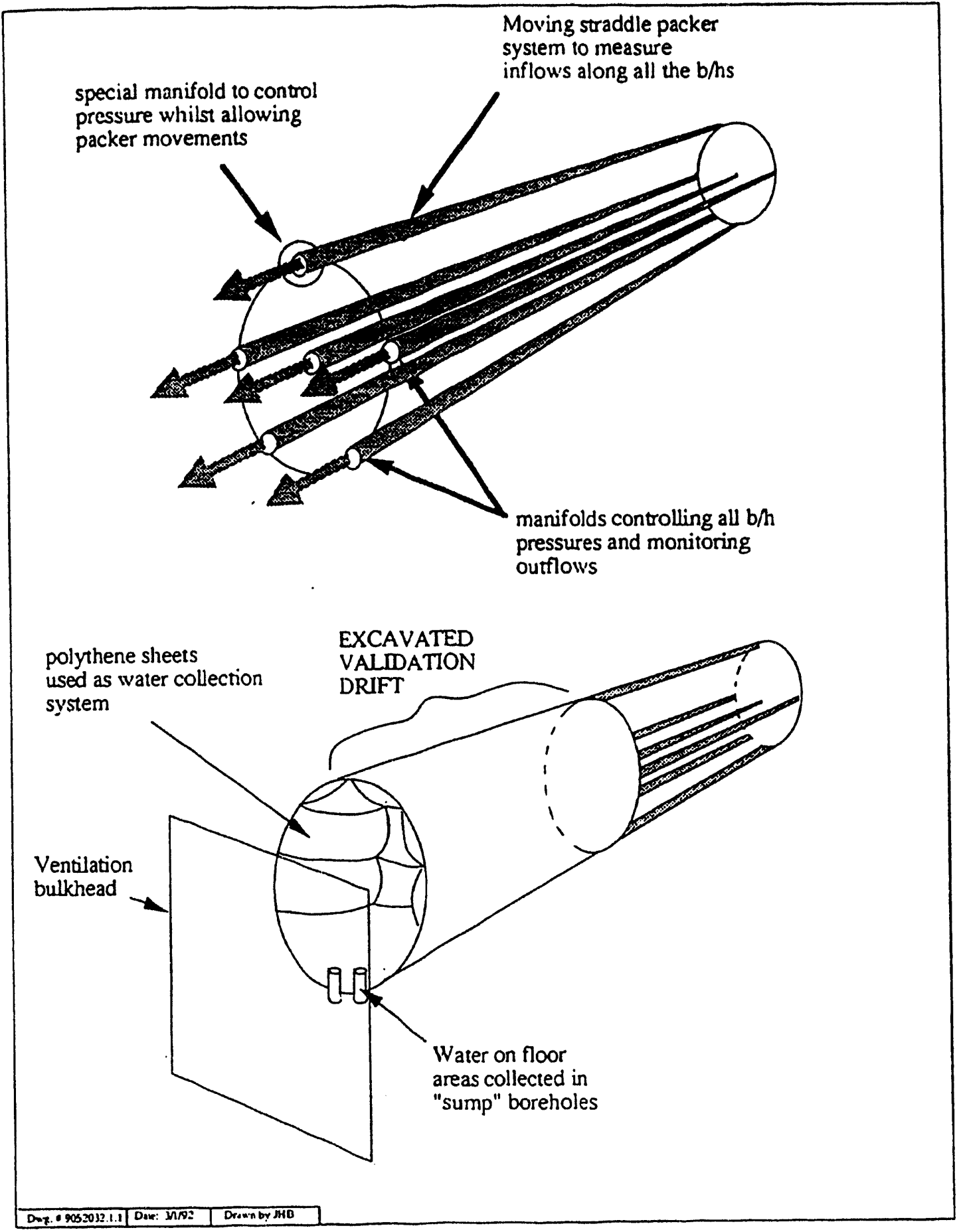

Figure 28. Validation drift experiment at the Stripa mine (from Harding and Black, 1992). 
H-ZONE
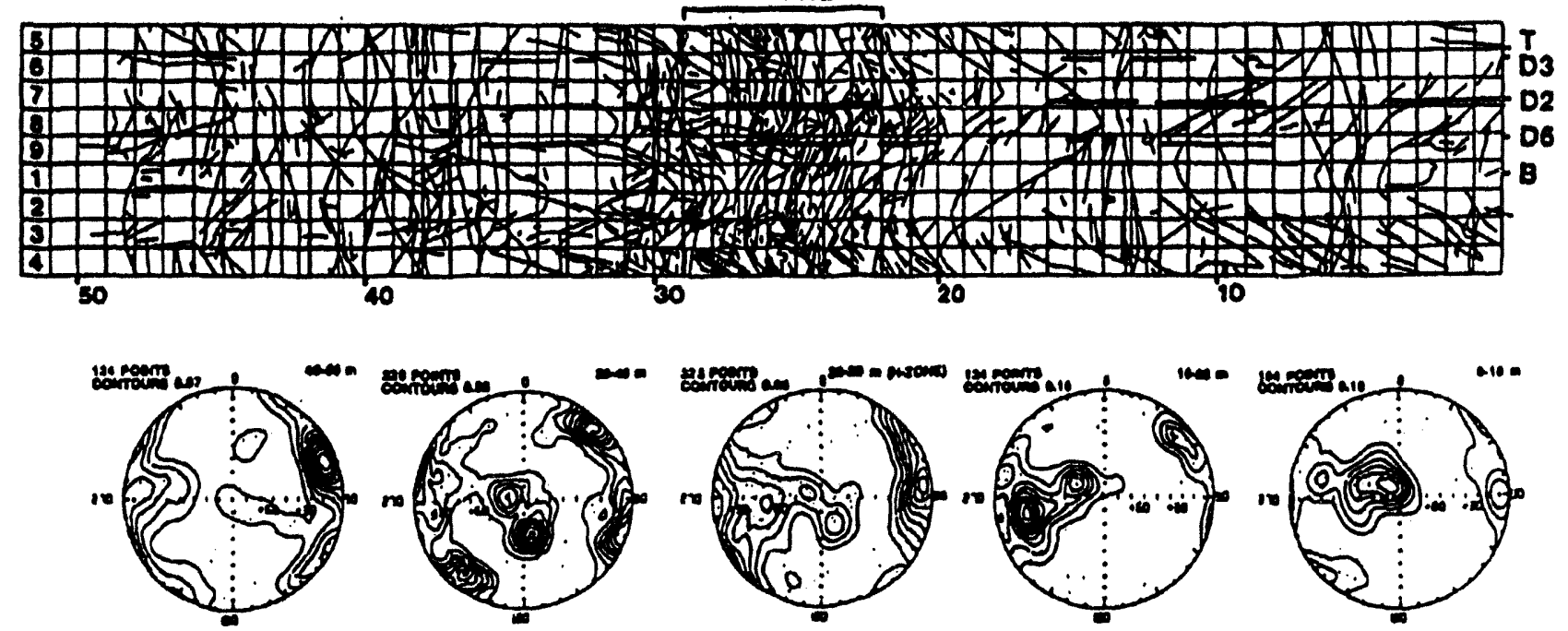

LEGEND

$T=$ Top center (or roon) of drift

$B=$ Bottom center of drin

D2, D3, D6 = D-borehole traces on the drift walls

Figure 29. Fractures mapped at the Validation Drift wall (from Olsson, 1992). 


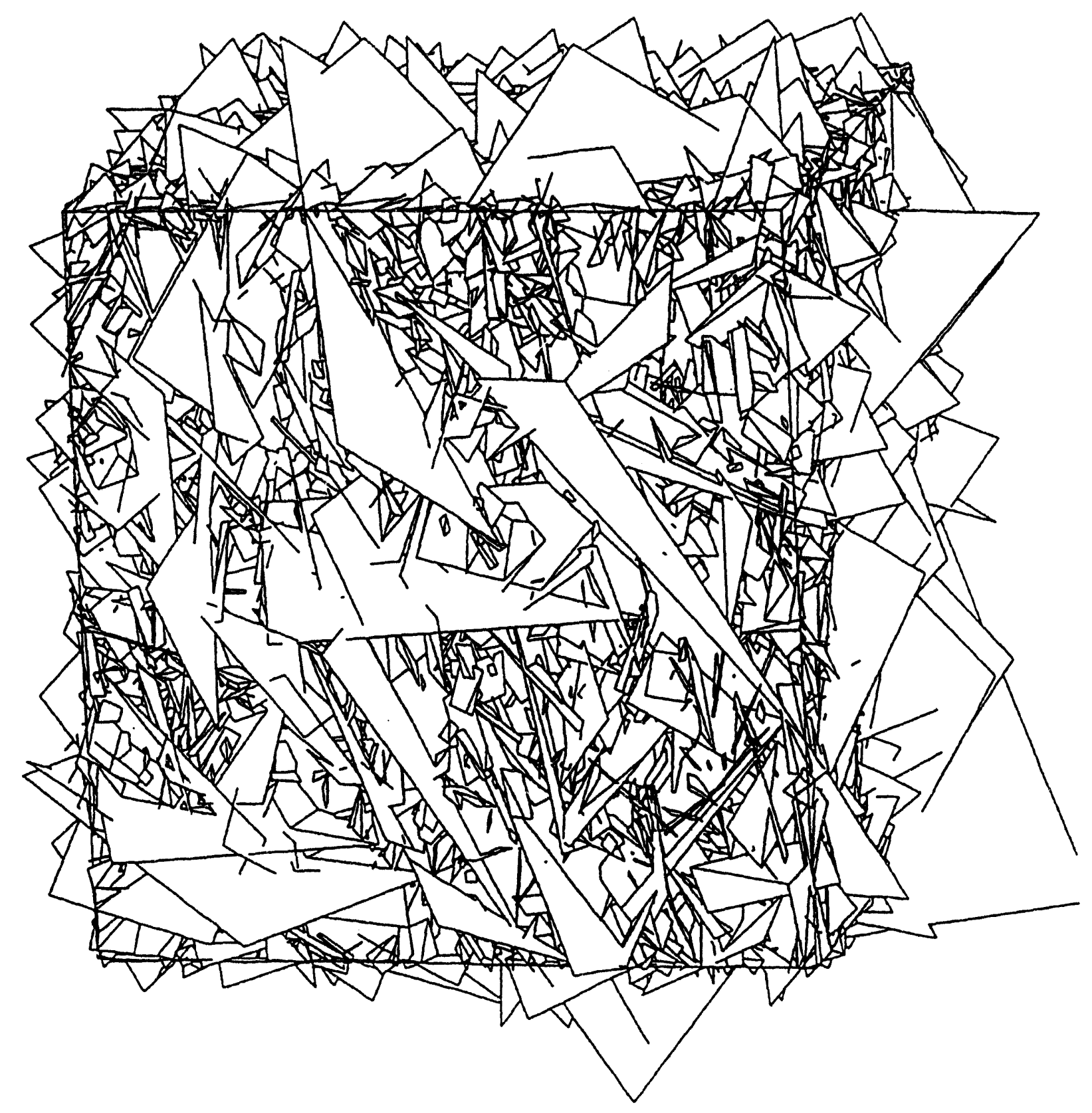

Figure 30. Computer-generated realization of a $12.5 \mathrm{~m}$ sided cube of averagely fractured rock at the Stripa Validation Drift (from Herbert et al., 1991). 


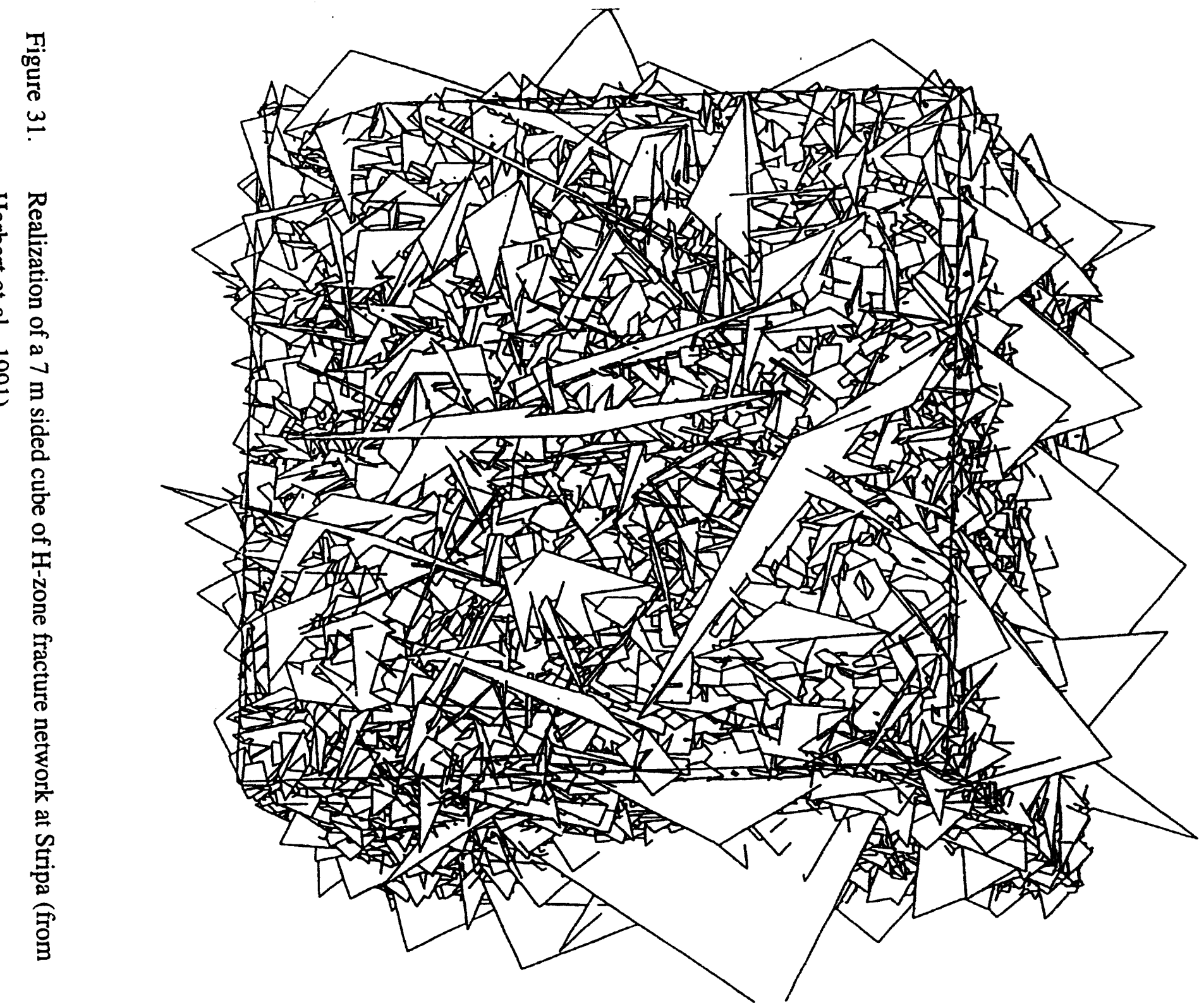




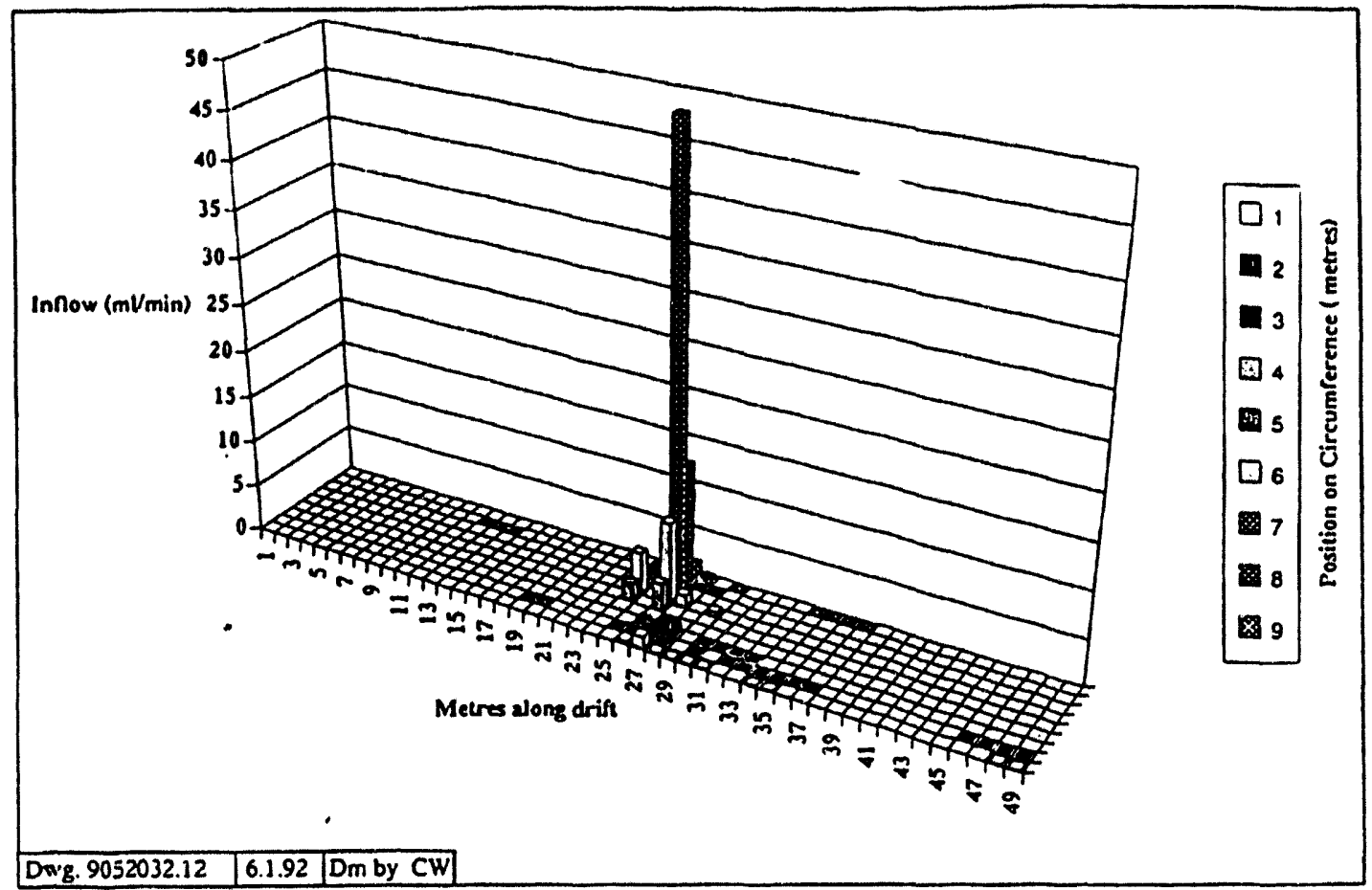

\section{$4.5 \mathrm{a}$}

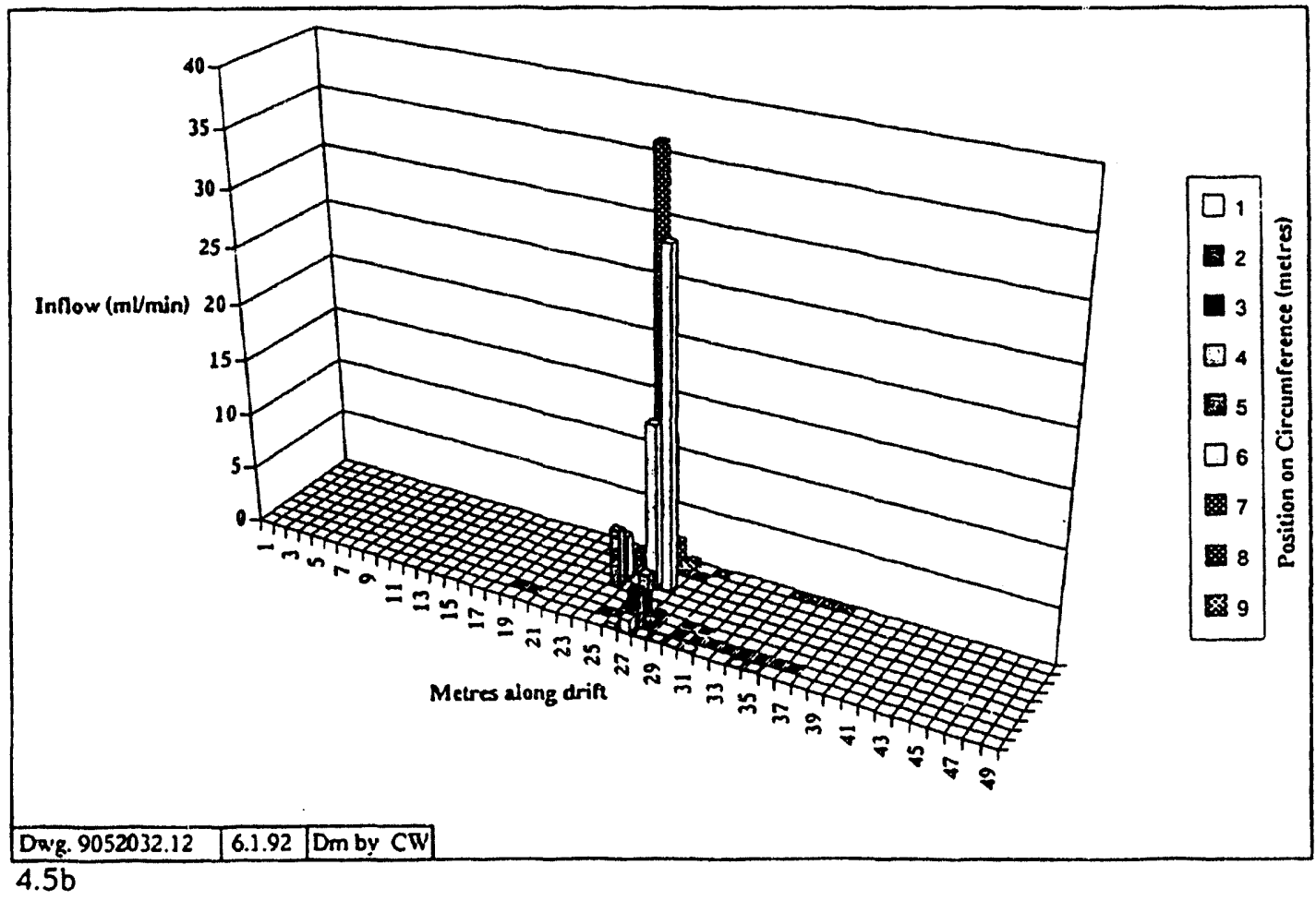

Figure 32. Measured inflow distributions at the Validation Drift after 5,000 hours (a) and 9,500 hours (b) (from Harding and Black, 1992). 


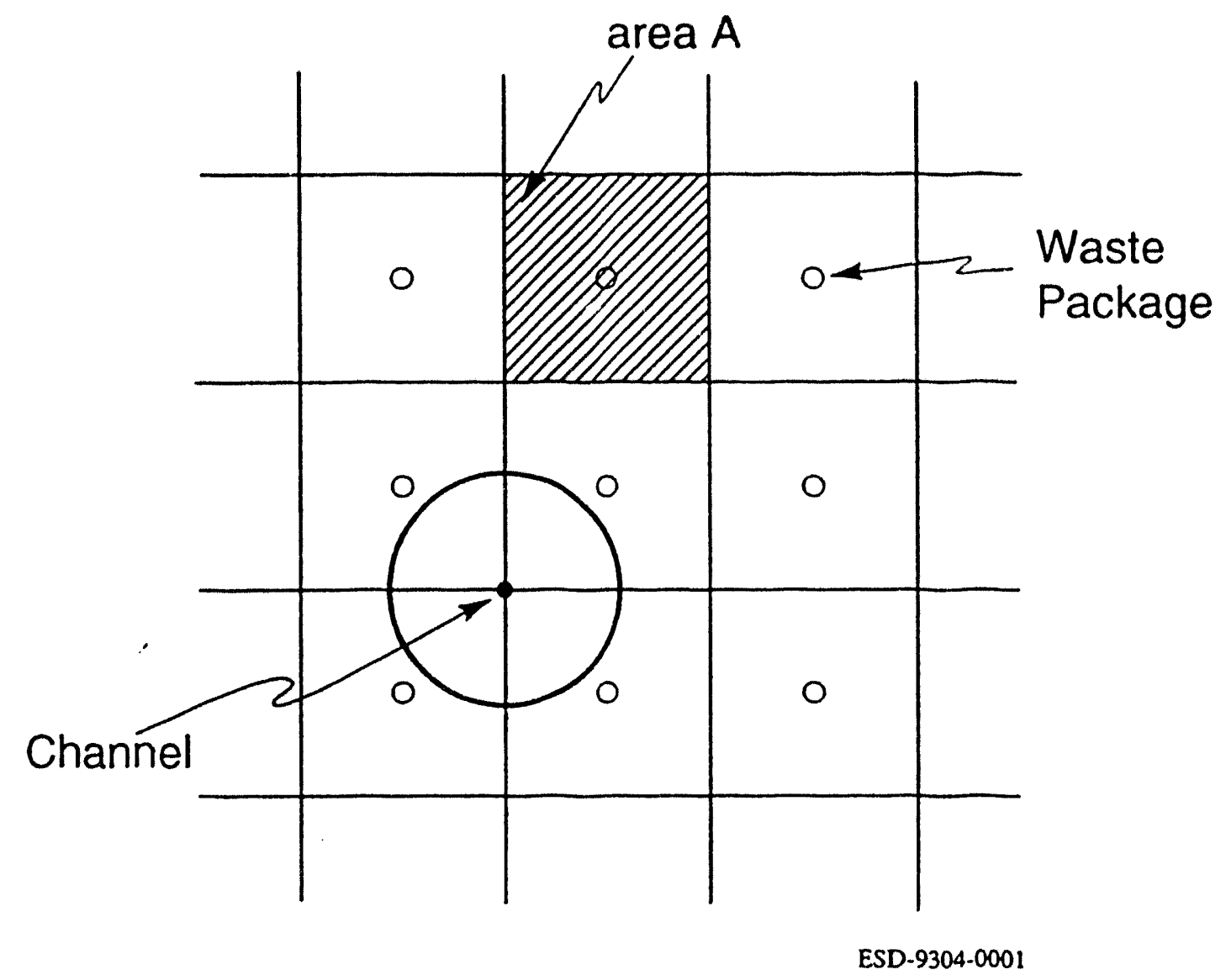

Figure 33. Areal view of waste package arrangement for analysis of channelized wate: flow. 


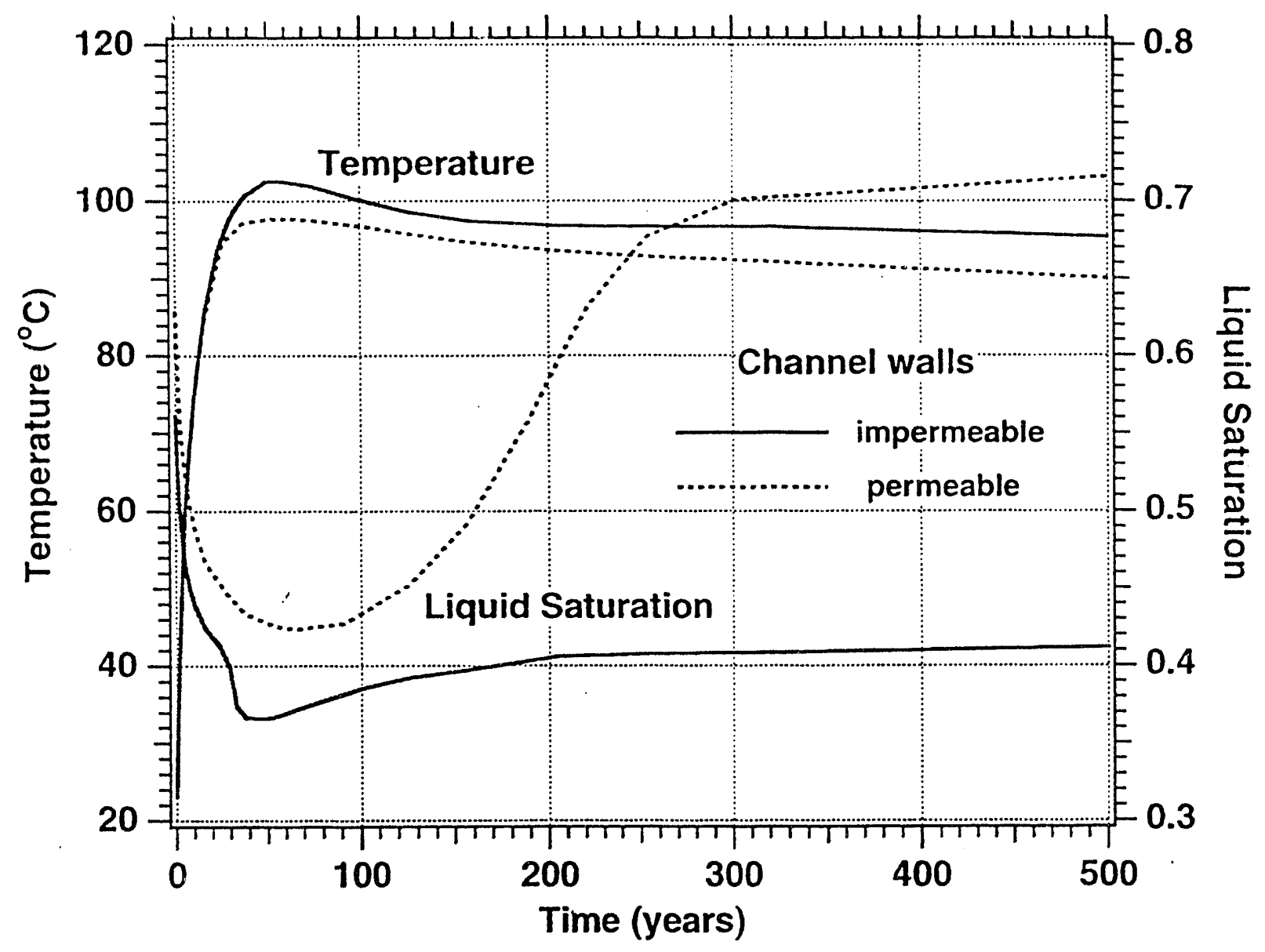

Figure 34. Temperatures and liquid saturations at repository horizon in vertical water channel. 

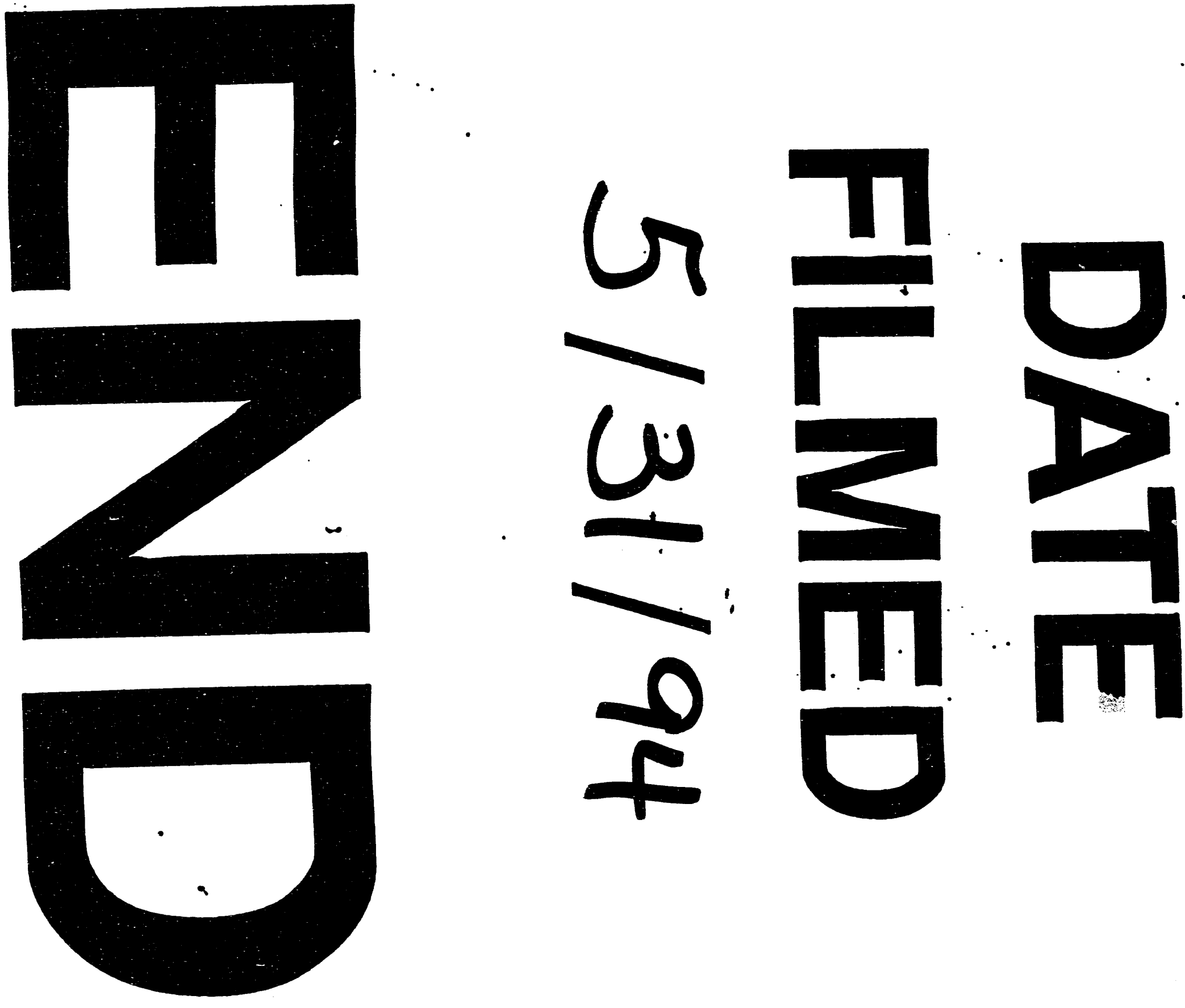

0

II
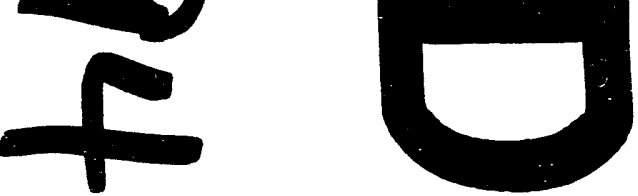


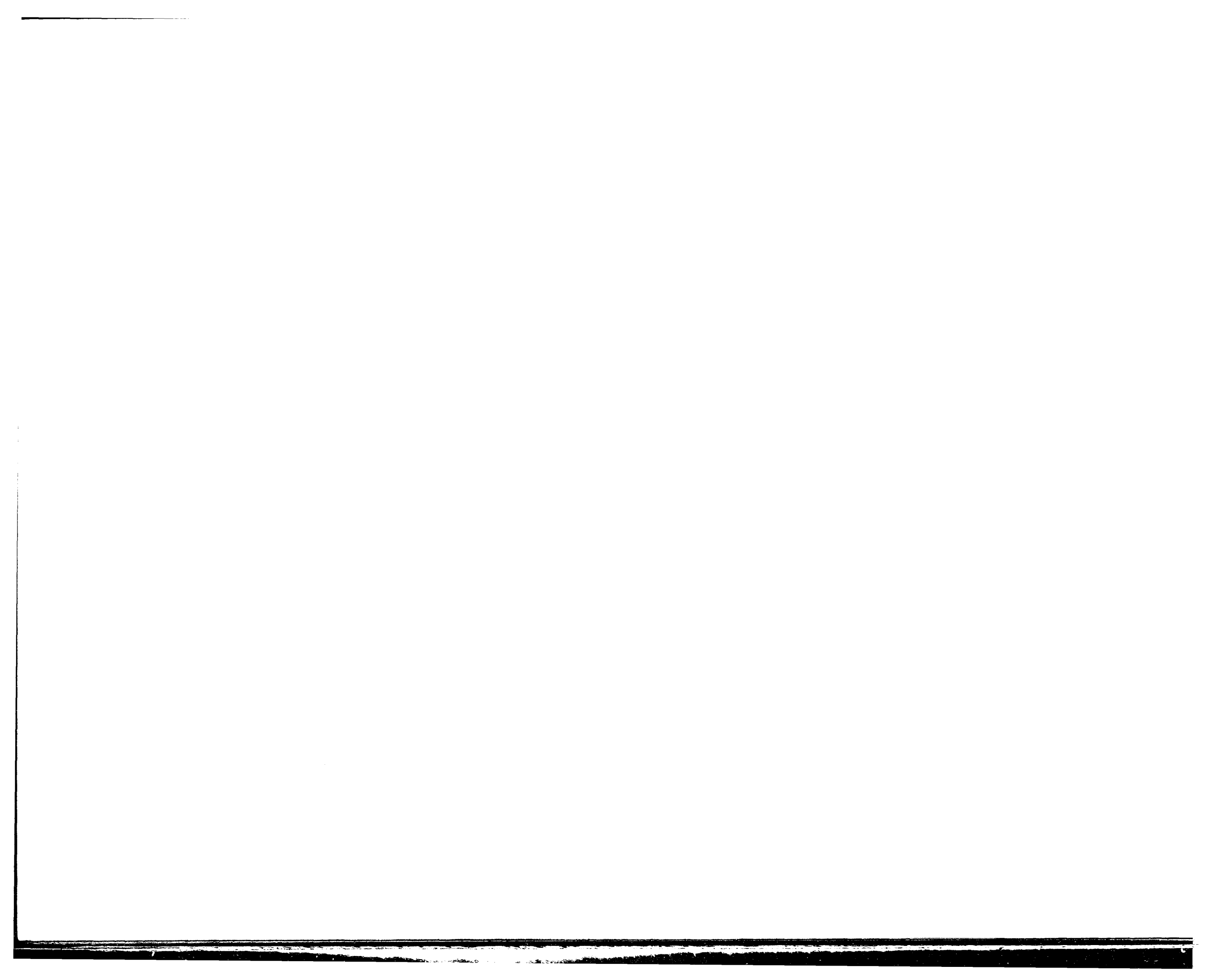

